How they carry disease How they are classinlec How they may be destroyed
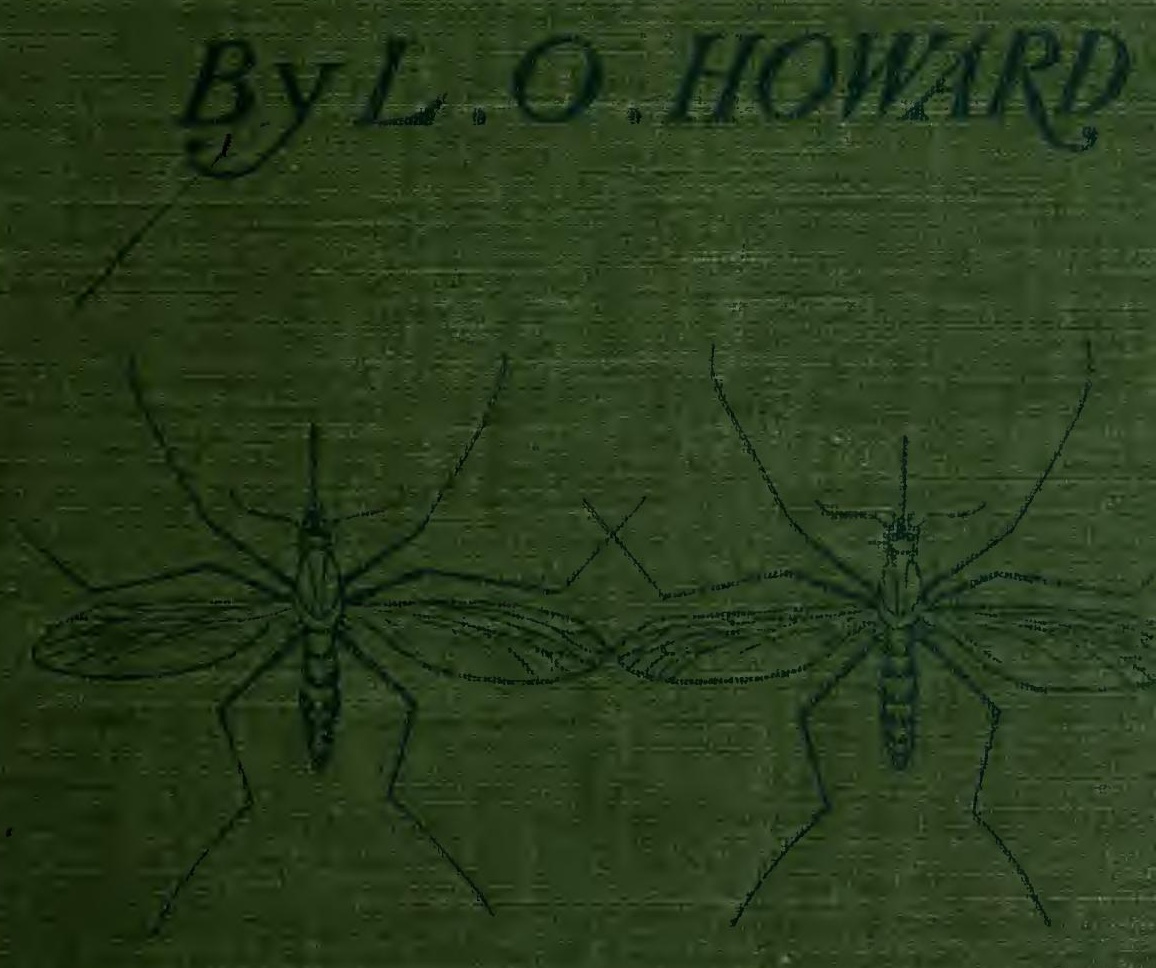


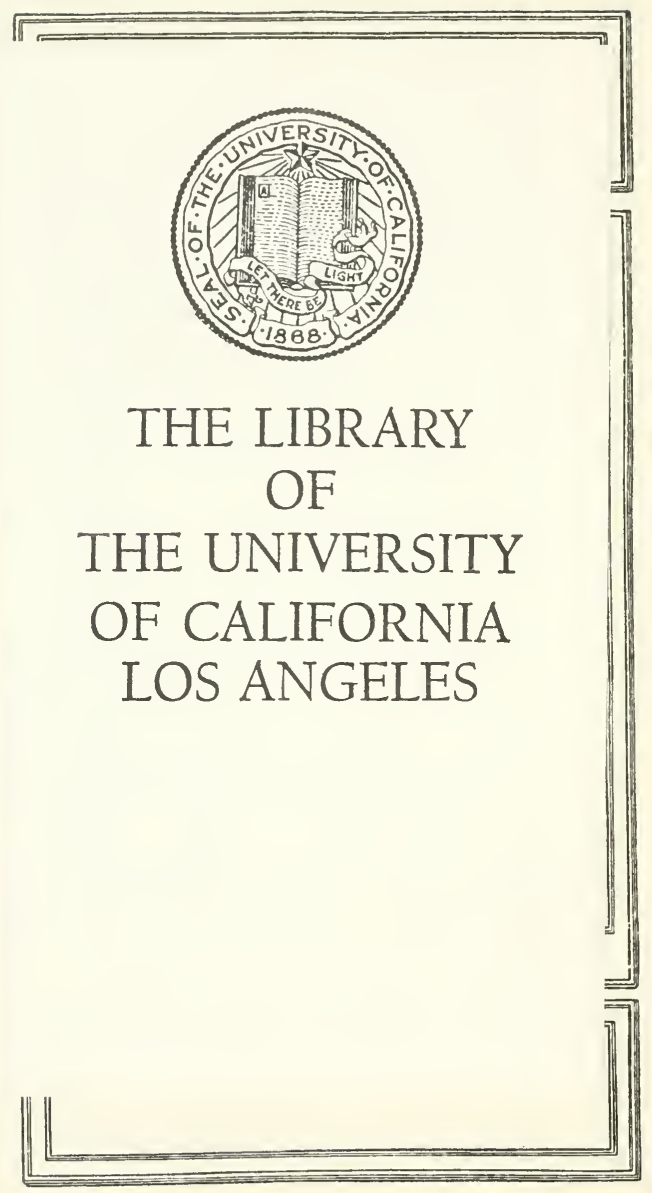


<smiles>C1=CC=C1</smiles> 



MOSQUITOES 


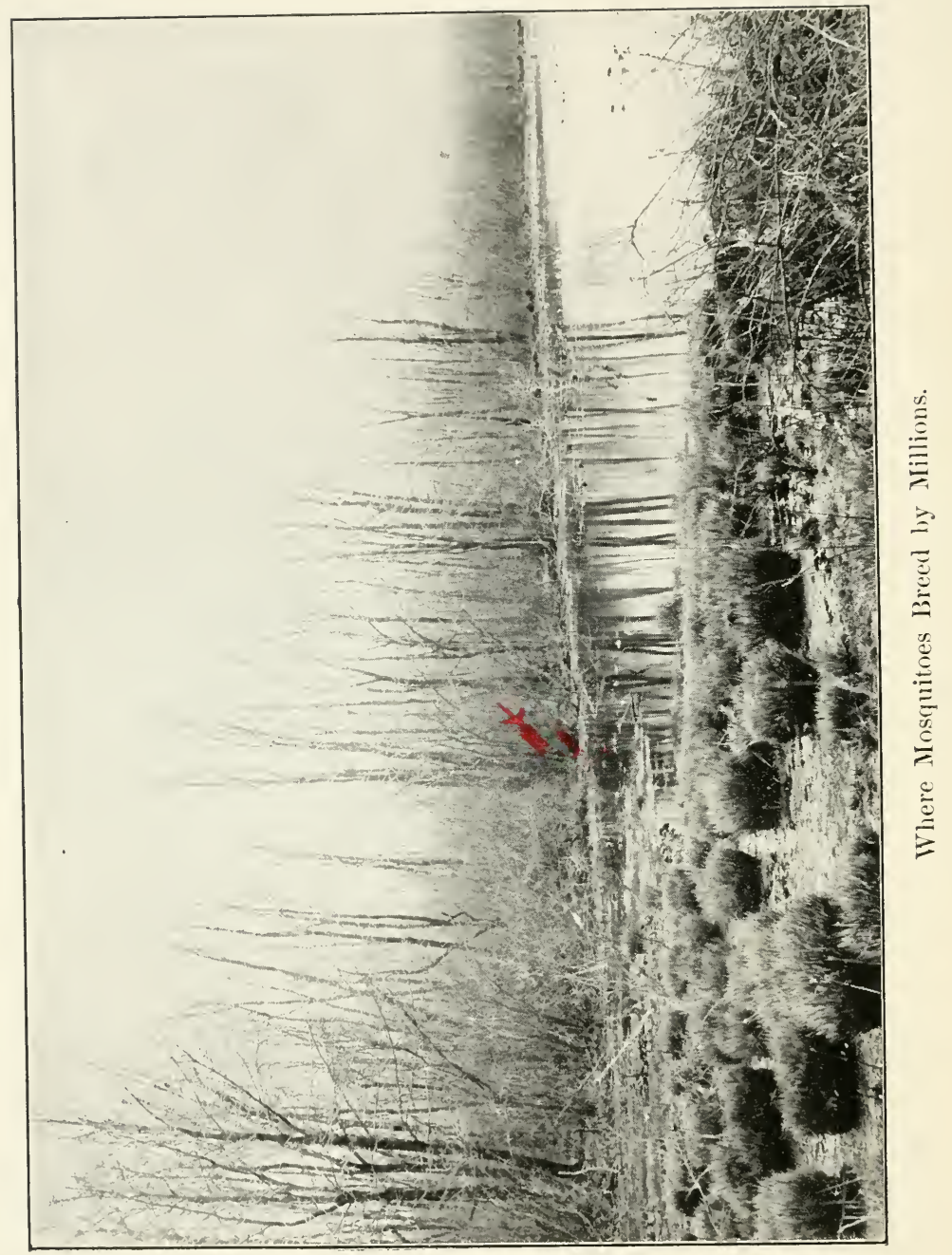




\section{MOSQUITOES}

HOW THEY LIVE; HOW THEY CARRY

DISEASE; HOW THEY ARE CLASSIFIED; HOW THEY MAY

BE DESTROYED

BY

\section{O. HOWARD, PH.D.}

DEPARTMENT OF AGRICUlture, WASHINGTON, D. C。

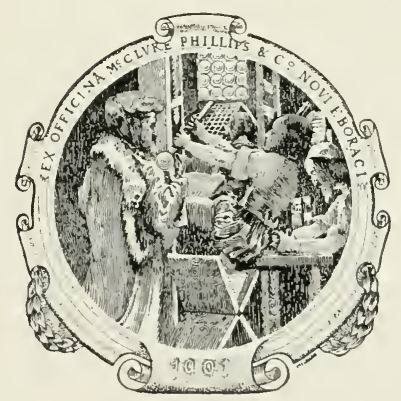

NE Y YOR Ḱ

MC̣CLURE, P'IIILLIPS \& CO

1901 
Copyright, June, 1901, BY

MCClURE, PHILliPS \& CO.

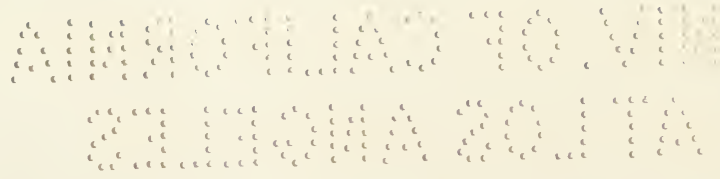




\section{Afrite. Dept.}

\section{INTRODUCTION}

Y OME years ago I was visiting a family in the mountains. It was during a dry season, and water was scarce. There were no swamps, no lakes or pools, and the drinking-water was taken from springs; yet mosquitoes were so plentiful that it was necessary to screen the porches, that sitting out of an evening might be made possible. I asked where the water came from in which they washed their clothes, and they replied, as expected, "From a rain-water tank," which, as it happened, was situated under the porch. I investigated the tank and found it literally alive with mosquito larvæ. A pint of kerosene stopped the breeding, and as the water was drawn from a faucet near the bottom of the tank the kerosene did not injure it.

The indifference of this family as to the source of their local mosquito pest, or rather their combined ignorance of and indifference to the subject of the breeding-places, was at that time-and it was not so very long ago-characteristic of people in general. It was my good fortume, through the wide-spread newspaper accounts of my kerosene experiments in the Catskill Mountains in 1892, to become more or less identified with many practical experiments in the destruction of mosquitoes from that time on. Interest in the subject became very great, especially 
among summer residents of the country, and especially near the sea-shore, even before the agency of mosquitoes in the spread of disease became established, and before it became a generally accepted fact. With the very perfect proof that the mosquitoes of the genus Anopheles are instrumental in the carriage of malaria, the interest became intensified, and the late discovery of our Army Yellow-fever Commission in Cuba, that a mosquito is the conveyor of yellow fever, has added to the general interest in the subject. In fact, the whole mosquito question is a live topic of the day. Knowledge of mosquito habits is more general than at any previous time, and almost everyone is interested in the subject of mosquito extermination. With the knowledge which we now possess, it seems almost incredible that people should all these years have suffered, more or less patiently, the tormenting bites of Culex and the insidious but more dangerous punctures of Anopheles without making the slightest effort to abate the nuisance and the danger, beyond slapping, in a revengeful way, at individual biters. In many places infested with mosquitoes nothing could be easier than to put a stop to the whole tormenting plague. In many other cases the problem is a more difficult one, but in even the worst cases, by a judicious effort, which should be a community effort, and by the expenditure of a greater or smaller amount of money, much relief can be gained. In fact, Mr. W. J. Matheson, of New York, was quite right when, in the summer of 1900 , just before commencing a successful crusade against the mosquitoes on the north shore of Long Island, he wrote me that there 
seemed to him to be no more reason for enduring the mosquito scourge than in allowing small-pox to ravage communities, as it used to do before the days of Jenner. Work against mosquitoes is being undertaken every where, by individuals and by communities. The interest in the subject, from both medical and lay points of view, has become so great that persons are not satisfied with half knowledge, but must know the whole mosquito story, and it has been with the purpose of supplying in some part this demand for information, that this book has been prepared. It tells what is known about mosquitoes from the biological point of view, from the medical point of view, and from the practical side. An especial effort has been made to show, in a straightforward way, to physicians how the different kinds of mosquitoes can be distinguished, and to indicate the characteristic habits and breedingplaces of those forms which spread malaria and yellow fever. Directions are given for collecting mosquitoes and for rearing their early stages, and an especial effort has been made to display fully and practically the remedial measures which should be adopted in mosquito-ridden neighborhoods. 



\section{TABLE OF CONTENTS}

PAGE

INTRODUCTION,

\section{CHAP'TER I.}

Mosquitoms in General, • • • • • • . 1

The Life Round of Mosquitoes, . . . . . 1

Parthenogenesis Among Mosquitoes, . . . 4

How Long can the Larva Live Under Water? . . 5

How Long may the Larve Live? • • • 6

How Long can the Larve Live Out of Water? . . 7

Length of Life of Adult Mosquitoes, . . . $\quad$. 9

Transformations of Mosquitoes Artificially Hastened, 12 Mosquito Songs, . • . . . . • . 13

How Far do Mosquitoes Fly? Are They Carried by

Winds? . . . . . . . . . . . 16

Carriage of Mosquitoes by Railway Trains and other Conveyances, . . . . . . . . 25

Queer Places in which Hosquitoes Breed, • • . 28

Food of Adult Mosquitoes, . . . . . . . 34

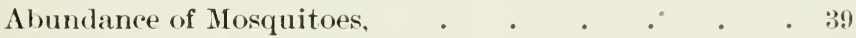

The Northern Mosquitoes, . . . . . . 42

The Poison of Mosquito Bites, . . . . . . 44

\section{CHAP'TER II.}

MALARIA ANT MOSQUITOE, . . . . . . . 48 


\section{CHAP'TER III.}

The Common Mosquitoks of the Genes Culex, • . 66 Dr. J. B. Smith's Observations on Culex pungens, . . 83

\section{CHAP'TER IV.}

The Malarial Mosquitoes of The Genus ANopheles, . 91

The Life History of Anopheles maculipennis, . . 93

European Observations on the Same Species, . . . 107

Natural Breeding Places of Anopheles, . . . . . 109

The North American Species of Anopheles, . . 113

Food of Anopheles Larve, . . . . . . . $11 \%$

Length of Life of Adult Anopheles, . . . . . . 118

How Anoplieles Bites, . . . . . . . . 119

\section{CHAP'TER V.}

Mosquitoes and Yellow Fever ; Mosquitoes and Fili-

ARIASIS, . . . . . . . . . 121

The Yellow-fever Mosquito, . . . . . . . 131

Mosquitoes and Filariasis, . . . . . . 140

CHAPTER VI.

Other Genera of North Americax Mosquitoes, . . 144

Genus Psorophora Desvoidy, . . . . . . 144

Genus Megarhinus Desvoidy, . . . . . . . 152

Genus Aëdes Meigen, • c . . . 153

Stegomyia, Toxorhynchites, Uranotrenia and Conchylias-

tes, . . . . . . . . . . 155

CHAPTER VII.

Natural Enemites of Mosquttoks, . . . . . 156 


\section{CHAP'TER VIII.}

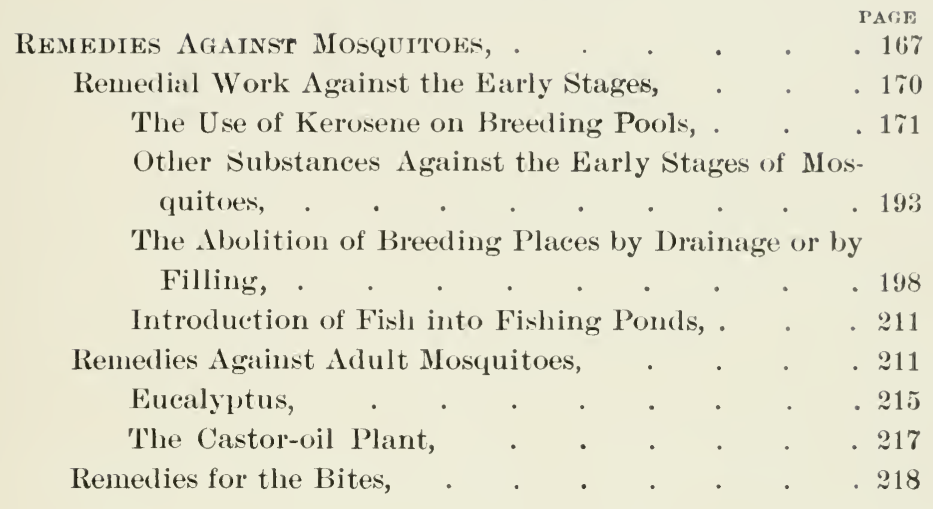

CHAPTER IX.

How to Collect and Preserve MosqutToes, . . . 220

(:HAP'TER X.

The Classification of THE UNiten States Mosquitoes, 229 



\section{LIST OF ILLUSTRATIONS}

Where Mosquitoes Breed by Millions, . . . Frontispiece FIG.

1. Culex toniorhynchus, Common Atlantic Coast " ringlegged" Mosquito, • • • • . • • . 3

2. Section of Mosquito's Head showing poison gland, . 45

3. Salivary Glands of Culex and Anopheles (after Christophers), . . . . . . . . . 4ti

4. Experimental House Oceupied by I)rs. Simbon and Low on the Campagna in the summer of 1900 (from the Journal of T'ropical Medicine), . • . • . 5:?

5. Malaria House on the Campagna, seen from a distance (from the Journal of Tropical Medicine), . . . . 5j

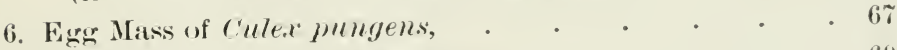

7. Young Larve of Culex pungens, _ . . . . . . 69

8. Mouth-parts of Larva of C'ulex mungeus, . . . . . 70

9. Full-grown Larval of Culex pungens, . . . . i1

10. Pupa of Culex pungens, with Anal Segment below,

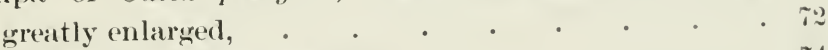

11. Adult Male of Culex pungens, . . . . • . it

12. Adult Female of Culex pungens, . • • • • i.j

13. Resting Position of Amplieles marulipennis, . . . 95

14. Anopheles and culex (after Waterhomse), . . . 95)

15. Anopheles marulipennis, Adult, . . . . , !nt

16. Egg Mass of Anopheles mantipennis, . . . , yi xiii 
FIG.

17. Individual Egrs of Anopheles maculipennis, . 98

18. Young Larva of Amopheles macnlipennis, . . 100

19, 19ג. Half-grown Larva of Anopheles maculipennis in comparison with Culex Larva, . . . . . 101

20. Half-grown Larva of Anopheles maculipennis, . . 102

21. Full-grown Larva of Anopheles maculipennis, showing

head upside down, with top of head above, at left ;

greatly enlarged, . . . . . . . . . . 103

22. Enlarged Head of Larva of Anopheles maculipennis, un-

der side (after Nuttall), . . . . . . . 104

23. Enlarged Head of Larva of Anopheles maculipennis, from

side (after Nuttall), . . . . . . . . 105

24. Pupa of Auopheles in comparison with Pupa of Culex, . 106

25. Head of Full-grown Larva of Anopheles punctipennis, . 108

26. Anopheles punctipennis, adult female, . . . . . 110

2\%. Anopheles punctipennis, adult male, from side, . . 111

28. Anopheles crucians, adult female, . • . . . . 114

29. Anopheles aryyritarsis, adult female, . . . . . 116

30. Stegomyia fasciata, adult female, . . . . . . 123

31. Stegomyia fasciata, adult male, . . . . . . 127

32. Stegomyia fasciata, adult male, from side, 132

33. Stegomyia fasciata, body scales, . . . . . . 133

34. Larva and Pupa of Stegomyia fasciata, with enlarged parts, . . . . . . . . . . . 135

35. Mouth-parts of Larva of Stegomyia fasciata, . . 137

36. Cross Section of Head and Beak of Mosquito, showing Filiarias entering Beak, . . . . . . . 141

37. Psorophora ciliata, adult female, . . . . . . 145

38. Females of Psorophora ciliata at rest on side wall and ceiling, . . . . . . . . . 146

39. Male of Psorophora ciliata, from side, . . . . . 147

40. Young Larva of Psorophora ciliata, . . . . . . 148 
FIG.

PAGE

41. Full-grown Larva and Pupa of Psorophora riliate, with

enlarged parts, . . . . . . . . . 149

42. Aëdesfuscus, adult female, . . . . . . . . 153

43. Toxorhynchites rutilus, adult female, . . . . . 15t

44. Gasterosteus aculeatus-Stickleback, . . . . . 158

45. Gambusia affinis, male and female-Top-minnows, . 159

46. Fundulus notatus-Top-minnow, . . . . . . 160

47. Lepomis pallidus-Sunfish, . . . . . . . 163

48. Claws of Front Feet of Culex stimulans, male and female, . . . . . . . . . . . 230

49. Claws of Front Feet of Culex perturbans, male and feinale, . . . . . . . . . . . . . . . . . . . . . .

50. Wing of Culex consobrinus and C'nlex pipiens, showing petiole of first submarginal cell, . • . . . 232 

MOSQUITOES 



\section{I \\ Wosquitoes in General}

The Life Romnd of Moscnuitoes.

LL mosquitoes, so far as known, are aquatic in their early stages. It has never been shown that I any of them lay their eggs anywhere except in water. Their larve live unler the surface of the water, although they are true air-breathers; that is to say, they must come to the surface of the water to breathe. This breathing is performed through branched tracheal tubes within the body, which terminate in an orifice at the end of a prolongation of one of the last segments of the abdomen, and which from this fact is known as the respiratory tube. This tube is pushed at intervals up through the surface tilm of the water and air is drawn down into the trachere. The larve feed either at the surface or below the surfice, and their food is composed of all sorts of floating particles, and in the case of some of the larger forms they may even bite aquatic regetation. They are rapid breeders and pass the pupal condition also in the water, but floating normally at the surface. In the pupre they breathe not from a breathing tule at the anal end of the abdomen, but from two trumpet-shaped tubes issuing 
from the top of the thorax. The thorax of all is much swollen, and with all pupa the bodies seem lighter than air, so that they float at the surface without exertion. The pupa, however, are active-sometimes very active. The abdomen, with anal oar-like flaps, may be quickly and violently agitated so as to draw them down below the surface, when it becomes necessary to escape from a fish or from some predatory aquatic insect. This great activity is necessary for the preservation of species, since stagnant pools abound with carnivorous forms of life, and such a little, fat morsel as a mosquito pupa, if it always stayed quietly at the surface, would stand no chance. When one tries to catch a pupa with his thumb and forefinger, at even the approach of the hand it disappears like a flash, rising slowly to the surface again when the active movements of the abdomen cease; that is to say, when it gets tired or when danger ceases to threaten.

All mosquitoes, so far as known, are rather rapid breeders. They pass through several generations in the course of a year, and hibernate in both adult and larval stages. Over-wintering mosquitoes may frequently be found in the cellars of houses, in cold garrets, in barns, under the lids of water-tanks, under bridges and stone culverts. In the extreme Southern States many mosquitoes are active all through the winter, and in most tropical regions they may breed all the year round. In dry, tropical regions, however, they breed only through the rainy season, and in the dry spell the species is perpetuated by the persistence of the adults, which either remain active, or more usually rather inactive or dormant, just 


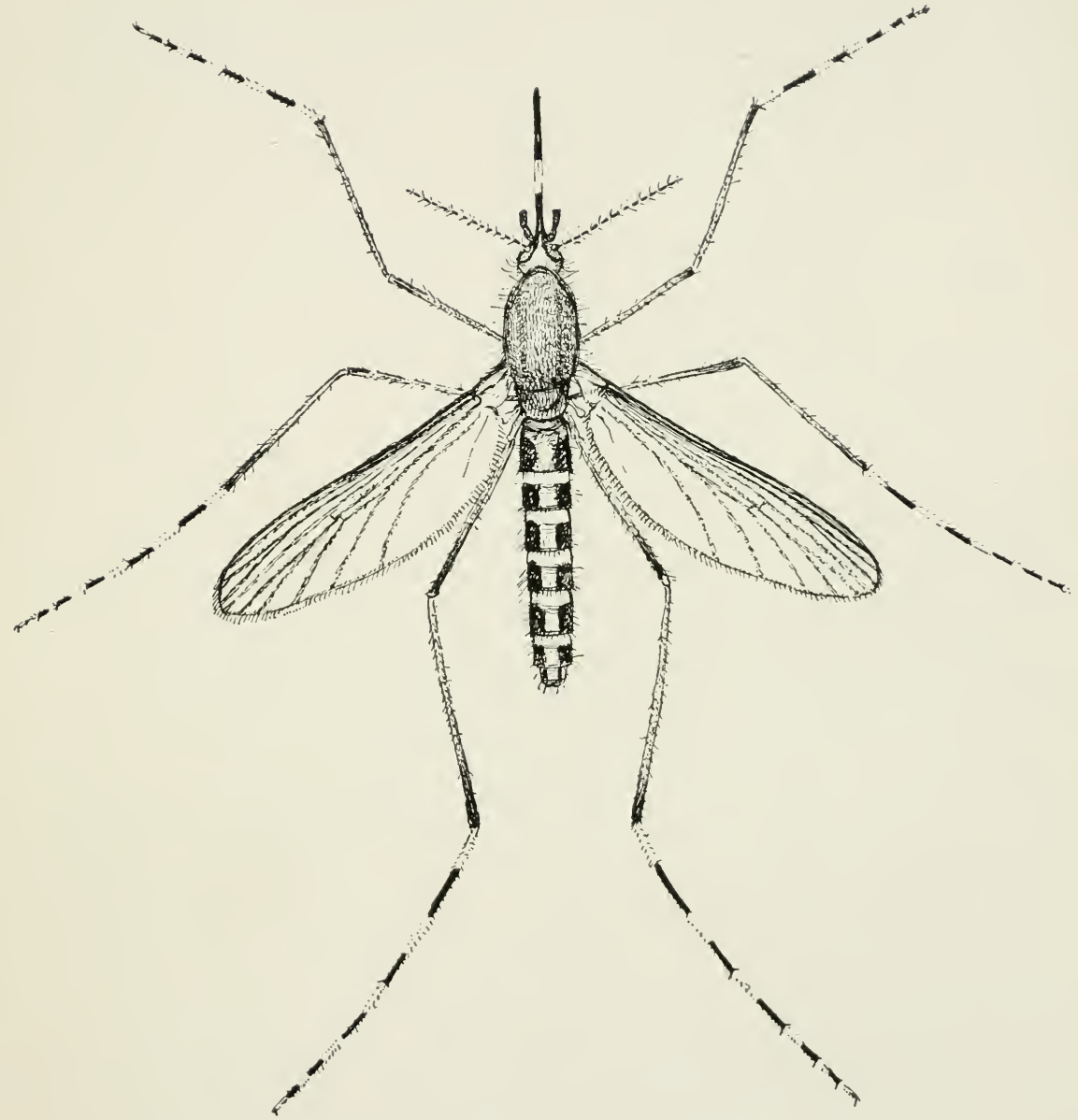

Fig. 1.-Common Atlantic Coast " wing-legged" Mosquito (Culex sollicitans) ; greatly enlarged. (Author's illustration.) 
as though they were hibernating. In such dry spells the males generally die and the gravid females live over. 'This is also the case in winter hibernation in the north; females are, as a rule, impregnated when hibernation time comes, and they live until the ice melts and the weather becomes of the proper temperature for the laying of eggs. As shown by recent observations by Mr. J. Turner Brakeley and Dr. John B. Smith, larve, on the approach of winter, may be frozen up in the ice and when thawed out resume their growth, so that many undoubtedly hibernate in this way.

\section{Parthenogenesis Among Mosquitoes.}

We have just stated that the males impregnate the females and then die during the early winter or during the early part of the dry spell in tropical countries, but there is evidence that parthenogenesis, or virgin birth, sometimes occurs with mosquitoes, as it does with so many of the lower forms of life.

Professor V. L. Kellogg, of Stanford University, reared in a covered jar, from the pupa a female mosquito which almost immediately laid egas. There was no other mosquito in the jar and certainly no mating. From these eggs there hatched larve, which grew very slowly and nearly reached full growth before they died. None of them succeeded in reaching the pupa stage. It is possible that they died on account of their abnormal birth, but there is also the possibility that they died from lack of proper food, and that under other conditions adults 
might have been reared. Professor Kellogg's observation indicates plainly that interesting studies can be made with mosquitoes in this direction, and it will be especially interesting to observe the sex of the adults reared from wigglers of virgin birth.

How Long can the Larve Live Under Water?

In observations which I have made upon mosquito larve of the genus Culex, I have been muble to time them below the surface for more than two minutes. As a rule they return to the surface to breathe after the expiration of not more than a minute. With the larræe of Anopheles, as will be shown later, the case is different. Although the larve remain at the surface of the water during the early part of their lives, when they become full grown they will descend to the bottom and mouth over the slimy grains of sand or water-plants which are to be found there. In this operation they have been timed by one of my assistants, Miss Sullivan, and remained ten minutes before ascending for air. It seems also, from observations made by Dr. John B. Smith, that even Culex larve may stay below for a longer period than I have observed. In the Entomological Ners for March, 1901, he states that he has timed them under water for as long a period as ten minutes, and in a later publication states that these same larve which were C'ulex pungens which had been taken in ice, remained under water for fifteen minutes and more. 


\section{How Long may the Larve Live?}

Professor Kellogg reported an interesting series of observations in the Entomological News for April, 1899, in which he shows that eggs were laid by a mosquito in his laboratory August 9th. (The eggs, by the way, were laid at 4.30 in the afternoon, a novel fact in itself, since it has been supposed that they were only laid after dark, and presumably usually in the dark hours of early morning.) These eggs hatched October 10th, and were kept alive in a jar of water at a temperature of from $50^{\circ}$ to $75^{\circ} \mathrm{F}$. under normal conditions as regards light. They grew in size very slowly and one after another died. But the sole survivor lived until February 16th, when it died at the ripe old age of four months and a week. None of them reached the pupal condition. As mentioned above, Professor Kellogg thinks that their death may have been due to the fact that their mother was a virgin and the slowness of their growth may have been due to lack of proper food and water.

We have stated above that mosquitoes hibernate in the adult condition. That has been a matter of common observation and has been a generally accepted fact. I have always supposed it to be the only mode of hibernation, but an observation by Mr. J. Turner Brakeley, of Hornerstown, N. J., made during the past winter, indicates that they may occasionally pass the winter in the larval condition. Dr. John B. Smith wrote me, under date of January 30, 1901, that Mr. Brakeley went out into the 
marshes and collected a considerable number of the leaves of the pitcher plant (Surracenic) filled with a solid mass of ice. He brought them into the house and thawed out the contents, and as a result sent Dr. Smith two bottles of very lively mosquito larvæ. It seems that the temperature of the marshes had been $22^{\circ} \mathrm{F}$. below zero and everything had been frozen solid for some time. Mr. Brakeley wrote that the larvie were embedded in different parts of the ice, and that in looking through the ice you could see the insects. He sent over one hundred of these thawed-ont larve to Dr. Smith, who stated that they reached him in good condition and that they lived, moulted, and grew thereafter in his laboratory. Adults issued in March and proved to be Culex pungens. The great numbers in which these larve were found, suggests to Dr. Smith that larval hibernation must be extremely common, not only in New Jersey and in pitcher plants, hut elsewhere and in other accumulations of water. The observations are of extreme interest and importance.

\section{How Long can the Larvie Live Out of Water?}

The fact that these insects remained lormant when frozen up in ice for an indefinite period, from the observations of Mr. Brakeley, might at first seem to indicate that the theory which has been advanced, that when their mud-bottomed breeding-places dry up they remain alive in the earth, is in a measure substantiated. But, in reality, it has little hearing upon summer temperature conditions. Experiments which I have tried on a small 
scale in glass vessels have shown that the larve of Culex will exist for some little time in wet mud and that some of them will snccessfully transform after water has been added, but in no case were we able to revive larve in mud from which the water had been drawn off for more than forty-eight hours, and after twenty-four hours only a small proportion of the larve revived. These results accord very accurately with those reached by English observers in Africa, and, in fact, accurate observations have not carried the larve out of water alive for more than forty-eight homrs. The impression to the contrary has probably been gained from observations on pools which in reality did not entirely dry mp. Mr. C. A. Sperry, of Chicago, has male observations upon a pond which dried up and in which he conld find no dead larve, but he writes that after a week it rained and as soon as the rain stopped he found the mosquito larve all throngh the water as lively as ever, and they began to issue as adults in abont a week from that time. Mr. Benjamin S. Pascal, of Newfield, N. J., has sent to me an account of olsservations of his own which indicate to him that mosquitoes may breed in grass or moist earth.

In the summer of 1900 , I watched a slowly evaporating pool with great interest. It contained a surface area of abont twenty-four square feet, and was fed entirely by rain-water and surface drainage. It was well stocked with mosquito larve, and after a long dronght the water was observed to have evaporated almost entirely, only a small puddle remaining in the centre, which contained at the outside only three or four cubic inches of water. It 
was dark in color, owing to the drainage from a manurepile near by, and when glanced at casually showed no signs of life ; but on dipping in a coffee-strainer it was found to be literally massed with nearly full grown mosquito larvi, many hundreds of which had been brought together into this restricted place. Drying continued until there was almost no water left, but before the larva died, that is to say, about twenty-four hours after the water contents were estimated at from three to four cubic inches, there came a heavy rainstorm which filled the pond with water, after which it was seen to contain apparently its usual stock of mosquito larræ. From this observation we are able to estimate the usual happenings in a mosquito pool. As the water dries the larve gradually retire to the deepest point, and after the pool is apparently dried up there is still enough moisture at this deepest point to keep the larrie alive a number of hours. That they may die, and that, as I believe, they invariably do die in the absence of all moisture and in a space of time which must be reckoned by hours and not by days, is evidenced by the laboratory observations mentioner above.

\section{Length of Life of Adult Mosquitoes.}

It is very difficult, in fact practically impossible, to estimate the normal length of life of the adult of any species of insect that flies. We may keep them in confinement and count the few days of their life, but the conditions are abnormal and camot be made perfectly 
normal. An insect in a breeding-cage may die in twentyfour hours, but that does not mean that it may not live for wceks ontside. Certain insects die quickly from fright under such conditions, or from riolent efforts to escape. I once covered a rery large Yncea plant with ganze netting and placed under the netting about a humdred honey bees, in order to see whether the flowers of Yucea could be fertilized by bees. In twenty-four hours every one of the insects was dead, and yet we know that the honey bee is a long-lived insect. Such evidence as we have, howerer, shows that mosquitoes are also longlived. It seems that they cannot live many days without plenty of air. Dr. Teazie, of New Orleans, writes me that he has kept them alive with various substances for a month. Withont water or food, the limit seemed to him, from his observations, to he five lays for all varieties he tried. If there is no water in the house he states that the mosquitoes will leave the house and seek water. He has seen them repeatedly go down into a pitcher or a glass, remain for a few minntes, and then fly away. He thinks that they do that principally to get a drink, although he has found eggs in a glass of water and in pitchers. Mr. Mitchell, of Victoria, Tex., however, writes that he kept a number of mosquitoes in a box once, to see how long they conld live on air, and that on the twenty-first day none had died. Medical observers in their experimental work with the mosquitoes of the genus Anopheles have been able to kecp adults alive muler glass, by feeding them npon slices of banana or some other fruit, for weeks, the hanana being renewed 
every three or four days. Dr. Woldert, of Philadelphia, has kept adults for two weeks or more in a bottle with a slice of banana, sprinkling the ganze-covering occasionally with water. He has even kept them for from fifty to sixty days, but this was in the fall of the year, and, as we have elsewhere shown, mosquitoes hibernate in the adult condition and the significant life-period of the adult is the summer period. We know that they will live through the winter, but we lo not know whether, under normal conditions, those hatching in the spring will live through eren half the summer. There used to be a current idea that when a female mosquito sucks a full meal of biood she is never able to bite again, since it was thought that she is mable to thoroughly digest such a meal. This idea, however, has been completely exploded in the experimental medical work, and a more approximate estimate of the length of the adult life has been reached in this experimental medical work, than has been elsewhere gained. The army surgeons who have been working on the subject of mosquitoes and yellow ferer have shown, as, in fact, had Dr. Finlay before them, that the same mosquito will bite and suck blood again and again, and Drs. Reed, Carroll, and Agramonte have demonstrated that the yellow-ferer mostuito will not convey the clisease until at least twelve diays have elapsed since the time when it hit a yellow-fever patient. In the case of Anopheles and malaria there must be an interval of seven or eight days for the proper development of the malarial oreanism in the body of the mosquito, before the disease can be conveyed throngh a 
puncture to a healthy individual. The best we can do, then, is to say that the adult mosquitoes live indefinitely - certainly, under favorable circumstances, even in summer, for several weeks-and that they may bite an indefinite number of times.

Observations by Fermi and Lumbao on Culex pipiens in Italy led them to believe that this mosquito, after emerging, devotes itself to blood-sucking and similar pleasant occupations, but that egg-laying only takes place after from fifteen to twenty days, and that after ego-laying the females die. This olservation may he perfectly correct, but it is contrary to the customary rule with insects, since it is almost a law that after the issuing of the adults the first and main business of life is the perpetuation of the species.

Transformations of Mosquitoes Artificially Hastened.

Tn the summer of 1900 , while engaged in making experiments as to the insecticidal effect of creosote-oil ponred upon the surface of water in breeding-jars containing mosquito larve, I male what seems to me to be a most interesting observation. In one battery jar containing three quarts of water, eighty nearly full grown larve of Culex stimuluns and C.perturlans were placed, and onefourth of an ounce of creosote-oil of a specific grarity 1.035 at $60^{\circ} \mathrm{F}$. was poured. This was jar No. 1. In another jar were two quarts of water in which were placed 150 larve of the same species, all full grown or nearly so. Upon this water, three-sixteenths of an ounce of a some- 
what heavier creosote oil was poured. This was jar No. 2. When at 4.15 P.x. the creosote was poured in jar's 1 and 2 , no pupe were observed, but all larve were full grown or nearly so. After fifteen minntes ten pupie were observed in jar 2 and five in jar 1 . Ten minutes later fifteen were counted in jar 2 and thirteen in jar 1. Twenty minutes later there were nineteen in jar 2 and twenty-two in jar 1. Fifteen minutes later still there were nineteen in jar 2 and twenty-two in jar 1 . Thirty minutes later there were seventeen in jar 2 (two having died in the interval) and twenty-eight in jar 1. As above stated, over night a number of adults issued, ten in jar 1 and eight in jar 2 , and twenty-four hours later ten more adults issued in jar 1. It must be remarked that the full grown larve struggled violently on perceiving the uncomfortable presence of the creosote, and as they were just ready to transform, this violent struggling evidently assisted in the breaking of the larval skin, leaving the pupa bare. This transformation from larva to pupa is hardly as interesting as the rapid development of adults, eighteen of which issued within fifteen hours after transformation to pupa, whereas previously the shortest duration of the pupal state which we had observed was forty-eight hours. It looks like an effort of nature to perpetuate the species in the presence of a unique emergency.

\section{Mosquito Songs.}

Probably owing to an association of idleas, the curious sound made by mosquitoes as they approach one's ear is 
to most people extremely irritating. 'I'his faint somud will waken many form the sommlest sleep. It is not lond, and in forality maty perhaps best be compared to the distant note of a bagpipe. 'The somed is apparently produced, as with flies and other dipteroms insects, not by the rapid viluation of the wings, but by the vibrations of a chitinoms pocess in the large trachoo just behind the thoracic spiracles. 'These vibrations are produced by the air during respiration. Dragon-flies and bees, as well as flies, sing in this way. With bees, however, the rapid vibration of the wings causes another hum, and the two notes are most readily distingnished, the wing tone of the honey bee being $\mathrm{A}^{\prime}$, while the breathing voice is at least an octave higher, and sometimes nine or tou full tones higher, going to $B^{\prime \prime}$ and ("'. 'Jhe exact musical note of the different species of mosquitoes seems not to have been investigated, hut as longer ago as 1874, A. M. Mayer, in the course of his reseatrehes in acousties, made some most interesting experiments with the supposed anditory apparatus of some species of Culex, which, unfortunately, was not named. Mayer established the fact that some of the antennal hatis of the male mosquito are anditory. With tuning-fork experiments he showed that some of the hairs are especially tumed so as to respont to vibations numbering 512 per second. Other hairs vibrated to other notes. Healso experimented with the somer of the female, and showed that the anditory hairs of the male antemme vibrate when the song of the female comes at right angles to them. If the song is directly in front of the heat it will be most fully perecived hy the hatis. If the song of 
the female affects one antemna more than the other, the male turns his heal until both antemme are affected, and is thus able to determine the exact direction of the female, to which he then flies. Mayer fomnd that the male can thus guide himself to within five degrees of the exact direction of the female. His conclusion is that "these insects must lave the faculty of the perception of the direction of sound nore highly developed than in any other class of animals." Mayer carried his experiments firther, and made large wooden models of the hair's, with which he conducted interesting experinents. His paper is published in full in the American. Jourual of Science and Aits, vol. viii. (187t), pages 89-103, and should be read by thoso interested in this subject.

Recently, Mr. A. DeP. Weaver, an electrical engineer of Jackson, Miss., wrote me that while engaged in some experiments in harmonic telegraphy, in which a musical note of a certain pitch was produced by electrical means, he was anazed to find that when the note was raised to a certain number of vibrations per second, all mosquitoes, not only in the room where the apparatus was, but also from other parts and from ontside, would congregate near the apparatus and would bo precipitated from the air with astonishing force, striking their bodies agrainst the apparatus. He states that he therefore corered a large surface with sticky fly-paper and after sounding the note for a few seconds eaptured all the mosquitoes in the vicinity. He then devised an apparatus to electrocute them. A section of wire window screcn with the paint removed was mounted on a board and small pins were 
driven between the meshes, the heals coming flush with the surface of the screen. All the pins were comnected together electrically, the whole forming one electrode of the secondary coil of an induction coil, while the wire screen formed the other electrode. An alternating current of high potential was then passed and when the note was sounded the insects precipitated themselves against the screen and were immediately electrocuted. Mr. Weaver, unfortunately, does not state whether males only were captured in this way. His letter was an extremely interesting one, and surely his sticky fly-paper experiment suggests that further experimentation in this direction would be worth while.

Apropos to the difference in the musical note of different kinds of mosquitoes it should here be stated that, as will be pointed out in our consideration of the malariabearing mosquitoes of the genus Anopheles, the somnd made by the female Anopheles is distinctly lower in pitch than that made by the less harmful mosquitoes of the genus Culex. An interesting parallel to this is the fact that the villain in the play has usually a bass voice!

How Far do Mosquitoes Fly? Are They Carried by Winds?

A very important point to be considered by persons who are engaged in extermination work against mosquitoes is the one suggested by the heading of this section. To the owner of a large estate it is most discouraging to anticipate that at the close of careful remedial work, in 
which the drainage of breeding-places and kerosening of breeding-pools has been carried on, hungry swarms of mosquitoes maly fly in from a distance or may be carried in by winds, to camp upon his grounds and in his house and renew the amnoyance of the irritating punctures, and perhaps even to seek out some neglected breeding-place and start new generations. Therefore the question of the length of flight is a most important one. In the summer of 1900, Mr. W. J. Matheson, living at Lloyd's Neck, Long Island, a spot formerly infested by mosquitoes to an extrarordinary degree, by intelligent exterminative measures succeeded in practically stopping the breeding of mosquitoes upon this rather narrow neck of land. It resulted that his house was mosquito-free until toward the end of Angust. 'Then, after a gentle and continuous wind of two or three days' duration, specimens of another kind of mosquito put in their appearance in large numbers. The explanation was obvious. These mosquitoes had flown across a strip of water forming one of the entrances from Long Island Sound to Oyster Bay, for a distance of a mile or a little more, aided by the gentle and continuous wind.

'This incident points out an important condition of affairs. Ordinarily, it may safely be said that mosquitoes do not fly far. Where there is water favorable for egg-laying in the immediate vicinity of the place of their birth, and especially where there are warm-blooded animals upon which they may feed, they have no migratory incentive. Then again, they are not strong fliers, as insects go. It seems perfectly certain, from the evidence 
which has been collected, and especially by that adduced by Mrs. C. B. Aaron in her essay in the little book entitled "Dragon-flies versus Mosquitoes" (The Lamborn Essays, Appleton \& Co., 1890), that mosquitoes are very careful not to take wing during a strong breeze. Mrs. Aaron's worls are wortl quoting:

The migration of mosquitoes has !een the source of much misapprehension on the part of the public. The idea prevalent at our seaside resorts that a land breeze brings the swarms of mosquitoes from far inland, is based on the supposition that this insect is capable of long-sustained flight and a certain amount of battling against the wind. This is an error. Mosquitoes are frail of wing ; a light puff of breath will illustrate this by hurling the helpless creature away, and it will not venture on the wing again for some time after finding a safe harbor. The prevalence of mosquitoes during a land breeze is easily explained. It is usually only during the lulls in the wind at such times, that Culex can fly. Generally on our coast a sea-breeze means a stiff breeze, and during these even the Odonata, and often the robust and venturesome 'Tabanidæ, will be found hovering on the leeward side of the houses, sand-dunes, and thick foliage. In the meadows south of Atlantic City, N. J., large swarms of Culex are sheltered in the dense grass or wind-battered tree-tops on the off side of the sand-dunes. Here, in common with all localities so exposed to searching wind, the trees and large bushes are much stunted in growth and battered down to a tlat top and common level by the wind. In these matted branches, dense with the close-clustered foliage, the mosquitoes may be discovered in such numbers as to bring despair to the heart of the student who is plotting their final extermination. While the strong breezes last, Culex will stick close to these friendly shelters, thongh a cluster 
of houses may be hut a few rods off, filled with musmspecting mortals who imagine their tormentors are far inland over the salt meadows. But if the wind dies down, as it usually does when veering, ont come swams upon swarms of the females, intent upon satisfying their depraved taste for blood. 'This explains why they appear on the field of action almost immediately after the cessation in the strong breeze ; on the supposition that they were blown far inland, this sudden reappearance would be unaccountable.

Many observations made by the writer and by his correspondents support these views which Mrs. Aaron has expressed. Mr. W. C. Kerr, of Staten Island, an excellent observer, is strongly of the opinion that mosquitoes are not blown over from New Jersey to Staten Island. Professor Herbert Osborn, formerly of Ames, Ia., has noticed that in dry seasons small pools within a quarter to a half a mile from the college buildiugs at Ames, dry mp, and the mosquitoes disappear, in spite of the fact that within about a mile there are large pools which never become dry. One of my former assistants, Mr. R. M. Reese, found in Baltimore that by treating breeling-places a humdred feet or a little more from his house with kerosene, the supply of mosquitoes in his house was greatly reduced, although there were many other breeding-places only twice as far away. Dr. John B. Smith, a well known entomologist, has recorded his observation that mosquitoes will not rise or take flight when a brisk breeze is blowing, and that even a comparatively slight loreeze will keep them from the upper stories of houses.

Dr. H. T. Fernald, however, after several summer's' 
work at the Cold Suring Harbor Laboratory, on Long Island, has stated that with a south breeze, especially after a prolonged and gentle wind of five or more hours' duration, mosquitoes become very troublesome and it is the local supposition that they are carried from the south shore of Long Island, fifteen miles away. 'This is, the writer finds, the general opinion at several points on the north shore of Long Island, but observations which he has made on the mosquito topography of that portion of the island have shown that there are usually many breeding-places much nearer than the south shore, and usually quite near the infested places, which will much more easily account for the mosquito supply. In fact, careful olsservations male by Mr. H. C. Weeks, of Bayside, Long Island, have shown that in the immediate vicinity of the Cold Spring Harbor laboratories there are many breeding-places of such extent and such capacity as to indicate that the south shore theory must be abandoned.

So many instances, in fact, have come to my attention, where extensive breeding-places profusely stocked with mosquito larve have been overlooked by the people of given neighborhoods, that I have, as a general rule, become more or less incredulous on the subject of extended mosquito flights. Fermi and Lumbao, in their report on operations in Sassari, state that the mosquitoes of the city do not go far from their original breeling-grounds, since they find sufficient food near the habitations of people and animals. The reason which the Italian anthors give for this absence of migration may be correct or incorrect, but their experience has shown that where a house loca- 
ted near the centre of a city or village is found to be infested by mosquitoes, search for the larræ should be made in the house or near it, particularly in cellars or cisterns, in wells, in water-troughs, in sinks and tubs in the yard, and so on. The truth is that people do not take the trouble to make the careful search, and prefer to jump to the conclusion that the mosquitoes have flown in upon them from a distance. Mr. C. A. Sperry, of Chicago, writes that he is perfectly satisfied that mosquitoes are never distributed by the wind. When the wind blows they are always on the ground, clinging to a support. They are seldom, if ever, seen as high as the third flat in the city. He further makes the suggestion that the idea that they are conveyed by the wind deters many people from making an effort to rid themselves of the nuisance, which can so easily be accomplished. In one case, at a summerresort on Long Island, a man told him that the mosquitoes came there from New Jersey, while not two hundred yards from his house was a pool that in Mr. Sperry's opinion produced all the mosquitoes that were such a troublesome pest and drove hundreds away from his place. Mr. Sperry is a close observer of mosquitoes and has studied them for years.

Dr. C. W. Stiles, of Washington, howerer, is inclined to take a somewhat opposite view from Mrs. Aaron. He informs me that it has been his experience, at his summer cottage on the New Jersey coast, that mosquitoes bother his family only after land breezes have continned for several days. The cottage is sitnated abont one-third of a mile away from the wooks, toward the sea and within one 
liundred yards of the surf. As it is absolutely isolated from trees, and as the mosquitoes do not appear luring a lull in the breeze, but only after several days of land breeze, it appears to him that the popular view of the influence of land breezes upon spreading mosquitoes seaward is not wholly without foundation.

All the evidence so far adduced refers to more or less normal conditions and, in fact, such conditions are the only ones which need practically be considered. Tnder very exceptional conditions, howerer, it seems perfectly plain that mosquitoes may migrate for considerable distances; two such instances are described in the following lines quoted from a recent letter received from the Honorable J. D. Mitchell, of Victoria, Tex., a reliable observer and a naturalist.

. . I have witnessed, in my life, two migrations of mosquitoes, that will always be fresh and vivid in my memory.

Where the Colorado River empties into Matagorda Bay, a marsh is formed over the lowlands, by a raft in the river ; this marsh contains about eighteen square miles, and is a magnificent breeding-place for mosquitoes.

I used to ranch it on the peninsula-like body of land, formed by Carancahua Bay on the east, Matagorda Bay on the south, Keller's Bay and Creek on the west, and the Calloun County north line on the north (refer to coast maps of Texas). The distance between my ranch property and the marsh above described is, by bay route, about forty miles; the way the crow flies, about thirty-five miles. My ranch was situated on Carancahua Bay, near the north end of land.

The first migration occurred in October, 18\%9. There had been an overflow from the upper country, which filled the aforesaid 
marsh, but the balance of that section was very dry and needing rain, and there were no mosquitoes. A fairly strong easterly wind had been blowing for three days; on the evening of the third day the mosquitoes arrived, flying ligh, about fifty feet, and looking like a cloud or mist coming over Carancahua Bay. At the ranch they set everything on fire that had blood in it, and all work was suspended by unanimous consent. Cattle and horses rounded-up milled continuously ; all work stock was turned loose as quick as possible and they went to the round-ups at full speed, and little or nothing was done for nearly five days; by this time the main body had passed, though plenty remained to make everything uncomfortable for about two weeks. This migration was from east to west and the line was about three niles wide-above and below this there were no mosquitoes.

Migration No. 2 occurred in October, 1886. They came from the same marsh before described-this migration confined itself to the Matagorda Bay shore line, reaching inland about half a uile; there were as many mosquitoes in this limit as there were in the three miles of migration No. 1 . They clouded the sky, bent down the grass with their weight, and made all driftwood and ground the same color. All stock left the shore and went north outside of the line of marsh. The wind was light and from the sorth, and did not affect the mosquitoes in their flight, which was westward; the main flight was low, ten or twelve feet high and always in the same direction. With three other men I rode into the swarm to a large pile of drift and trash and set it on fire, and stool in the smoke for some time watching them. They passed sometime during the third day, leaving very few stragglers behind. By inquiry, I traced both of these swarms from the marsh before described to fifteen or twenty miles west of my ranch, a total distance, air line, of fifty or sixty miles.

No. 1 crossed 'Trupalacios Bay, where it was five miles wide, and Carancahua Bay, where it was one mile wide. No. 2 holding to 
the shore line, crossed Trupalacios Bay, three miles, Carancahua Bay, at Pass, 300 yards, Keller's Bay, at Pass, half mile, Cox's Bay, one and a half miles, and Port Lavaca Bay, four miles.

It may incidentally be stated that malarial mosquitoes of the genus Anopheles seem much less capable of extended flight than the commoner mosquitoes of the genus Culex. Dr. F. A. Young, of the British Army Medical Service, on his way home from Shanghai, where he had been conducting experimental work against malarial mosquitoes, called on me in February, 1901, and stated that it was his firm conclusion that, as a rule, Anopheles will not fly over two hundred yards, and that a breeding-place more than two hundred yards from the house will not supply malarial mosquitoes to that house, provided there are other houses nearer. He mentioned a number of circumstantial instances supporting this view. Christophers and Stephens, however, in their reports on the malarial expedition to Sierra Leone, state that it is certain that under some circumstances Anopheles may fly much greater distances than has been supposed. In one small inland house which had been occupied by one old man, five or six Anopheles were to be caught each morning. These were freshly hatched and could only be derived from a breeding-place three to four hundred yards away. In another place the same writers show a flight of six hundred yards. But, after all, what are even six hundred yards? In an effort to free a locality from malaria such distances become insignificant.

On the whole, it seems to the writer that in almost no 
cases need an individual or a community be deterred even for a moment from attempting remedial work against mosquitoes by the idea that the mosquito supply is likely frequently to be renewed by flights from long distances or even from distances of much more than a single mile. A far more serions sonrce of re-establishment of the mosquito supply will be considered in the following section.

\section{Carriage of Mosquitoes by Railway Trains and other Conveyances.}

That mosquitoes are carried by railway trains must be a matter of common observation to everyone who travels. That this method of distribution is and has been a very important one, has, however, been rather generally overlooked. It is said that mosquitoes were nuknown in Hawaii until bronght over in sailing vessels from the Cnited States. On these sailing ressels they harl probably bred more or less continnonsly in the water-larrels, and when once introdnced into the islands they lired with great facility in the swamps and fresh-water ponds, and to-day these insects are said to be very abmulant there.

Beyond the statement which occurs in Nuttall's monograph (1899), where the probable influence of winds, railways, and ships in the dissemination of moscquitoes is briefly mentioned, the sulject had received practically no consideration until it was bronght ont in the bulletin entitled, "Notes on Mosquitoes," prepared by the anthor and published by the Cnited States Department of Agri- 
culture, in August, 1900. It was there stated that by means of railway trains unlimited quantities of mosquitoes are carried unlimited distances, and on emerging from the cars they start to breed, even where mosquitoes are ordinarily rare, or would be rare under ordinary conditions. In this way, even mountain-resorts were said to get their supply of lowland mosquitoes, and the constantly increasing danger of this method of distribution, throngh the perfection of the railway service and the increase in the number of through cars, was pointed out. It was shown that although the State of New Jersey, as an example, has a bad mosquito reputation, that does not necessarily mean that there are any more breeding-places in the interior of the State, or that New Jersey mosquitoes are any more prolific than elsewhere. The constant abundance of mosquitoes in New Jersey seemed to the writer to be dependent upon the fact that the coast is lined by many swamps, and that all through the summer evenings many trains are started inland from nearly a dozen points on the coast, from Weehawken to Cape May. These trains may contain mosquitoes by the hundreds, and at every stop they may fly from the cars and seek breeding-places near the railway.

A discouraging feature of this method of spread is that although exterminative work of the most thorough character may be carried on in any locality near a railroad. new supplies of mosquitoes are constantly being brought in and will begin to breed wherever water can be found. I called attention to the fact that in the Catskill Momntains one place which had come under my observation 
was free from mosquitoes, until through cars on the railroads brought them up from the vicinity of New York City.

After the publication of this bulletin some doubt was expressed by the newspaper reviewers of the importance of this method of dissemination; but confirmatory evidence of a striking character has since been gained, although, as a matter of fact, the proposition was so selfevident that it did not need confirmation. The interesting community work undertaken against mosquitoes by the city of Winchester, Va., and which will be referred to in detail in the chapter on remedies, has brought ont the fact that Winchester was at one time a farorite summerresort, and that mosquitoes were practically mnknown, lut that with the establishment of a night train on the Baltimore \& Ohio Railroad, running from Camden Station, Baltimore, in the summer-time, mosquitoes began to be a positive annoyance in Winchester. Unfortunately, with the establishment of this night train, or about the same time, Winchester extended its system of water-works and did not build sewers. As a result, with the arrival of the mosquitoes from Baltimore there was a plentiful supply of standing water all throngh the city, and conditions were thus perfect for the development of mosquitoes in enormous numbers.

Mr. C. A. Sperry, of Chicago, who formerly lived in Mexico, has informed me that in the ('ity of Mexico, before the railroals were built to 'Timpico and Vera C'ruz, there were no mosquitoes. They wre hronght up from the coast, however, in the cars, and established them- 
selves there. Tampico and Tera Cruz, both low-lying cities, had always had mosquitoes in numbers. The City of Mexico, lying on a table-land 7,000 feet above the sealevel, and with a cool and pleasant climate, having no mosquitoes, thus with the adlition of railroad facilities became infesterl.

Mr. C. P. Lommbnry, govermment entomologist of the Cape of Good Hope (in litt.), is responsible for the statement that the railroads in Cape Colony have been responsible for taking mosquitoes to many inland towns which before the alvent of the iron horse were quite free from the pest. Another correspondent gives the details of a precisely similar introduction of mosquitoes into a high-lying Missouri town.

In a similar way, stage-coaches are responsible for the sprear of mosquitoes. Grassi, the Italian investigator, states that he comnted two humbred specimens of Anopheles on the insile of a coach, during a drive lasting two hours through the plains of Capaccio, and the same olserver has recorded the eapture of malarial mosquitoes in a railway carriage travelling from Florence to Berlin.

Queer Places in which Mosquitoes Breed.

In the report of the Liverpool School of Tropical Medicine's Malaria Expedition to Sierra Leone, it is stated that mosquitoes were found breeding in the broken botthes which were placel mpon the top of a stone wall to act as a cheral de firise, and that they were found also breeding in the flower vases on the tables in the houses 
of European residents, the servants having conscientiously changed the flowers every morning, but with a corresponding lack of conscientionsness onitted to change the water. I have found them breeding in an old tin tomato-can on the dumps in Washington. Mr. W. P. Seal, of Delair, N. J., writes that he finds the larve of mosquitoes in rain-filled hollows in apple, maple, and other trees, often at a considerable distance from the gromud. Mr. Pratt has found them breeding in a hollow stmmp near Bladensburg. Mr. Pergande has shown that they breed in the closed sewers in Washington, entering through the perforated sewer-traps and emerging through the same holes. Mr. Matheson showed ne an old disused well which was covered with a board cover, but on lifting the cover mosquitoes were found roosting on the under side in large numbers. There was a crack in the cover sufficiently large to admit them, and they smelled the water below, worked their way throngh the crack and bred in the old well. They will breed in all water-tanlis, and the cover must be absolutely tight, since gravid females are so strongly attracted by water that they will work through a crack which seems almost too small to admit their bodies. Dr. John B. Smith says that they are found in New Jersey in great numbers in the pitchers of the pitcher plants of the genus Survecmin.

These statements refer for the most part, if not entirely, to the common mosquitoes of the genus Culex, which we assume to be comparatively hammless from the diseasecarrying standpoint, but they indicate plainly that where one's object is to rid a house or a neighborhood of mos- 
quitoes, in order to aroid their irritating punctures and to produce the condition of general comfort which the absence of mosquitoes brings, no possible spot where water can accumulate should be orerlooked. The smallest possible collections of stagnant rain-water become breeding places and may swarm with larve. Mr. E. E. Austin, of the Liverpool Tropical School Expedition, has seen in West Africa that discarded bottles, Swiss milk and sardine tins, and cocoanut husks, frequently swarm with larve, while the water which accumulates in disnsed calabashes and other ressels lying about outside of houses is used for breeding. Mr. R. H. Pettit (Bul. 186, Mich. Agric. College Exp. Sta.), in a report on "The Insects of the Upper Peninsula of Michigan," writes as follows: "Land that is being cleared furnishes an ideal place for them to breed. Holes made in removing stumps and into which water has settled are often fairly alive with wrigglers." $\mathrm{He}$ collected a large number of larve and pupie from a hole which would hold only a small quantity of water, and bred adults from them.

We have mentioned above that Dr. Smith has found them breeding in the pitchers of the pitcher plant, and Dr. Henry Strahan, in the Journal of 'Tropical Medicine for Angust, 1900, shows that mosquitoes breed in Lagos, West Africa, in similar plants. In the summer of 1900, Mr. W. J. Matheson, of Lloyd's Neck, Long Island, after a most successful work, which included the drainage or treatment with kerosene of every possible ascertained breeding-place within a half mile or more of his house, in October, on going into his greenhouse, noticed three or 
four mosquitoes, and on looking around for their breedingplace he discovered it in a tank at the corner of the greenhouse, in which the gardener was in the habit of keeping from thirty to forty gallons of cistern water, in order that it might be of the temperature of the greenhouse. The tank was apparently full of mosquito larvæ. On measuring out in a quart jar, and counting them, Mr. Matheson estimated that there were probably in the neighborhood of three thousand larvie. This is a very interesting instance as illustrating the point upon which we have just insisted, since, after the exterminating work which had been done, these three thousand mosquitues would have caused considerable annoyance to the household, and might have given rise to the opinion that they had flown in from an unknown distance.

Mr. H. C. Weeks, in the Scientific American Supplement for January, 1900, very forcibly puts one aspect of mosquito breeding in the following words: ". . . a careful supervision by those whose study of the subject quickly enables them to detect the dangers from old sources, as well as from new ones arising from constantly changing conditions, especially about the towns - the building of a railroad, the making of a drive, the blocking of an outlet to water by the washings of a storm or the falling in of some excavated materials, the building of a new house whose waste water is" not properly cared for, these and a hundred others are exigencies which require an interest in the subject and a careful and minute watchfulness."

Mr. Pergande's interesting discovery that they breed 
in the closed sewers in Washington, deserves more detailed mention than we have given it. His house in northeast Washington being infested with mosquitoes and no exposed standing water occurring in the vicinity, he thonght of covering the small perforated sewer-trap in his back yard with a wire screen. To prevent the possibility of mosquitoes entering the screen from the outside, a layer of cotton was placed around the edge of the trap on which the screen rested. On August 24th two females of C'ulex pungens were found under the screen. September $3 d$ another was found in the same place, but it went back to the sewer as soon as the rays of the sum struck the screen. September 6 th, 10 th, and 11 th, five more were caught. Female mosquitoes in search of breeding-places had evidently flown through the sewertrap perforations, hat found standing water in the sewer and laid their eggs, from which a generation of adults was developed.

There are other localities in Washington, far removed from the Potomac River front, where mosquitoes are more or less abundant, and where there seems to be no standing water in which they can breed. It therefore seems reasonably sure that this sewer-breeding may be rather conmon in certain cities where the general slope is so slight that the water may almost stand still for a few days, in the absence of very heavy rains which flush the sewers. Of course such breeding will easily be stopped by a little neighborhood work, either by occasionally pouring a little kerosene down the sewer-traps or by covering them with a wire screen, as did Mr. Pergande in his experiments. 
Another instance of the necessity of searching out of the way places for mosquitoes and larve has recently been told me by Dr. James Carroll, U. S. A., a member of the Yellow-fever Commission. Visiting an army officer in charge of a post in Cuba, he found the yellow-fever mosquito in numbers in the quarters. The officer in charge could not imagine where they came from, as, under orders, he had had every possible breeding-place exterminated, either by surface drainage or by petrolizing. Dr. Carroll noticed that the table in the dining-room had been insulated by placing its legs in small jars of water, the surface of the water being carefully covered with kerosene. In going into an adjoining room, however, he found that a table there had also been insulated in the same way, but that the water about only one of the legs of the table had been covered with kerosene, while the jars under the other three legs were swarming with mosquito larve. This was the fault of the orderly, an Irishman, who literally obeyed orders in kerosening such vessels as had been pointed out to him, but no more. Enough mosquitoes bred in these three jars to stock a large community.

It is common opinion that mosquitoes do not need standing water in which to breed. It is generally supposed by non-observant people that they are able to breed in wet grass, and it is a common observation, as recently expressed by a correspondent of the Pucitic liural P'reses of San Francisco, that mosquitoes are more abunclant about well watered lawns than in racant lots, with the dry, sandy surface which they naturally have in a dry summer season. But there is not the slightest evidence 
that any such condition of affairs can exist. In such cases as that described by the Californian, the mosquitoes are naturally attracted by the moist air. They search for breeding-places, and are attracted by moisture, however slight; and then, too, it is well known that they drink water, and while the drops on the grass-blades will not induce them to lay eggs, they can readily fill their stomachs in the absence of the more highly nutritive liquid known as human blood. Some men drink water instead of beer, but it is a sad fact that no mosquito is ever known to drink water when she can get blood. In the California case, the humidity of the air around the sprinkled lawn pleased the mosquitoes better than the dry air of the vacant lots, and in the face of the multifarious and unobserved opportunities for the collection of small quantities of water, many of which we have just indicated, there will always be found some explanation for mosquito abundance, other than that they will breed in wet grass. There is this to be said, however, as has been pointed out more fully in another paragraph, that in dry seasons mosquitoes will live until the rains come, and this is especially true of pregnant females. Nature cares for the perpetuation of the species, and in some way provides for the existence of individuals until the perpetuation of the species is assured.

\section{Food of Adult Mosquitoes.}

With little doubt it is only the females of mosquitoes which draw blool, and with as little doubt female mosquitoes are normally plant-feeders. When we consider the 
enormous numbers in which mosquitoes occur, it is safe to say that only an infinitesimal proportion of them ever taste the blood of a warm-blooded animal. They have been seen with their beaks inserted into juicy plants; they have been observed sucking ripe fruit, watermelons, and even boiled potatoes. There are in this country great tracts of marshy lands into which warm-blooded animals never find their way, and in which mosquitoes are breeding in countless numbers.

But they are not confined to plants and warm-blooded animals. They attack other insects, although observations on this point are not common. Dr. H. A. Veazie, of New Orleans, informs me, however, that he has seen mosquitoes stinging the Cieada, or "locust," as it is incorrectly called, and also the soft skinned pupa of the same insect. Dr. H. A. Hagen has recorded an observation where he saw a mosquito in the Northwest engaged in feeding on the chrysalis of a butterfly. Cold-blooded vertebrates are also attacked. Mr. J. 'Turner Brakeley, of Hornerstown, $\mathbf{N}$. J., writes that he has seen a black terrapin surrounded by a swarm of mosquitoes, but that she paid no attention to them, possibly because she was engaged in ego-laying. Moreover, there are several instances on record in which mosquitoes have been seen puncturing the heads of young fish. That mosquitoes suck the blood of birds is also well proven. In the course of Ross's original olservations in India with a malarial disease of sparrows, he had no difficulty in inducing mosquitoes to bite these birds. and a recent correspondent of the Bullimore sun nearly lost some pet canaries 
throngh the bites of mosquitoes, which seemed especially attracted to these birds.

To revert once more to the plant-feeding habit, persons engaged in the study of malarial relations of mosquitoes have found that they feed readily upon fruit, and bananas are a fitrored article of diet. Dr. John B. Smith, of Rintgers College, informs me that he has seen males and females of what is probably Culex sollicituns attracter by the blossoms of wild cherry, and appear to dig into the centre of the blossom, at Anglesea, N. J. So abundant were they that he captured hundreds by sweeping his net over the blossoms.

The male mosquito seems to be exclusively vegetarian in its diet. The beak in this sex is weaker, and does not seem fitted for the penetration of the skin of even a tender-skinned animal. Its food it probably chiefly gained by sipping exposed liquids. They are often seen sucking at drops of water or molasses, or beer, or wine. Dr. St. George Gray, of St. Lucia, British West Indies, finds that down there he can almost daily catch one or two males on the neck of a decanter, or in a wineglass that has just been used. He has made some interesting observations on the intoxicating effect of wine upon the males. It appears from these observations and the beer-drinking habit of the males, as observed by Schwarz, that in any discussion of sex habits into which the mosquito may be lugged as an example that bloodthirstiness may exist in the female sex, this statement may be offset by the fact that even with this creature the male sex is the one that is prone to alcoholism. 


\section{MOSQUITOES IN GENERAL}

In spite of what we have just said about the non-penetrating mouth parts of male mosquitoes, Dr. C. W. Stiles informs me that he and Hurst (the author of an important paper on the pupal stage of Culex, Manchester, 1890) made an observation in the summer of 1889 , at Leipsic, which convinced him that either the males do occasionally bite or that occasionally females possess feathered antenne. Stiles and Hurst were out in a rowboat one evening and were bitten a number of times by Culex nemoralis. One individual which bit Stiles on the left hand was crushed, and in the crushing act a considerable quantity of blood exuded-enough to make a fairsized blood-stain on his skin. Upon examining the dead borly he was surprised to note that it possessed male antenna. Hurst also examined it, and remarked that it was the first instance he had known where a male Culex had actually been caught sucking blood. Dr. Stiles tells me that Hurst intended to place the observation on record, but that he loes not think it was ever published. Dr. Stiles is so well known as an accurate observer, that some other explanation than faulty observation must be offered in this instance.

This observation, althongh apparently without precedent, leads to a decision coinciding with that of Jïrdens (1801), who thought that the male mosquito could bite, and wrote, according to Dimmock, "But since the male is also provicled with a sucking seta it is not comprehensible why it shonld not use it for the same purpose." Dr. Dimmock, in his admirable dissertation upon "The anatomy of the month-parts and of the sucking ap- 
paratus of some Diptera" (1881), made a most careful study of the motith-parts of both male and female mosquitoes. His conclusions are decidedly against the possibility that male mosquitoes can bite warm-blooded animals. He says, "I have tried to have the male mosquitoes bite me when in the field where they were abundant, but they did not seem attracted, as the female mosquitoes were, to my person; they flew away incifferently without lighting upon me. I have often taken male mosquitoes, with all possible care to prevent disturling them, beneath a glass cover on $\mathrm{my}$ hand, letting them remain long enough to be as tranquil as they were when upon the leaves and grass of the field, but they wonld neither bite nor show any desire to do so, nor have I been al,le to feed male mosquitoes with water, saliva, or fresh blood, all of which liquids the females often drink with avidity.

"Upon anatomical grounds, I helieve that male mosquitoes take liquid food, although I have never dissected their stomachs to see what this food was. They have mouth-parts and pharynx developed sufficiently to suck liquids; but the absence of barbed maxillie, of a free hypopharynx, and of cesophageal bulb, leads one to suppose that they take a smailer quantity of food than the females do, and that they do not obtain it by piercing the skins of animals."

There is a Enropean species of mosquito, Culex sulinus Ficalbi, which is said to be dimmal in its habits, and to live in salt water, of which the male is sail to bite, and to possess month-parts quite like those of the female. 
Abundance of Mosquitoes.

In modern times everyone who likes ont-door life, especially men interested in hunting and fishing, is able to tell mosquito stories which rival the somewhat rare instances which come down to us from ancient times. I have heard sportsmen, in fact, vie with each other in describing the abundance of mosquitoes in certain localities, but, familiar with the tendency of hunters and fishermen to indulge in the rhetorical figure known as hyperbole, as evidenced in the general acceptance of a specific meaning as applied in the expression "a fish story," or the adjective "fishy," one is warranted in a certain measure of clisbelief. It is undoubtedly true, however, that certain localities in this country are almost uninhabitable because of the great numbers of mosquitoes found there, many otherwise desirable neighborhoods do not improve for this reason, and some regions are absolutely unsettled on this account. Professor E. W. Hilgard, of the University of California, has written me that up in northern Washington, in the pine forests north of Spokane, the gray mosquito, or Culex, seems to be the sole possessor of the land, and is a fearful nuisance, as in aretic regions. The first thing on going into camp is to establish a close line of smudges ahove the wind, so as to enable the pack animals and the men to eat in comparative peace, but about milnight the entire swarm is back again. He states that there are scattered lakes in that region where they breed, but they must migrate considerable distances. He further 
writes that in Montana he has seen all the work-horses in the field sheathed in sheets during the day, and these were dotted with small blood spots.

An observation made by my colleague, Mr. E. A. Schwarz, at Corpus Christi, I have had occasion to quote several times. He says that at this place, when the wind blows from any other direction than sonth, "hundreds of thousands of millions" of mosquitoes blow in upon the town. Great herds of horses rum before the mosquitoes in order to get to the water, but that with a change of wind the mosquitoes disappear. The instance mentioned by the Hon. J. D. Mitchell, of Tictoria, 'Texas, and which is quoted in the section on "How Far Do Mosquitoes Fly?" is another indication of the enormous numbers in which these insects may occasionally occur, even in localities where they are ordinarily not very abundant.

In olden times, mosquitoes appear to have been quite as numerous as they are to-day, and the literature of popular entomology contains many instances of the enormous numbers in which mosquitoes have occurred in times past.

In ancient Greece, according to Pausanias, inhabitants were forced to abandon their homes on account of mosquitoes' making it impossible for them to remain. Mionte, a rich eity of Ionia, was abandoned by its inhabitants on account of mosquitoes which forced them to flee to Mileta. The same thing happened with Pergamo, a beautiful city in Asia. Someone has called attention to the fact that Theodoretus says that Sapor, King of Persia, was compelled to raise the siege of Nisibis by a plague of gnats, which attacked his elephants and beasts of burden, and 
so caused the ront of his army. Kirby and Spence say, "In the neighborhood of Crimea the Russian soldiers are obliged to sleep in sacks in order to defend themselves from the mosquitoes, and even this is not a sufficient security, for several of them die in consequence of mortification produced by the bites of these furious bloodsuckers." The same writers state that Captain Stedman, in America (probably in ante-Revolutionary days), mentions that he and his soldiers were forced to sleep with their heads thrust into holes in the earth, and their necks wrapperl around with hammocks, and Humboldt says that somewhere in South America the inhabitants pass the night buried in sand, which covers them to the depth of three or four inches, leaving ont only the head, which is covered with a cloth. There is even a mosquito story which possibly affects the veracity of George Washington! Isaac Weld, in his "Travels through North America, 1795-1797" (London, 1799), in speaking of Skenesborongh, in northern New York, dilates upon the number and ferocity of mosquitoes and says, "General Washington told me that he never was so much annoyed by mosquitoes in any part of America as in Skenesborongh, for that they used to bite throngh the thickest boot." Now, knowing that the boots of those days were very thick, and that the mosquitoes of that time must have been structurally identical with those of to-day, there arises instantly the ques. tion of veracity between Mr. Weld and General Washington, and as we know from Dr. Weems's veracious history that General Washington was so constituted that he could not tell a lie, it looks very much as thongh Mr. Weld, like 
certain other travellers who have written books on their return home after extended travel, was somewhat inclined to overstate the truth.

\section{Far Northern Mrosquitoes.}

As is well known, the mosquito-pest is by no means confined to the tropics or even to temperate regions. The stories which the returning gold-hunters from Dawson City and other Alaskan localities tell of the abundance aud ferocity of Alaskan mosquitoes, are hardly to be matched by any mosquito story which I have heard, historical or otherwise. Many of my friends in the United States Coast and Geodetic Survey, and the United States Geological Survey, who have formed members of summer parties for survey work in Alaska, have come back to this country with a much stronger idea of the importance of the practical study of insects than they had when they started, their acquaintance with mosquitoes haring become so intimate and their knowledge of their ferocity having reached such a pitch that the first question which they ask on returning is: "If I have to go up there next summer, what under the sun can I do to keep from being bled to death by mosquitoes?" They state that they never experienced or even imagined anything in the mosquito line quite equal to those found in Alaska. Mr. W. C. Henderson, of Philadelphia, says, concerning Alaskan mosquitoes, "They existed in countless millions, driving us to the verge of suicide or insanity." 
That mosquitoes should develop in such extraordinary numbers in the arctic regions is remarkable when we consider the extreme brevity of the summer season. Surely only a very few generations have an opportunity to develop. They must therefore hibernate in great numbers even in that extreme cold, and their occurrence in this way in such localities, when we consider the comparative scarcity of mammalian life, indicates in a forcible way how small a part the blood of warm-blooded animals plays in the normal economy of mosquito life.

It did not need these recent experiences, however, to assure us of the abundance of mosquitoes in arctic regions. Kirby and Spence tell extraorlinary stories of their occurence in Lapland, where their numbers are said to be so prodigious as to be comprared to a fall of snow when the flakes are thickest, or to the dust of the earth. There is a mention of this abundance in the narrative of C. F. Hall's second arctic expedition, and on the Polaris Experlition, Dr. Emile Bessels was obliged to interrupt his work in the Davis Straits (latitude $72^{\circ}$ north) on account of the multitude of mosquitoes.

In explanation of these extraordinary numbers-and all these stories are unquestionably measurably true-we must only think of the miversal occurrence of standing water and of the fact that the food required by mosquito larve is very small and very insignificant, consisting mainly of the micro-organisms which exist in stagnant water, and of the further fact that enormons numbers can breed successfully in a very small water supply. As an indication of this latter fact, Lugger, in 1896, undertook 
to count the larve in an ordinary rain-water barrel. On July 6th, the water in one barrel was filtered and was found to contain 17,259 eggs, larva and pupre. On July $221,19,110$ additional ones were counted. If anyone is mathematically inclined, let him assume that half of these developed into female mosquitoes, each one of which laid 400 eggs, and that twelve generations breed in a summer in the northern Tnited States. It will then be perfectly obvious that a large neighborhood may be well supplied with mosquitoes from a single neglected rain-water barrel.

\section{The Poison of Mosquito Bites.}

That fine old observer, Réaumur, rather thought that a poisonous fluid was secreted by the mosquito and that its purpose was to cause the blood to flow more readily when it bites. Later observers have accepted this statement, or have denied the existence of such fluid, stating that the swelling following the bite was caused by the irritation of the puncture, withont the aid of poison. Dimmock (1881) convinced himself that a poisonous saliva was introduced. He noticed that if the mosquito punctures the skin without entering a blood-ressel, although it may insert its proboscis for nearly its full length, no poisonous effect is produced upon the skin; but when the proboscis strikes blood and the insect draws its fill, the subsequent swelling and poisonous effect are obvious. He argued that these effects indicate a constant outpouring of some sort of poisonous fluid luring the bloodsucking process. 
'The question was finally set at rest by Macloskie (1887), who sncceeded in demonstrating a poison gland in mosquitoes and in showing that this poison gland is comnected by a duct with the month-parts. This venemo-salivary duct is very fine, ruming backward in the lower part of the head in the throat and terminating in the prothorax in glands of characteristic structure. The glands are in two sets, each set consisting of three glands, two of which
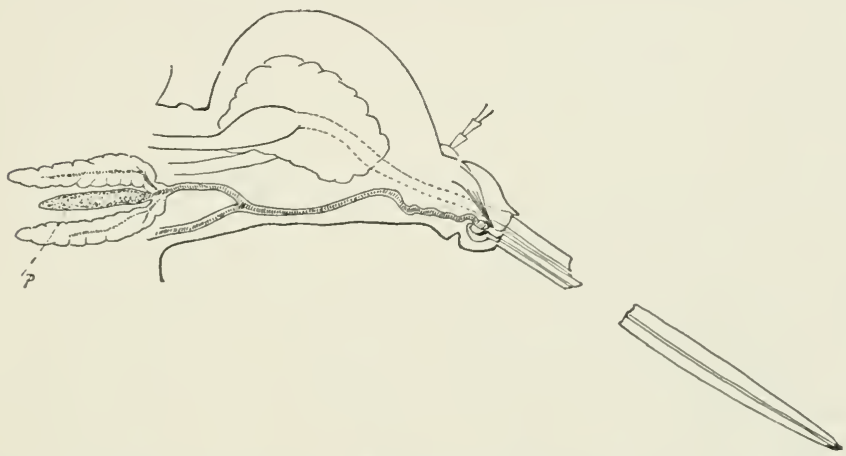

FIt; 2.-Section of head of Mosquito showing poison gland at $p$ : enlarged. (Redrawn from Macloskie.)

are ordinary salivary glands and the third (between the other two having a different appearance and structure and secreting the poison.

Miall, of England, as late as 1895 stated that it could not positively be said whether poison is injected into the wound or not. Overlooking, or not accepting, Macloskie's demonstration, he says: "No poison has hitherto been demonstrated, and there is some reason to believe that the 
irritation of the wound is slight in cold weather and only becomes intense during great smmmer heat."

The purpose of the mosquito poison has been a subject of some conjecture. The old Réammur hypothesis, that it causes the blood to become more liquid and more readily sucked up, by the mosquito, has had its adherents.

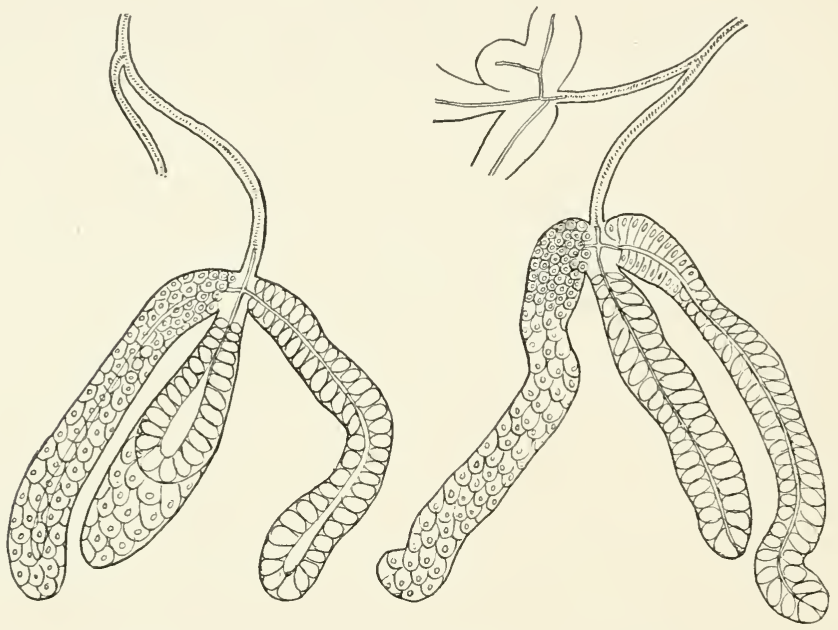

Fic. 3.-Salivary glands of Culex at right, Anopheles at left: greatly enlarged. (After Christophers.)

Osten Sacken and Miall, however, believe that it is probable that the piercing mouth-parts of the inosquito were originally acquired for the purpose of sucking the juices of plants, and Macloskie advances the idea that the chief food of mosquitoes is not animal blood but the proteids of plants, and that probably the poison ejected may prevent 
the coagulation of all proteids and so promote the process of suction.

The amount of irritation caused by the poison of mosquitoes varies greatly with different individuals. Some people suffer severely from their bites, while others are not at all affected. 'This is a matter of common olservation. I have seen a man hunting snipe in a marsh with his face protected, but with his neck left exposed. His neck had been repeatedly bitten and was so poisoned as to utterly destroy its symmetry. At the end of the day he no longer possessed a neck, but from his shoulders to his head was simply a gradual slope!

There can be little doubt that people become inoculated against this poison. Persons living in mosquito-ridden localities as a rule suffer less than those who come there from more favored regions, and it seems likely that after: a severe case of mosquito-poisoning the inoculating effect may last for a long while. An instance of this has been sent me by the Rev. Edward Everett Hale, who wrote, under date of Angust 29, 1900:

"I think I am an instance of inoculation by mosquitoes' virus. More than fifty years ago I went into the Maine woods going to Katalidin. The first afternoon we were out hardly an hour, but at night, when we went into camp, I counted sixty well defined mosquito bites on my right hand alone. Now from that time to this I have hardly been troubled by mosquitoes. I dislike their song at night, and if I saw one on my hand I shonld kill it, but after the moment of the sting I never remember that I have been bitten." 


\section{II}

\section{Malaria and Mosquitoes}

THE principal canse of the present widespread interest in the subject of mosquitoes and mosquito1. extermination is the perfectly satisfactory proof which has been gained during the past few years that they are responsible for the transmission of the malarial germ from malarial patients to healthy people. The causative micro-organism of malaria was discovered by the French army surgeon, Laveran, in Algeria in 1880. From that time to the present, a small army of workers of several different nations have been working upon the life history of the malarial parasites, not only of human beings but of birds, and our present knowledge is quite complete. The idea that mosquitoes might possibly spread malaria had been suggested a number of times. The most forcible argument, however, was presented by Dr.A. F. A. King at Washington, with whom the idea was entirely original, in a paper read before the Philosophical Society in 1882. The actual demonstration, however, was not brought about milil much later, and in this actual demonstration workers of several nations had a share. The researches of MacCallum, of Johns Hopkins University, while investigating the malarial disease of the com- 
mon crow, contributei greatly to the eluciclation of a knotty point in the life history of the parasite; the studies of Ross upon the malarial disease of sparrows in India proved effectively the transmission of this disease by mosquitoes; while the experimental demonstration of the transfer of the parasite of human malaria by mosquitoes was first performed by Italian investigators, although it has since been done many times in many parts of the world by workers of many different nationalities.

The life history of the malarial parasite of limman kind may be briefly summarized as follows: All of the malarial parasites are protozoans, that is to say animals-and not bacteria, that is to say plants. In the human blood these protozoa inhabit the red blood corpuscles and in the blood they go through a sporulating existence, which may continue indefinitely unless checked by quinine or in some other way. In the red corpuscle the parasite appears as an amobula which gradually grows until it nearly fills the interior of the corpuscle, digesting apparently the red coloring matter of the blood and forming, as the result of this digestion, pigment spots in its interior. On reaching full growth the nuclens of the amobula subdivides, each division gathering about itself a certain amount of protoplasm, mntil instead of the single amobula the corpuscle eontains a large number of spores. The walls of the corpuscle then break, and the spores are liberated into the blood serum. From a single infection this sporulation or liberation of the spores takes place practically simultaneonsly and marks the beginning of the malarial spasm. 
'The three different kinds of malaria, namely, that in which the fever recurs every two days, known as tertian malaria, that in which the fever recurs every three days, known as quartan malaria, and the severe autumn fever, known as restivo-autummal fever or tropical malaria-by far the most dangerous of the three-are by some writer's supposed to be caused by distinct species of parasites. This view is not held by other writers. But at all events, the periol of development of the spormlating stage of the organism liffers in length of time. As is very well known, it frequently happens that the malarial fever or chill will recur every day. That means, in tertian malaria, that there has been a reinfection on one of the alternate days, the development of the amobulas being constant in point of time, one set sporulating twenty-fom hours after the other set. It is just as this sporulation occurs-just as the spores are liberated into the blood serum-just as the malarial spasm is about to begin, that the administration of quinine is most effective. It seems to kill the spores when they are liberated, but appears to have very slight effect upon the organism when it is enclosed in the red blood corpuscle.

This sporulating development, each of the liberated spores attacking and entering new red corpuscles, may continue as above stated indefinitely. But not all of the amobulas undergo this development. Some of them, so long as they remain in the human body, apparently die and are digested by the lencocytes.

When, however, these forms are taken from the human body, even when a blood sample is simply placed under 
the microscope for examination, they undergo a development entirely different from the sporulating form. Some of them grow large, other's put out slender filamentary arms, or flagella, as they are ealled, which separate from the body of the organism and fuse with those which do not flagellate. This is the true sexual generation of the parasite, the flagellating forms representing the male sex and the receptive forms the female sex. The development up to this point will take place anywhere outsicle of the human body-in the stomach of mosquitoes of the genus Culex, or, presumably, of other biting insects, but it is only in the stomachs of the genus Anopheles, so far as observed, that a further development takes place. After the fusing of the flagella with the female germs in the stomach of the Anopheles mosquitoes, the fertilized organisms attach themselves to the walls of the stomach, penetrate the inner walls, and locate themselves just under the onter muscular wall. They then rapidly increase in size until they eventually become five times as large as at first. They are now known as zygotes. Clear spaces login to appear on the surface. These clear spaces are known as centromeres, and they are rapidly surrounded by minute short lark lines, which, when seen under a very high power of the microscope, are shown to be spindle-shaped cells, known as hlasts. These blasts rapidly increase in number until eventually they fill the entire zygote, olsscuring the centromeres, and when this condition of affiars is reached the zygote bursts and the blasts are liberated through the muscular wall of the stomach into the body cavity of the mosquito. 'They 
are active and penetrate rapidly into the tissue of the salivary duct and so into the proboscis of the mosquito, and, with the saliva or poison, they enter the blood of the next warm-blooded animal which the mosquito bites. It is then supposed that the blasts enter the red blood corpuscles and the development re-begins at the stage where we took it $u p$.

It is thus shown that the full development of the malarial parasite cannot take place within the human body; that the Anopheles mosquitoes are necessary secondary hosts; that the sexual generation of the parasite takes place only in mosquitoes of the genns Anopheles; and further, that the old ideas of malaria from bad air (and of course the word muluria means bad air), swamp " miasma," and so on, are to the minds of those familiar with the subject of the biology of these low forms of life completely overturned.

Reasoning from the life history of the parasite alone, as observed, would not, however, satisfy the minds of people at large, and, in fact, it did not satisfy many medical men who were not especially familiar with this field of biological research. Very many practical demonstrations have therefore been made. One of the most interesting was that carried on by Professor Grassi, the Italian, during the summer of 1900, in the Plain of Cappacio, near Salerno. The objects of this experiment were: (1) To afford an absolute proof of the fact that malaria is transmitted exclusively by the bite of Anopheles mosquitoes; (2) To found, on the results of recent research, a cole of rules to be adopted for freeing Italy from malaria 
in a few years. The experiment consisted in protecting from malaria railway employés and their families, living in ten cottages, at the stations of St. Nicolo, Varco, and Albanella, situated along the Battipaglia-Reggio

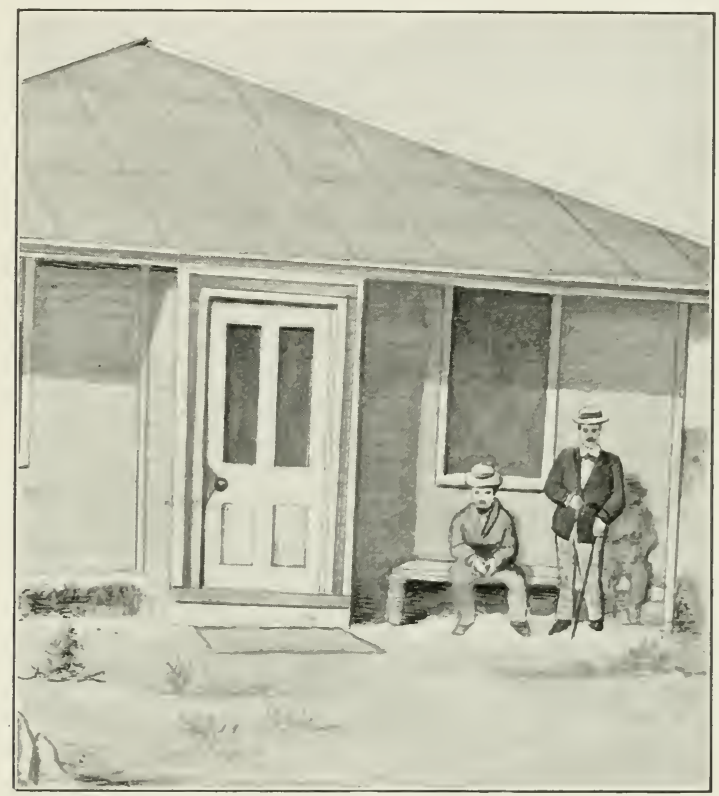

Fir. 4.-Experimental IJouse Ocenpied by Drs. Sambon and Low on the

Campagna in the summer of 1900. (From the Journal of Tropical Medicine.)

Railway. They numbered 104 persons, including tihirtythree children under ten years of age. Of these $104 \mathrm{in-}$ dividuals, at least eleven, including four children, had never suffered from the lisease, not having previonsly 
lived in a malarious district; a certain number, it appeared, had not suffered from it in two or three years, and all the others, that is to say, the large majority, had suffered from it during the last malarial season, some of them even in the winter. During the malarial season, the health of the protected individuals was good, with the exception of a few cases of bronchitis and a case of acute gastro-enteritis. None of these cases were treated with quinine. 'The 104 persons, with three exceptions, had remained free from malaria up to September 16th, the date of the report.

Another very striking experiment which during the autumn of 1900 was mentioned in newspapers all over the world, was that performed by Doctors Sambon and Low, of the London School of Tropical Medicine, in the Roman Campagna, during the late summer and early antumn of 1900. They had constructed a comfortable little fiveroomed wooden house about three hours' drive from Ostia, in one of the most malarious portions of the Campagna. The house was tightly built and was thoronghly screened. The experimenters lived in this house throngh the period when malaria is most prevalent. They took no quinine and no health precantions beyond the fact that at sumdown each day they entered the house and remained there until daylight the next morning. Dr. Rees, of the London School, visited them and occupied the house with them for a portion of the time, and all three conducted laboratory work in one of the rooms, which was fully equipped for such a purpose, and led a busy and contented life. They visited the neighboring villages and investigated 
outbreaks of the fever in men and cattle. They received and entertained many visitors who were interested in the experiment. They turned indoors before six o'clock and then stood at the windows and timed the first appearance

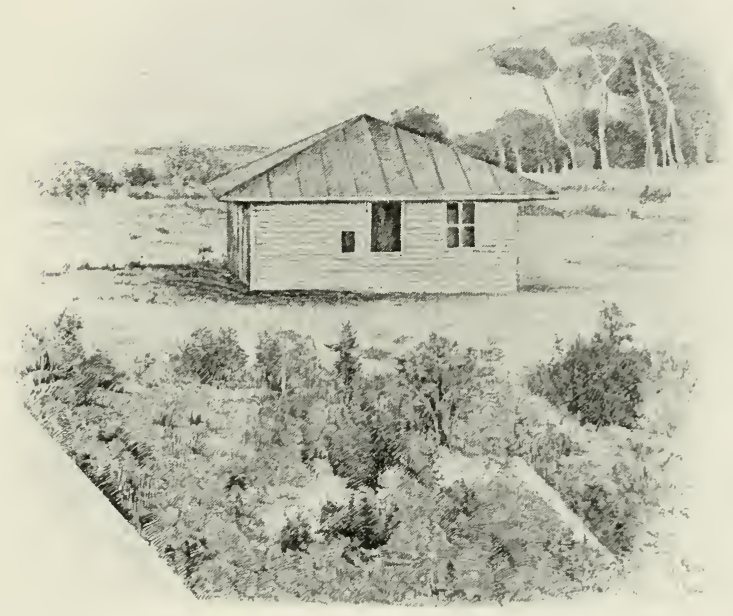

Fig. 5.-The Malaria IIouse on the ('ampagna, seen from a distance. (From the Journal of Tropical Mecticine.)

of Anopheles, which wonld come at a certain hom each evening and try to enter the screened windows and doors. As Dr. Rees expressed it, "It must have been very tantalizing for them to be mable to get at ns." When the rains set in, everyone said that that was the critical time 
of the experiment. The people in the surrounding comntry generally became feverish and ill, which meant simply that they were all full of malaria, and the chilling canse? by the rain brought about an explosion of the fever. The experimenters, however, went out into the rain and got soaked to the skin, but their health remained perfect. Not the slightest trace of malaria developed in either of them; as above stated, the spot where the house was built was probably the most malarious one in the whole Campagna, and it was situated on the banks of one of the canals, which was literally swarming with Anopheles larve. The prevalent idea that the night air of the Campagna is in itself so dangerons was included in the experiments and the windows were always left open at night, so that if the marsh air had anything to do with malaria they would have contracted it.

A check experiment was carried on at the same time. Anopheles mosquitoes which had been fed on the blood of a sufferer from malaria in Rome, under the direction of the Italian anthority Bastianelli, were sent to London early in .July. A son of Dr. Patriek Manson, the famous investigator who first proved the transfer of filaria by mosquitoes, offered himself as a subject for experiment, and allowed himself to be bitten by the mosquitoes. He had never been in a malarious comntry since he was a chilı, but in due time was taken with a well-marked malarial infection of the double tertian type, and microscopical examination showed the presence of numerons parasites in his blood.

No more perfectly practical demonstration is probably 
demanded than is offered by these two experiments, but it will he interesting to American readers to give the results of some American work.

Dr. W. N. Berkeley, in the Merlical Recomd of January 26, 1901, gives a most interesting account of a malarial ontbreak in a small town near New York City during the summer of 1900. Around a large pond in the ricinity of the town four or five fresh cases had recently developed in Angust. The first case was that of a coachman who hat canght malaria elsewhere and had relapsed. From his quarters in a long row of stables on one side of the pond the infection had passed along to other stablemen and servants on the same side, to the distance of a quarter of a mile from the original site, and a cuarter of a mile in another direction across the pond one other case appeared in a small child. Dr. Berkeley went to the town and discovered that Ampleces muculipenuis was fairly abundant in every betroom in that area in which proper search was made. The breeding-places seemed to be segregated pools at the end of the pond (the pond itself contained fish) and post-holes and excavations. These last were numerous, as many buildings were going up. The following practical measures were adopted: (1) Extermination of all the Anopheles found in honses by a party of men sent out for the purpose, and this was followed by a systematic introduction of screens in windows and doors; (2) Filling in of the smaller breeding-places and the drainage of the pond; (3) The sechusion of every malarions patient loy netting and otherwise from the bite of 
mosquitoes, so long as he had germs in his capillary blood. The results were as prompt as they were gratifying. Not a single new case of malaria developed; Anopheles disappeared entirely from houses where it had been previously a night terror. and Culex was greatly diminished in numbers.

The results reached by Dr. Berkeley were admirable, and he advises the following ofticial steps for greater New York:

1. Require malarial cases to be reported as scarlet fever and diphtheria are now. Malaria is at least as dangerous as scarlet fever; economically it is far more of a scourge, for it affects adult breadwimners as well as children.

2. Send an inspector to every infected house, who shall instruct the people to kill all the Anopheles in the house, to provide the windows and doors with screens, to isolate the patient with particular care from mosquitoes, and to cause all the standing water in the vicinity to be drained or heavily petrolized.

Rigirl treatment with quinine should be insisted mpon and the drug furnished gratis to those muble to pay, as diphtheria anti-toxine is now supplied. Dr. Berkeley believes that in a summer or two it would be possible, by these measures, to reduce the number of local cases by more than ninety per cent.

Another interesting case has been reported to me by the Rev. Wm. Brayshaw, of Chaptico, Md. Chaptico is situated at the head of a wide-spreading bay or elbow of the Wicomico River, abont eight miles from the point where this river euters into the Potonatc at Rock Point. 


\section{WALARIA ANI MOSQUITOES}

The tide is ordinarily about two feet at the full. The village rests between two hills of 80 or 90 feet elevation. The valley is almost flat, and consists of marshy pools, in which the mud or ooze can easily be pierced with a strong pole to a depth of sereral feet. 'Three of these pools or ponds are directly in the rear of the house known as the rectory, in which he resided with his wife on June $24,1899$. Neither of them had ever had malaria or fever before, but the moscuitoes were so numerous that it was impossible to take rest at night for a while. On July 11th his wife was taken with malaria, and on September 4 th har to be remored to the mountains. Mr. Brayshaw himself was sick most of the time, and every house in the rillage had from one to five persons suffering from malaria. He proposed ditching and drainage, but there was no money, and everybody langhed at the idea, as many of the citizens had lived there from childhood to an adranced age. 'There did not seem to be sufticient fall to carry off the "effete matter." On May 19, 1900, he gained the consent of the property owners to ditch throngh their land a distance of 560 feet to Chaptico Creek. He paid for this himself. The expense was about $\$ 10$. The result he sums np as follows: "During the summer of 1899, from May to October, the mosquitoes were so numerons that life was a burden during the night, and they were so small that nets seemed to have no effect upon them. From May to October, 1900, quite a $110 \mathrm{mb}$ her visited us, intil June 12th, when they disappeared, and we were free from them until the last six days in September, when I foumd a local canse for their breeding. In the summer of 1899 every house in the 
village had from one to five persons sick with chills and fever, and other malarial troubles; doctor's in constant attendance. In the summer of 1900 there were only two sporadic cases of chills, both caused by negligence or inattention to ordinary cantion. Everyone in the village seems quite free from malaria since July 10th."

In Cuba, as a result of the moscuito-extermination work, which will be mentioned in the chapter on "Yellow Fever and Mosquitoes," Colonel J. R. Keane, U. S. A., Surgeonin-Charge at Havana, wrote me, Jannary 12, 1901, that in his opinion there had been a very marked reduction of malaria at the military posts in western Cuba.

The principal arguments in favor of the idea that malaria may also enter the human system in some other way, are that there is malaria where there are no mosquitoes, and that there are many mosquitoes in localities where there is no malaria. These points are adduced by persons who, while admitting that it has been proved that Anopheles transmits malaria, and that possibly this is the only method which has been proved, still insist that there may be, and even that there must be, other methods. As a matter of fact, it is practically impossible to prove that there is local malaria where there are no Anopheles. The bite and method of attack of Anopheles is so insidions that these mosquitoes attract very little a'tention where they are not especially numerous. One may be bitten by them while asleep at night almost without realizing it. Anopheles may be present where there is no malaria, since it will always remain uninfected unless some vertebrate animal suffering with the disease comes to its neighborhood. 
There was no autochthonous case of malarial ferer for years at the League Island Nary Yard, although there was a distinct breeding-ground for Anopheles near by. Woldert has canght larvie of Anopheles in a clear pool of water in the Pocono Mountains of Pennsylvania, a notable health resort, at an elevation of three thousand feet above sea-level. The statements that malaria has prevailed when there were few or no mosquitoes are always too vague to be of valne, because it is not definitely stated whether the cases were relapses or fresh infections. In cases where mosquitoes are numerons, moreover, and there is no malaria, to the point which we have already made that probably no malaria has been brought into the vicinity may be added the fact that when mosquitoes are numerons, almost without exception they are found to be the common species of Culex, which, as shown, have nothing to do with malaria. It is often stated, for example, that malarial fever is caused by excavating the ground; newly turned earth is said to be responsible for it, but, as a matter of fact, as pointed out by Ross, there are millions of people constantly engaged in digging without suffering from the disease more than do others, and then also excavations always result in surface pools of water, 11 which for a time Anopheles will frequently be found breeding. One curious case has been mentioned by Mr. D. E. Hutchings, in the English journal, Neture, in which he stated that he knew of a medically authenticated case of malaria having been caused by fresh earth carried past a window in buckets by coolies. This statement is criticized by Ross in the following words: "Which fact was medically 
anthenticated - the fact that the patient suffered from malaria, or that his malaria was caused by the earth carried past in buckets? I can understand the first being certified to by a doctor, hut scarcely the second. How did the doctor prove that the fever was produced by the earth in the buckets? It seems to me that the only way in which he could have done so in a trustworthy and scientific manner would have been to infect a second person by having the buckets carried past a second time. I doubt whether such instances-and we see hundreds of them in the press - will bear close examination."

It has been claimed by Italian observers and others, that there is a very exact coincidence between the geographic distribution of malaria and Anopheles mosquitoes. Bearing on this point, the conclusions reached by Nuttall, Cobbett, and Strangeways-Pigg, in their studies in relation to malaria (Journal of Mygiene, vol. i., No. 1, January, 1901), are very important. They are as follows :

1. The disappearance of ague from Great Britain does not depend upon the extinction of mosquitoes capable of harboring the parasites of malaria.

2. Three species of Anopheles (A. maculipemis, $A$. bifurcatus, $A$. nigripes) are to be found in Great Britain in all districts which were formerly malarious, but also in places concerning which there is no record of the former prevalence of ague.

3. The Anopheles to-day are most numerous in lowlying land containing many ditches, ponds, and slowly flowing water, suitable for their habitat, and correspond- 
ing to the districts where agne was formerly prevalent.

4. Since the disappearance of agne does not depend upon the extinction of Anopheles, it is probably due to several causes operating together:

(a.) A reduction in the number of these insects consequent upon drainage of the land, this being in accord with all the older authors, who attributed the disappearance of ague largely to this cause.

(b.) Reduction of the population in infected districts as the result of emigration, about the time when ague disappeared from England. This would naturally reduce the number of infected individuals, and thus lessen the chance of the Anopheles becoming infected.

(c.) It is possible that the use of quinine has reduced the chances of infecting the Anopheles, through checking the development of the parasites in the blood of subjects affected with ague.

Of these, the first-mentioned cause seems to have been chiefly operative. The possibility is not yet excluded of there being another intermediary host besides man, capable of harboring the parasite, and, assuming that this were so, this host may have become extinct in the lowlands where it is known that the famma and Hora have altered.

5. The coincidence of the geographical distribution of agne and Anopheles as claimed by Grassi for Ttaly, and as probably holding good for other parts of the world, is hereby disproved for England, and consequently the generalizations are proved to be premature whereby he ex- 
cludes other blood-sucking insects from being possible hosts of malarial parasites on the strength of his supposed geographical agreement.

6. Since the geographical distribution of Anopheles in England is wider than the former distribution of ague in that country, we are forced to conclude that it is not a matter of the geographical distribution of Anopheles as much as of their numerical distribution.

7. Our observations having proved the existence of Anopheles in non-malarious districts, we believe that they will explain the occasional occurrence of ague in out of the way places, without making it necessary to assume that malaria-bearing mosquitoes have been freshly imported, for, given suitable conditions of temperature and the requisite number of Anopheles, a malarious subject coming from other parts might well infect the local insects, which in turn would spread the infection to healthy persous.

8 We would suggest to those engaged in the investigation of malaria in other comtries, that they search as carefully for Anopheles in non-malarious as in malarious regions. More data as to the number of these insects in various localities are certainly required, though we are fully aware that numerical estimates permit of a considerable degree of error. Nevertheless, they would always possess a relative value.

Grassi has repeatedly asserted that the geographic distribution of Anopheles in Italy coincides with that of malaria, and on the strength of their wider geographic distribution he excludes a number of blood-sucking creat- 
ures, such as mites, ticks, stable-flies, gad-flies, l,lackflies, punkie-flies, liee, bedbug's, and Culex, from being possible carriers of malaria.

Probably nothing more need be said in regard to the general subject of malaria and mosquitoes. The case is abundantly proven, and it remains necessary from the health standpoint to know all abont the moscuitoes of the genus Anopheles-how and where they live and breed, and how to distinguish them from other mosquitoes in all stages of their existence. All these facts will be considered in Chapter IV. 


\section{III}

The Common Mosquitoes of the Genus Culex

CULEX is an old genus named by Linnæeus in 1735, which for a long time comprised all the mosquitoes. But other genera have been erected, and now the mosquitoes are included in a family known as the $\mathrm{Cu}$ licidæ, which comprises several genera and very many species. Culex, however, is the typical genus, and includes the commoner, most abundant, and most widespread kinds of mosquitoes. We liave at least twelve species in the United States, and probably more than two hundred species exist in different parts of the world. The genus has no geographic limitation, and its species are found in the Arctic regions as well as in the tropics. Not only has the genus itself apparently no territorial re. strictions, but the individual species are many of them widespread. There are a half dozen or more which may be found practically everywhere in the United States. There are other's which extend from Cuba to Alaska. A few others are more restricted. The life history of the common European Culex, known as Culex pipiens, was studied and described very accurately as long ago as 1691, by Bonanni, in his "Micrographia Curiosa," published at Rome that year, and I am not sure that mosquito biology 
Was not well known at an even earlier late. The French observer, Réaumur, studied the same species more than 150 year's ago, near Paris, and his account of the development of Culex has remained standard from that time almost to the present day. The full life history of no American species of Culex, however, was published until 1896, when the life history of Culex mugens Wiedemann was worked out by the writer at Washington and published in Bulletin 4, n. s., of the Division of Entomology, of the United States Department of Agriculture.
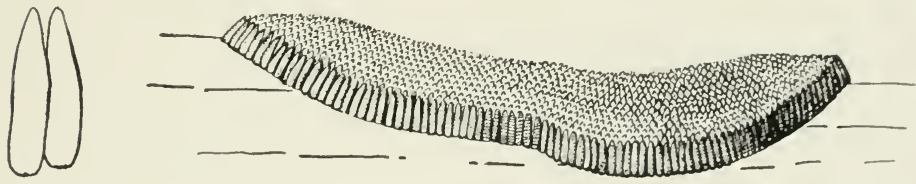

綮"

FIG. 6.-Egg Mass of Culex pungens; enlarged; witli individual eggs, still more enlarged, at left. (Author's illustratiou.)

Culex pungens is one of our common North American species. It abounds everywhere, from the White Mommtains of New Hampshire down into Central America, and is, perhaps, the most abmudant of our mosquitoes. It breeds exclusively in fresh water, and its larva may everywhere be found in water buckets and barrels, in transient pools of rain-water, in fresh-water swamps, along the borders of inland lakes and ponds, and, in fact, in all of the out of the way places which have been mentioned in Clapter I. Its life history may be taken as typical of the genus Culex, all other species probably closely re- 
sembling this form in all of their early stages and in their periods of development.

The female lays her eggs upon the surface of the water, balancing herself upon some floating object during the operation, and extruding them in an irregular, raft-shaped mass, which is usually shaped something like a pointed ellipse somewhat convex below and concave above, all of the eggs standing on end and closely applied, side by sicle, in from six to thirteen longitudinal rows, with from three or four to forty eggs in a row. The number of eggs in each batch varies from 200 to 400 . As seen from above, the egg mass is gray-brown, from below, silvery-white, the latter appearance being due to a film of air which protects them from the water. It seems impossible to wet these egg masses. They may be pushed under the water, but bob up apparently as dry as ever. As the eggs are very small, being only $0.7 \mathrm{~mm}$. long, and 0.16 $\mathrm{mm}$. in diameter at the base, the entire egg mass is not a large object, seldom, in fact, reaching a length of more than a quarter of an inch. The mass separates rather regularly and the eggs are not stuck together very firmly. After they have hatched, the mass will disintegrate in a few lays, even in perfectly still water. The individual eggs are slender, broader and blunt at the bottom, and somewhat pointed at the tip. The tip is always dark grayish-brown in color, while the rest of the egg is dirty white. Sixteen or more hours after laying, the eggs hatch, generally about noon on warm days, but sometimes they will remain unhatched for two days or even longer, especially in cold weather. 
The larvæ issue from the under side of the egg masses and are extremely active at birth, wriggling rapidly in the water about the eggs. They are very minute and move so rapidly that it is difficult to form any impression of their shape and structure except when they are at rest.
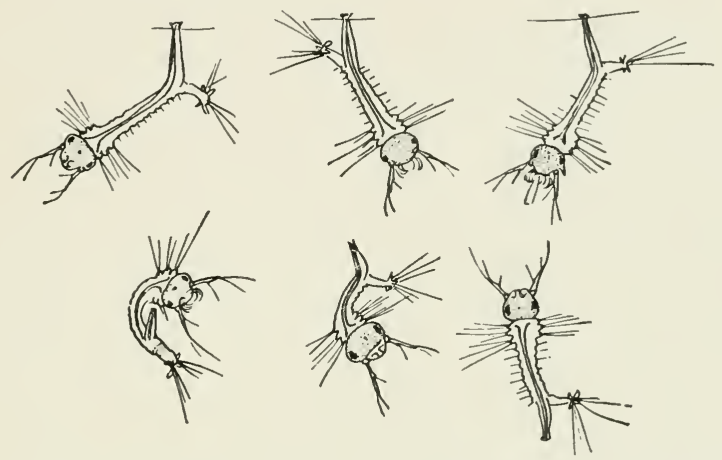

Fic. 7.-Young Larve of Culex pungens; enlarged. (Author's illustration.)

They come frequently to the surface to breathe, and during the first few hours many of them remain under the egg mass, where they get air from the air film by which the egg mass is surrounded. One of the first peculiarities which strikes one on observing these newly hatched larve or wrigglers under the lens is that the month is furnished with tufts of filaments which are constantly in vibration. The head is large, the antenno long, the thorax somewhat swollen, and the abilomen slender. The sides of the body are furnished with stiff bristles. From the next to the last segment of the abdomen there protrudes 
a long tube noarly as thick as the body itself, and it is this tube which is extruded from the surface of the water every time the larva rises to breathe. The object of this extrusion is to get air, and this tube is the breathing tube of the insect. Its extremity is furnished with a breathing

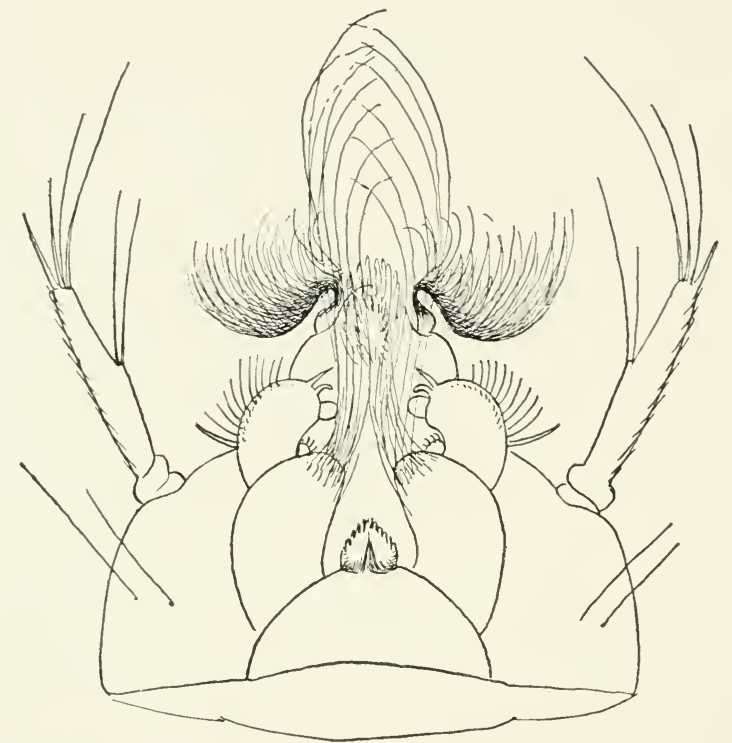

FIG. 8.-Mouth-parts of Larva of Culex pungens; greatly enlarged. (Author's illustration.)

hole, or spiracle, and into it rum two main trachere, or breathing tubes, which extend through the body of the insect, giving off branches here and there, and thus carry. ing air to all of its tissues. The true end of the body is furnished with four Hat flaps, the exact purpose of which 
is not known, but which may possibly function as gills while the larva are very young, and are certainly of use as swimming organs. When the breathing tube is at the surface of the water the body of the wriggler extends down below the surface at more or less of an angle with the water surface, and its mouth-parts, as just stated, are constantly in vibration, bringing into its mouth any minute particles which float in suspension in the water. Occasionally it descends to the bottom, jerking its body violently from one side to the other. The flaps at the end of the body undoubtedly assist in this motion. The jerking motions are not so evident when the larva or wriggler is descending as when it becomes necessary for it to ascend once more; in other words, its specific gravity

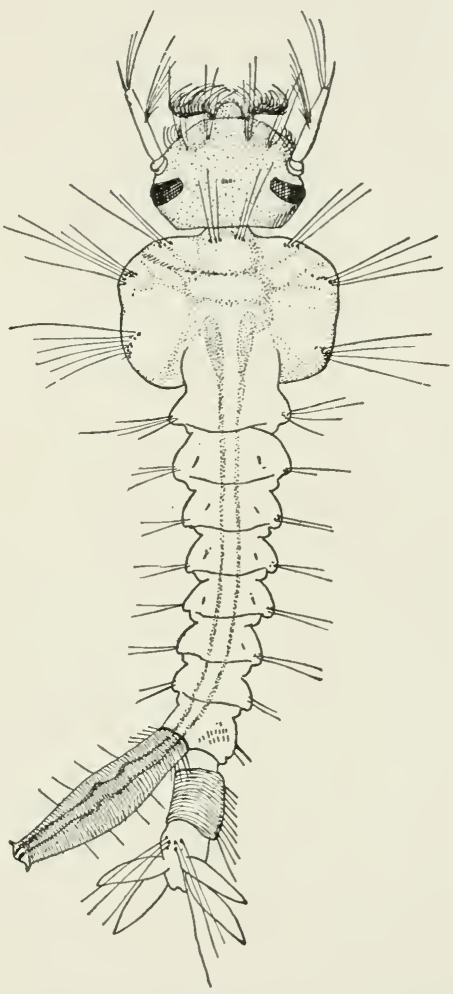

Fig. 9.-Full-grown Larva of Culex pungens; enlarged. (Author'sillustration.)

seems to be greater than that of the water and sometimes it can be seen to descend without effort, simply sinking 
down. After one of them has wriggled up to the surface of the water, its breathing tube extrudes, fresh air runs into its tracher, and the tension of the so-called surface
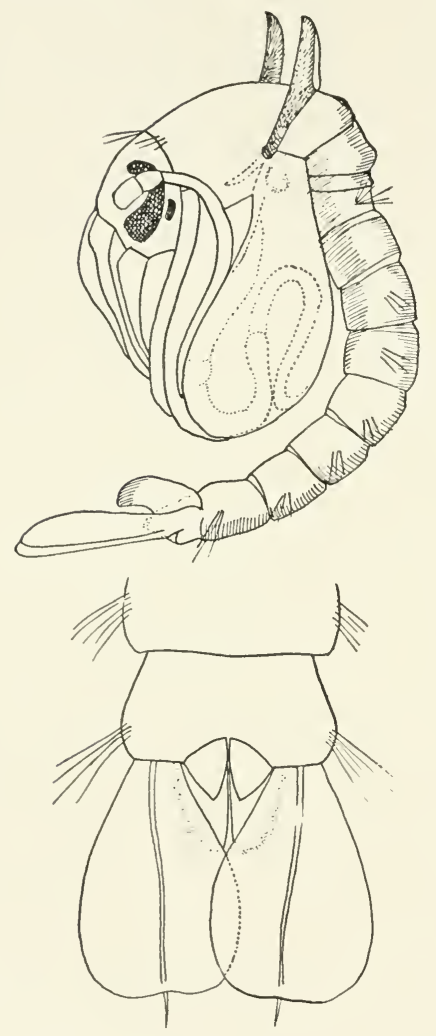

Frg. 10.-Pupa of Culex pungens; enlarged, with Anal Segment below, still more enlarged. (Author's illustration.) film of the water assists it in maintaining its position. After an introductory wriggle, which pulls the breathing tube below, the insect sinks. The larval Culex appears to pass through three different stages of growth, reaches maturity, and transforms to pupa, in a minimum of about seven days in warm summer weather.

The pupa differs markedly from the larva in the great swelling of the thoracic segments, as shown in the accompanying cut. The pupa seems to be all head and thorax, with a slender abdomen and with two large flaps at the end of the abdomen, which assist it in swimming whenever it feels that it has to swim. In this stage the insect is lighter than water. It remains motionless at the surface and when disturbed 
does not sink without effort, as does the larva, but is only able to descend by violent muscular action. It wriggles and swims as actively as does the larva and soon reaches the bottom of the water. As soon as it ceases to exert itself, however, it floats gradually up to the surface once more. As pointed out in our consideration of the habits of mosquitoes in general, this activity on the part of the pupa is necessary to preserve it from fishes and from its natural enemies. It is very active and difficult to capture. The mortality of the pupe, however, is not great, except through the efforts of fish and its other enemies, while that of the wrigglers or larve is apt to be great through drowning. Whenever a larva becomes sick or weak, or for any reason unable to exert sufficient muscular force to wriggle to the surface at frequent intervals, it drowns. It seems almost like a contradiction in terms to speak of an aquatic insect as drowning, but this is a frequent cause of mortality among mosquitoes. This fact also explains the efficacy of the remedial treatment which causes the surface of the water to become covered with a film of oil of any kind. Aside from the actual insecticidal effect of the oil, the larva drown from not being able to reach the air. Or. they may draw drops of oil into the tracher, clogging them and preventing the passage of the air. The structure of the larre and pupæ at the different stages is so well shown in the accompanying figures as to render it unnecessary to describe them fully. One peculiar structure of the pupa, however, has already been pointed out in the general consideration of mosquitoes, and that is the 
trumpet-shaped breathing organs, which now issue from the thorax and no longer from the abdomen as with the larva. In Culex pungens, these ear-shaped, trumpet-like

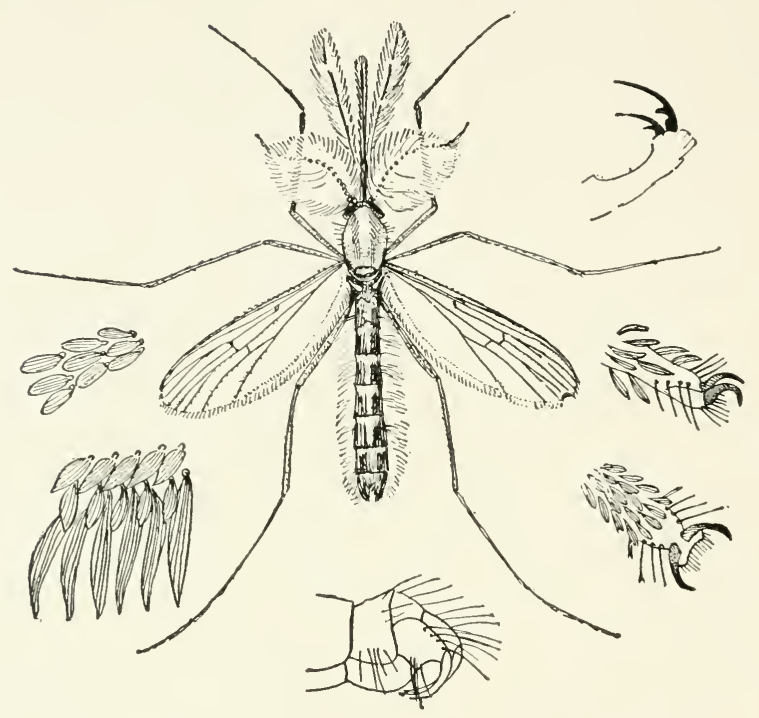

FIG. 11.-Adult male of Culex pungens; with parts enlarged. (Author's illustration.)

breathing organs are rather slender and of the proportions indicated in the figure.

The duration of the pupal stage in midsummer with this species at Washington is about two days. A minimum generation, therefore, of Culex pungens will occupy ten lays, as follows: sixteen to twenty-four hours for the egg; seven days for the larva, and two days for the pupa. 
In my observations on this species I was interested to notice that on the first day the adults which emerged from the pupe were invariably males; on the second day

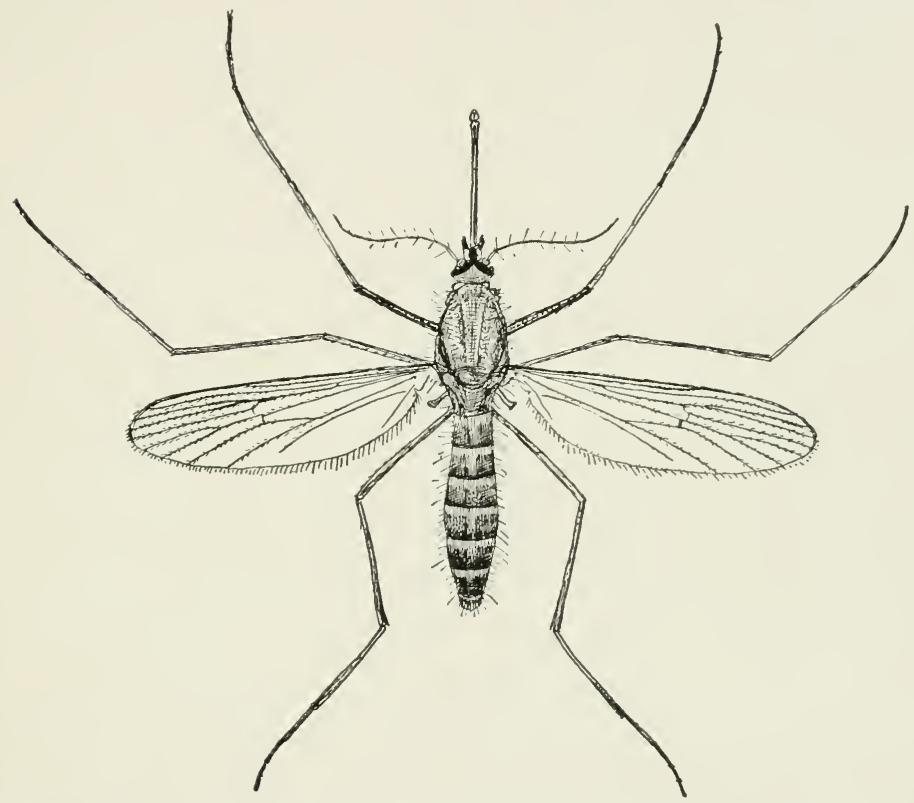

FIG. 12.-Adult female of Culex pungens; enlarged. (Original.)

the great majority were males, but there were also a few females ; the preponderance of males continned to hold for three days ; later the females were in the majority.

The duration of a generation as indicated above, is, as we have seen, a minimum duration. If a spell of cold weather should come in the middle of the summer, the 
life of the wrigglers may be almost indefinitely prolonged. I have watched them for twenty days, during which time they did not reach full growth. The shortness of the minimum generation, however, is very signifi. cant and accounts for the fact that swarms of mosquitoes develop upon occasion in surface pools of rain-water, which may dry up entirely in the course of two weeks or Jess, or in a chance bucket of water left undisturbed for that length of time.

Dr. John B. Smith has reared the species, as elsewhere stated, from larve found in January frozen in ice. In studying the larve after they had been thawed out he found that they remained under the water for a long time, certainly fifteen minutes, and probably much longer. These observations thus differ radically from those which I made in summer, and show that these larro must be studied still more before we know all that may be found out about them.

This species, Culex pungens, is said by Dr. H. A. Veazie, of New Orleans, to breed most extensively in the gutters in that city. They are found in gutters in which the water runs slowly, but more plentifully in those where there is no current. In gutters that receive the refuse of the gas works, tar factories, soap works, and oil establishments, there are no larve. They live in gutters containing Missiosippi River water, but do not prosper. Dr. Veazie thinks the fine sediment in the Mississippi water blocks their breathing tubs, since they flourish well in this water after it has been filtered.

Reverting once more to the distribution of the different 
species of Culex, I have been able to determine, by examination of the locality labels in the collection of the United States National Museum, that in almost every locality in the United States there may be found five or six species of this genus. The commoner forms are Culex consobrinus, C. stimulans, C. perturbans, C. pungens, and C. impiger, and these forms are found almost all over the country, from New England to Texas, and even to southern California. C. consobrinus is perhaps a more northern form than the other's, and is one of the species which occurs in Alaska. It is also found in the White Mountains in New Hampshire and in the Catskill Mountains in New York, and occurs on the Saskatchewan River in British America, and in Minnesota and North Dakota.

We have in this country no species of the genus Culex which inhabits really salt water and, in fact, no species of mosquito can definitely be said to occur in water as salt as the ocean. Three or four Australian species are said to live in salt water, but, so far as I have been able to learn, there is not sufficient substantiality in this record. Culex salinus of Europe is also said to breed in salt water. We have in the United States, however, a species of Culex which occurs in brackish water, that is to say, it is able to breed in, and prefers apparently to breed in, the brackish swamps which are occasionally overflowed at very high tides, though not affected by the daily high tide. This is Culex sollicituns (see Fig. 1), a small gray mosquito which has its legs banded with black and white. It is ordinarily known as the ring-legged mosquito and is the most common form on the Atlantic sea- 
coast. It occurs along the New Jersey coast, the Long Island coast, along Staten Island, at Virginia summer resorts, and at 'Tybee Island, Ga., aud St. Augustine and Charlotte Harbor, Fla. Curiously enough, Dr. A. D. Hopkins states that what is probably this same species apparently breeds in West Virginia in pools and small streams fed from coal-mine drainage, the water of which contains a large percentage of sulphate of iron.

There is no loubt that this Culex breeds in great numbers in the pools left by the highest tides, which subsequently become freshened to some extent by rains or by the entrance of spring water. It has been canght, how. ever, considerable distances inland, and the question arises, has it been carried to such spots by trains only, or will it breed after being so carried for at least one or two generations in fresh water? Mr. Benjamin S. Paschall, of Newfield, N. J., canght this species in August, 1900 , in his garden. They could be found anywhere in the long grass, practically by the thousands. Newfield has one of the highest altitudes in South Jersey, being about 130 feet above the tide and over thirty miles from the sea. In Mr. Paschall's opinion, the species must breed there. There had been no wind for a long time before their appearance and the microscope showed all specimens to be freshly hatched. On September 4th, he tried an experiment and placed a pail of water in a spot where these insects were thickest. By the end of a week he had procured many eggs, and September 14th he succeeded in hatching out several hundred mosquitoes, but not one single specimen of sollicituns; all were mu- 
gens. He concludes that Culex sollicituns appears in the perfect state throughout South Jersey, being found from May to October, but is not always common. Mr. La Rue Holmes, of Summit, N. J., has several times sent me specimens of sollicitans taken at Summit, which is about twelve or fifteen miles from the nearest salt marsh. I am inclined to think that although this species may be found widespread through the summer in various parts of New Jersey, this abundance is due to its carriage in numbers from the sea-coast by railway trains, and even if it does breed for a generation or two in fresh water, the supply is constantly renewed from the sea-shore.

C'ulex impiger is another of the more northern mosquitoes, having been collected by Mr. Trevor Kincaid on the Harriman Alaskan Expedition, and having been given me by Dr. Walter Evans, of the United States Department of Agriculture, who has investigated the agricultural resources of Alaska. Mr. F. C. Pratt has found it breeding in privy vaults in Alexandria, Va., and this species is likely to be the one found usually in such places, where the water is fouled with decomposing or excreted animal matter.

The distribution of our commoner species of Culex, so far as known to the writer, is as follows:

Culex consobrinus Desv.

Habitat: White Mountains, N.H. ; Beverley, Mass., September 28 (Nat. Mus.) ; Catskill Mountains, Greene County, N. Y., 2,500 feet (Howard); Illinois, March 21, April 29, May 6, October 16 (Nason); St. Anthony Park, Minn., April, 
May, on snow (Lugger); Saskatchewan River, British America; South Dakota (Nat. Mus.); Lincoln, Neb. May, September (Bruner); Colorado (Nat. Mus.); Hot Springs, Ark. (Curry); Los Angeles, Cal., February (Coquillett) ; Argus Mountains, Cal., April (Nat. Mus.) ; Santa Fé, N. Mex., July (Cockerell) ; New Orleans, La., November ('Thayer) ; Ottawa, Canada, May (Howard) ; Summit, N. J. (Holmes) ; Trenton, Ontario, May 24 (Fletcher); Flat River, Mo., November (Pergande).

Culex andulatus Meig.

Habitat: New Bedford, Mass. (Johnson); Lincoln, Neb., May (Bruner) ; Santa Fé, N. Mex., July (Cockerell); Stanford, Cal. (Kellogg); Laggan, British Columbia (Wickham).

CULEX IMPIGER Walk.

Habitat: White Mountains, N.H. ; Beverley, Mass., May 24, June 2 (Nat. Mus.); Ithaca, N.Y., July 9 and 1\%, August 28 ; Wilmuth, N.Y., June 10 (Comstock) ; Saskatchewan River, British America (Nat. Mus.); Minnesota (Lugger); Loudoun County, Va., August 26 (Pratt); Tyrone, Ky., July 14 (Garman); Georgia (Nat. Mus.) ; Mesilla, N. Mex. (Cockerell); Isle of Pines, West Indies (Scudder) ; Portland, Jamaica (Johnson) ; District of Columbia, September 12 (Barber); Alexandria, Va. (Pratt) ; Ogdensburg, N.Y., June 3 (Howard); Buffalo, N.Y. (Wright); Middletown, Conn., June (Davis) ; Ottawa, Canada, May 31 (Howard); Chats Rapids, Quebec, May 24 (Fletcher) ; Buckeye, Wash. (Nat. Mus.) ; Stikine River, British Columbia (Wickham); City of Mexico (Herrera).

Culex Perturbans Walk.

Habitat : Lakeland, Md., August 8 (Pratt) ; Virginia, August 17 (Pergande); Tick Island, Fla., May 12 (Johnson); 
Texas (Nat. Mus.); Bayanon, Porto Rico, January (Busck); District of Columbia, September 1-5 (Barber); St. Elmo, Va., June, July, Virginia Beach, August (Pratt); Melbourne, Fla. (Peek); Cuba (Lazear, Read).

Culex Pungens Wied.

Habitat: Ottawa, Canada (Fletcher); White Mountains, N.H. ; Beverley, Mass., September 5 ; Cambridge, Mass., September 16 to November 5 ; Boston, Mass. ; Baltimore, Md., November 5 (Nat. Mus.), November 26 (Lugger); Charlton Heights, December 1 (Pratt); District of Columbia, January 30 , March 5, May 6 and 15 , June 28 , July 11, August, October 10, 15, 25 and 31, November 4, 8, 13, 16 and 23, December 23 (Pergande); Ithaca, N. Y., May 29, July 17, August 28 (Comstock) ; Illinois (Nason); Minnesota (Lugger) ; Lincoln, Neb., September 20 (Bruner); Lexington, Ky., November 10 (Garman); New Orleans, La., December 17 (Howard); Sun Antonio, Tex., May is (Marlatt); Hot Springs, Ark. (Curry); Georgia, August (Coquillett); Melbourne, Fla. (Peek); Portland, Janaica (Johnson) ; Mexico City (Barrett) ; District of Columbia, August 22, 28, September 1 (Barber) ; Jackson, Va., October (Thayer); Woodstock, Va., June (Pratt) ; Newport News, Va., October ('Thayer); Stillwater, Okla., June (Bogue); Philadelphia, Pa. (Woldert); New Orleans, La., June (Veazie) ; Eastern Texas (Woldert); Summit, N. J., May (La Rue Holmes) ; Newfield, N. J. (Paschall) ; Middletown, Conn., June (Davis); Cuba (Lazear, Reed); Agrie. College. Miss. (Herrick); Flat River, Mro., November (Pergande), Bluefields, Nicaragua (Wailes); Guanajuata, Mex. (Dugés).

Culex stinulans Walk.

Habitat: White Mountitins, N. H. ; Beverley, Mass., June 2, July 9 ; Cambridge, Mass., May ; Jamaica Plain, Mass., 
August 25 (Nat. Mus.) ; Siasconsett, Mass. (Wilder) ; Baltimore, Mal. (Lugger); Illinois, August 1, September 15, October 5 (Nason) ; Agricultural College, Mich. (Gillette); Saskatchewan River, British America (Nat. Mus.); Lincoln, Neb. (Bruner) ; Colorado (Nat. Mus.) ; Ithaca, N. Y., June 13, 18, 29, July 14, August 28 ; Wilmuth, N. Y., Jume 10 (Comstock) ; Rochester, N. Y. (Ewers); Buffalo, N. Y. (Wright); Brooklyn, N. Y. (Van Matie); Georgia (Nat. Mus.); Bladensburg, Ma., May 27 (Barber); St. Elmo, Va., June 5 (Pratt) ; District of Columbia, September (Barber); June 10 (Miss L. Sullivan); Ottawa, Canada, June 1 (Howard) ; Ogdensburg, N. Y., June 3 (Howard) ; Rochester, N. Y., June (Ewers) ; Summit, N. J., May (Lat Rue Holmes); Middletown, Comn., June (Davis); Lake Maxinkuckee, Ind. (Evermann); Mesilla, N. Mex., October 26 (Cockerell) ; 'Tacna, Ariz., April 13 (Hubbard) ; Juarez, Mexico, May 12 (Cockerell) ; Summit, N. J. (Holmes); Flat River, Mo., November 1 (Pergande).

Culex sollicitaxs Walk.

Habitat : Maine, August ; Beverley, Mass., June, September 15 (Nat. Mus.) ; Siasconsett, Mass. (Wilder) ; Avalon, Anglesea, and Atlantic City, N. J., July 10 to 29 (Johnson); Summit, N. J., September (Holmes) ; Far Rockaway, Long Island, N. Y., August 30 (Howard) ; District of Columbia (Pergande) ; Georgia (Nat. Mus.) ; St. Augustine and Charlotte Harbor, Fla., July ; Portland, Jamaica (Johnson); Chesapeake Beach, Md. (Barber) ; Baltimore, Md. (Thayer); Plymoutl, N. C. (Thayer).

Culex tarsalis Coq.

Habitat: Argus Mountain, Cal., April ; Folsom, Cal., July 3 (Nat. Mus., Koebele) ; Stanford, Cal. (Kellogg) ; Corvallis, Oregon (McElfresh). 
CUlhX TRISERIATUS Say.

Habitat: White Mountains, N. H. (Nat. Mus.); Delaware County, Pa., June 12 (Johnson) ; Washington, D. C., May 5 and June 10 ; London County, Va. (Pratt) ; Near Baltimore, Mr. ('Thayer); Roanoke, Va., October (Thayer); Middletown, Conn., June (1)avis) ; New Jersey (Woldert).

\section{Dr. J. B. Smith's Observations on Culex pungens.}

The observations made by the well-known State entomologist of New Jersey on the larve hibernation of C'ulex purgens in pitcher plants are of such great interest that they are given in full from advance sheets of an article which Dr. Smith has been good enough to send me and which was prepared for the Entomological News.

New Jersey's reputation for mosquitoes is well established, and more people come into our State annually to be bitten by our shore species than go to any other State in the Union for any like purpose. In some of the swampy districts in the Pines they make life a burden at times, so when my good friend, J. Turner Brakeley, wrote me in the late summer that in looking at the contents of some pitcher-plant leaves he had found mosquito larve in abundance in the water they contained, it male no especial impression upon me. It was in a way what I would have expected, though no one had noted this so far as I could then remember. Dr. Riley at one time bred a number of species from this plant; but seems either to have found no mosquitoes or to have ignored them. Mrs. Treat made many interesting olservations on the feeding habits of the plant itself, feeding the leaves with raw meat in place of the insects that ordinarily fall into them : but she also ignored the mosquitoes. 
Late in November (1900), I spent three days with Mr. Brakeley at Lahaway and one of our walks was into a huckleberry and wild cranberry swamp, where pitcher plants were abundant. Though the weather was yet mild, mosquitoes were no longer obtrusive. There were ocrasional specimens, to be sure, but they seemed to be left-over's not yet in hibernating quarters. The interesting point was that in every leaf examined there were wrigglers, varying in size from an eighth to a quarter of an inch in length. There was always a mass of insect fragnients at the bottom, say from one half to an inch in depth, and in composition this varied from a dense black ooze at the lowest point to entirely or only partly decayed specimens at the top of the mass. The question arose at once whether these larve would yet develop that season, and from published accounts I assumed that they must, or perish. Dr. Howard, in his careful account of the species of Culex, and especially $C$. pungens, says nothing of larval hibemation. He records finding adults and, indeed, this was in accordance with my own experience.

The matter dropped here until late in January when, during a bitter cold spell, Mr. Brakeley cut out a few pitcher leaves, stripped them from the core of solid ice they contained, and looking through it saw wrigglers imbedded in all parts of it, in all sorts of shapes; but mostly in a half coil. The temperature of the bog had been down to $2^{\circ}$ below zero, as registered by a standard minimum thermometer, and radiation probably lowered this even more.

A number of leaves were gathered, the cores of ice with all they contained were removed, and the lumps were placed together in a jar in a moderately wam room. The ice melted slowly, and as the larve were gradually freed, they dropped to the bottom, where for a time they rested, apparently lifeless. But as the amount of ice decreased, feeble motions here and there indicated a revival, and long before the lumps were completely melted, 
those first released were moving about actively. This, be it noted, was in water not nuch above the freezing point. Soon after the ice had melted and the debris had settled, the insects were busily engaged in apparent feeding.

The specimens were sent to me as a curiosity, January 22d, and arrived in very good condition. A few had sucmmbed to the dangers of the journey, hut altogether there was a good lot of lively wrigglers. The bottle was nearly full of water, it had had a five mile wagon drive over a rough roar, had been transshipped no less than four times before it reached New Brunswick and was thrown into the delivery wagon. Inder these circumstances any regular breathing of the kind usually described was utterly out of the question, and drownings should have been numerous; but really only a very small number of specimens died.

At short intervals other jars were received, all of melted ice taken from pitcher plants, until 1 had several hundred active wrigglers in eight different jars. Some of the leaf chunks, Mr. Brakeley informs me, had only a very few larve - ten or a dozen; others ran as high as thirty or more.

The jars were all placed on a counter shelf noar a stean radiator and it was expected that in a few days there would be pupe and adults. But the days passed into weeks and the weeks into months, without change other than a gradual-a very gradual, increase in size. The larve were just as active and lively as they could be expected to be, and were feeding contimumsly; but evidently something was lacking. Besides, they did not in all respects behave as, acoording to Dr. Howarl's account, they should have done. I do not suggest that the acrount as printed is not a perfectly accurate record of facts: merely that ny specimens were Jersey mosquitoes and therefore a law unto themselves.

As the fragments sottled to the bottom, the water beeame 
almost entirely clear and larve congregated over this sediment, feeding head down and frequently rooting into it; varying the process by working along the glass of the jar on the side away from the light. It was very rare that an individual was observed at the surface with the spiracle in breathing position. I watched patiently several times, for fifteen minutes at a time, withont noting a single individual rising to the top. Mr. Dickerson, one of the students, watched more or less continuously for two hours on one day and declares positively that during that period only a small percentage of the entire number came to the top. On two or three occasions where my work was such as to allow it, I kept a jar within sight the entire day, and I have no hesitation in saying that some individuals remained below the surface for hours.

Occasionally a number of specimens would be at the surface, feeding, head up, so that the mouth-brushes skimmed the surface, and these were watched on occasions for fully twenty minutes without noting any attempt to assume the breathing position. In fact, during the two months that these larve were under daily observation, the rising to the surface to breathe was the rare exception rather than the rule.

As to feeding positions, all of those figured by Dr. Howard were noted. Usually they were head down, over the bottom sediment, or head up, feeding along the sides of the glass or at the top. The mouth-brushes serve as organs of locomotion as well as for feeding, and the insects are perfectly able to make their way from place to place without moving any other part of the body.

The jerky, wriggling motion is used when they wish to get away quickly, and as often to get down to the bottom as to get up to the surface. They can, and often do, sink slowly to the bottom without any motion whatever, and often, to sink more rapidly, they curl themselves up into a ring. Occasionally a speci- 
men will get hold of a bubble of gas forming at the bottom, and will allow itself to be floated to the surface. It is immensely interesting to watch these little creatures; but as week after week went by without change it became just a little tedious. To hasten matters a little, on March 1st I placed the two jars first received on a water bath, which was kept at a temperature as nearly constant as the varying gas pressure allowed. Ordinarily the thermometer ranged between $100^{\circ}$ and $110^{\circ}$, but it has gotten as high as $120^{\circ}$ and as low as $90^{\circ}$. These were exceptions, however, and not exceeding the ordinary ont-door range in June. The temperature of the water in the jars ranged between $80^{\circ}$ and $90^{\circ}$ almost uniformly.

A difference in the rate of growth was observable after a few days, and several specimens seemed approaching the adult condition ; finally, on March 18th, I noticed the first pupa, seventeen days after placing the jar on the water bath. From this the adult emerged March 21st and proved to be a female Culex pungens. Three other pupæ were formed within a week after the first, and a second adult, also a female, was obtained March 24 th.

As to the habits of the larvæ in the two jars artificially forced there was little to note as different from those in the normal laboratory temperature, which varied from $40^{\circ}$ to $\% 8^{\circ}$, averaging a little under $70^{\circ}$ for the twenty-four hours. They fed in much the same manner, kept away from the light as much as possible, passed most of their time at the bottom, but were more lively and more frequently at the surface. The jars were kept covered except for a few minutes each day and in none of them did the water foul, despite the vegetable and animal matter present in each.

On March 24th I made an experiment that resulted fatally. It occurred to me that possibly the slow growth was due to lack of food, and Mr. Brakeley had written me that the wrigglers attacked and devoured a small gnat which was breeding in his jars, 
suggesting that possibly a mutton chop might help matters along.

On March 24th, I put a small lump of raw beef chopped fine, into each of five experiment jars. The next day I could give only a casual glance before going out of town, and this showed nothing unusual ; but the day after, March $26 t h$, when I reached the laboratory at 8 A.M. I saw at once that something was wrong, because all the living larve were at the surface, head down, spiracles reaching the air. In every jar into which I had placed the meat I noted the same appearance, and I hastily fished out every particle. But it was too late : more than half were already dead, others seemed to show fungoid growth proceeding from the segments, so, to prevent their dying, I killed them off with a dose of formalin. One large jar received in February was left mnharmed, and this was placel on the water-bath March 26th. Nothing has come from it at the date of present writing, and nothing may ever come from it, but its history must be written later.

But this experiment, fatal as it proved, was of some value. It shows that water too foul with animal decay is not suitable for mosquito larva.* Vegetable decay and the harder refuse from insect bodies will help along the development; but beyond that the water must be clean. It seems to indicate further that the condition of the water may very largely determine the frequency with which the supply of oxygen must be renewed from above the surface. In June, with a supply of water at a relatively high temperature in which microscopic life is swarming, I have no doubt Dr. Howard's observations would be exactly duplicated. With the same species in clear water, at relatirely low temperature, the breathing habits are quite different and the insects obtain, I have no doubt, a goodly portion of their oxygen from the

* This generalization is much too broad. The larve of Culex impiger, for example, will swarm in water foul with decomposing animal matter, and so, possibly, will larve of certin other species of Culex.-I. O. H. 
water itself. Just how they do this I am not prepared to say. One thing may be considered as certainly established by this series of observations: the insect can and does hibernate in the larval stage, if this is not, indeed, the prevailing method. Mr. Brakeley has scoured the swamps for miles about within the last few weeks, and wherever he fomd pitcher plants almost or quite every leaf had its supply of wrigglers. It is not, therefore, a local phenomenon. Nor is it even suggested that pitcher plants alone furnish breeding-places where the larve hibernate; but they are remarkably safe resorts, protected to a very marked extent from natural enemies. Is there any relation between plant and insect, whereby the plant receives a benefit? Do the wrigglers in any way prevent a foulness of the water from the insect fragments until the plant has absorbed what it needs?

It is noticeable that during the whole winter only a single example of Culex pungens was taken in the barns, storehouses, or cranberry-sorting rooms, though they were diligently sought. Anopheles punctipennis were found quite abundantly-between twenty and thirty specimens having been taken on the windows of the sorting rooms; but no Anopheles larve were found in any of the collected leaves. As a Jerseyman, Mr. Brakeley ordinarily pays little attention to mosquitoes, but he could not easily overlook Anopheles, did it orcur in any numbers in summer. He says that it does not, and that he has never seen as many during his years of residence in the Pines as he did this past winter.

My own experience is similar. I remember that about three years ago I was annoyed by Anopheles very early in the year in my store-room in the basement of the Station Building. Later on I saw nothing of them, and I can say positively that the species of this genus form no part of the often considerable swarms in and near New Brunswick.

In the cellar of my residence I took Culex pungens, female, March 22d, flying. It conld not well have developed there, and 
of course there can be no doubt that the species hibernates as an adult as well as in the larral stage.

These pitcher-plant leaves contain, besides mosquito larvæ of this species, considerable numbers of other larve, which $\mathrm{Mr}$. Brakeley succeeded in breeding. Some examples submitted to Mr. C. W. Johnson he pronounced to be Aërles fuscus O. S., a species by no means commonly observed.

The present series of notes are not by any means a complete record of the observations male on the wriggler colonies at New Brunswick and in the Pines, and they are not even ended; but they will serve to call attention to one or two heretofore unobservel facts. They also contain a suggestion. Is it not probable that the mosquitoes that swarm in Alaska and in aretie regions may pass the winter in the larval stage, frozen in the solid ice, ready, when the melting time comes, to mature rapidly?

Hiding-places for adults are occasionally somewhat scant in such regions, and the swarms are said to be even more numerous and vicious than they are in New Jersey.

[Note.-Since this matter was put in type, Dr. Smith writes me that from recent rearings he is led to believe that most of his statements, especially with regard to the ability of larva to remain under water a long time, refer to Aëdes and not to Culex.-L. O. H.] 


\section{IV}

\section{The Malarial Mosquitoes of the Genus Anopheles}

T/O physicians and others who are investigating the malarial conditions of a given neighborhood it 1 becomes very important to know everything connected with this most noxious genus of insects. Not only is it necessary to be able to recognize them in every stage of their existence, but also to know the character of the pools in which they will be found in their early stages, since much time may be wasted in searching for them in places where they conld not possibly occur, or in which they are not likely to be found. This point must be borne in mind, therefore, by those who, looking through this chapter, think that the writer has gone into the subject with apparently unnecessary detail.

The genus Anopheles was founded by Meigen in 1818. The first reference to its early stages which is to be found in literature is in a paper entitled "Description of a New Fish which I found in the water of the basin of S. Margloire of the Fanxbourg S. Jaques at Paris, which can be called an Aquatic Caterpillar," published in Paris in 1754 by an observer who possessed the euphonious name of 
Joblot. He figures the lirva, which is recognizable as that of Anopheles. The Dutch observer, Meinert, gave the next accurate description and figure of the larva in 18s6, and other descriptions and figmes were published by the Italian, Ficalli, in 1899, and the Englishman, Giles, in 1900. The varions stages of one of these species were described and fignred in 1900 by the Italian, Grassi, and by the present writer. At the time I publisher these observations, I supposed that I was the first person in America to have seen Anoplieles larve, but Dr. Charles Sedgwick Minot, of the Harvard Medical College, wrote me, after seeing the first edition of Bulletin 25 , that he raised Anopheles twenty-fire year's or more ago withont suspecting its iclentity. At that time Dr. Minot was much interested in entomology. He has since hunted up his old notes, and has published an account of his early observations in the jommal of the Boston Society of Medical Sciences, vol. v., .Jannary, 1901.

The species which I stulied in full in the summer of 1900 , and which was treated in my Bulletin 25 as Anopleles quarlrimaculatus Say, has been definitely decided to be identical with the Anopheles maculipemmis of Europe.*

* Osten Sicken, Entomologists Monthly Mryjazine for December, 1900, pages 281-283, shows that Anopheles claviger Fab. has no existence. It never existed either as a type specimen, or as a scientific concept of a species. The correct name, therefore, of the common Anopheles of northern and central Europe is Aropheles maculipennis M., of which our American A. quadrimaculatus Saly, is a synonym, as has been shown by Theobald. Ruthe wrote in Oken's Isis (1831, p. 1203), as pointed out hy Osten Sacken in the above article, as follows :

"Anopheles maculipennis M. is not uncommon in the Mark Brandenburg, in localities where water is abundant; for instance, it is quite 
Dr. W. S. Thayer saw the European species in Cirassi's laboratory in Italy, and on his return to this comntry told me that he thought the two forms were identical ; and the English student, F. V. Theobald, who is monographing the mosquitues of the Old World for the British Museum, has studied a large series of specimens from this comntry and has decided that the European and American forms are identical. This at once suggests the interesting question as to whether this abominable creature was introduced from Europe to America or the reverse. It is quite within the bounds of possibility that malaria was originally an European disease and that not only was the disease itself carried from there on sailing vessels, but the mosquitoes which propagate it as well, at least to America.

The Life History of Auspleeles maculipemis.

The Adult.-The accompanying illustration (Fig. 15) will show very well the general appearance of the adult insect. It is a rather large mosquito and is very bloodthirsty. It is attracted to the house in numbers. The differences between the males and females are well brought out in Fig. 15, and the striking feathery antenne and palpi of the male render it very conspienous. The wing markings and the color of the palpi differentiate this species from our other species of common about Frienwalde in mickummer. Its sting is more painful than that of any gnat I know, and has a much more pernicions effect. During a botanical excursion of several days which I made with some of my pupils, I noticed that the sting proiluced deep purnlent liounds, which it took several weeks of careful medical treatment to heal." 
Anopheles, and the long palpi of the female at once distinguish it from all species of Culex.

Resting Position.-Owing to the publication of a field sketch made at Sierra Leone by a member of the Rioss expedition, the writer has been much interested in watching the resting positions of the adult insects. He finds that when resting upon a horizontal surface--such as the ceiling of a room or the covering of breeding-jars-the insect clings with its four anterior legs in a nearly perpendicular position, its beak thrust forward toward the surface to which it clings. The hind legs are frequently in motion, but as a rule hang downward with more or less of a bend at the knee joint (femero-tibial articulation). When resting upon a perpendicular surface, however-such as the side wall of a room or the side of a breedingjar-the body is held only at a comparatively slight angle from the surface. Sometimes it is nearly parallel with the surface. At other times it assumes an angle of $10^{\circ}$ to $20^{\circ}$ (occasionally even as great an angle as $30^{\circ}$ to $40^{\circ}$ ), the proboscis being held nearly in line with the body. Here again the insect supports itself by the four anterior legs, the hind leg dangling down with more or less of a bend at the knee. This position is common to both males and females, and is illustrated in Fig. 13. When the body is held parallel, it will generally be found that one of the middle or hind legs has been broken off. 'They are very delicate and readily break.

The writer has taken the liberty of having Figure 14 engraved from a drawing sent him by Mr. C. O. Waterhouse of the British Museum. Mr. Waterhouse made the 


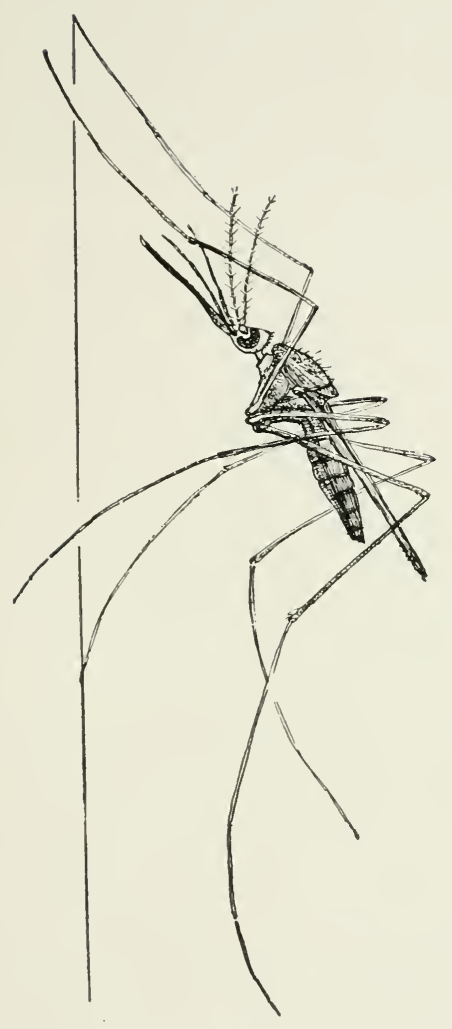

FIG. 13. - Resting Position of Anopheles; enlarged. (Author's illustration.)

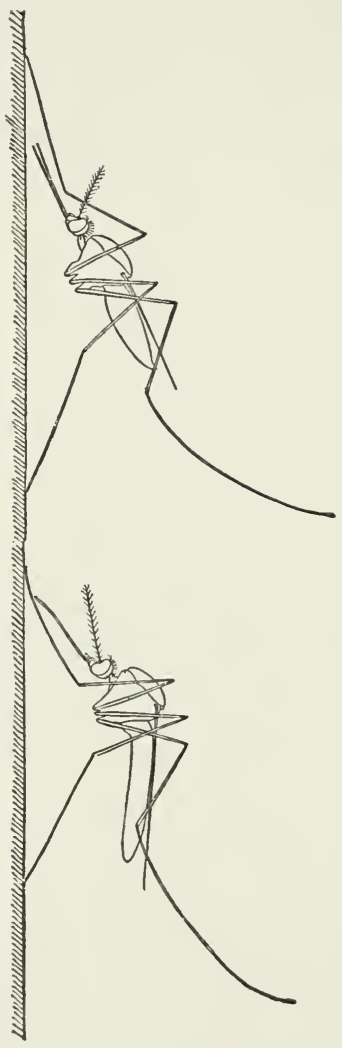

FIG. 14.-Resting Position of Anopheles above, Culex below ; eularged. (From sketch by C. O. Waterhouse.) 
drawing himself and wrote: "Whatever may be the attitude of Anopheles, it is all in one line. Culex is angular, humploacked."

Note of Female.- The peculiar hum of the mosquito is well known. There is a distinct difference between the

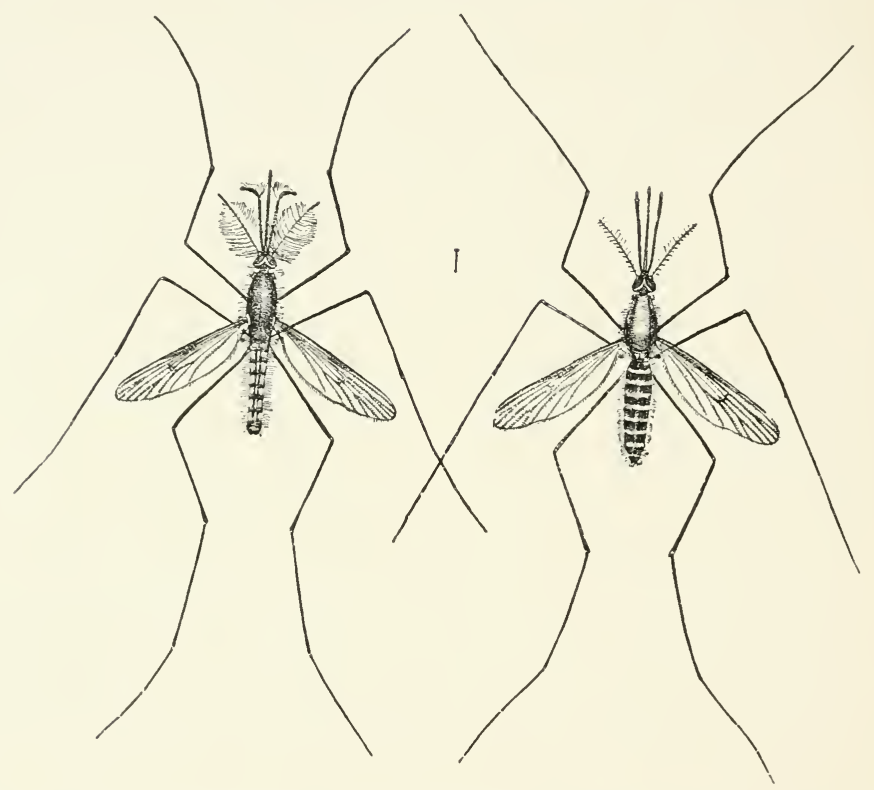

Fig. 15.-Anopheles maculipennis, male at left, female at right; enlarged. (Author's illustration.)

hum of Anopheles maculipennis and that of the common species of Culex, in that the former is noticeably lower in tone. The note of Culex as it approaches the ear is high in pitch; that of Anopheles is certainly sev- 
eral tones lower and of not so clear a character. In quality it is something between the buzzing of a house fly and the note of Culex. Mr. Pratt states that he can at once distinguish the two genera in this way as he is sitting reading in the house, and the writer feels quite sure

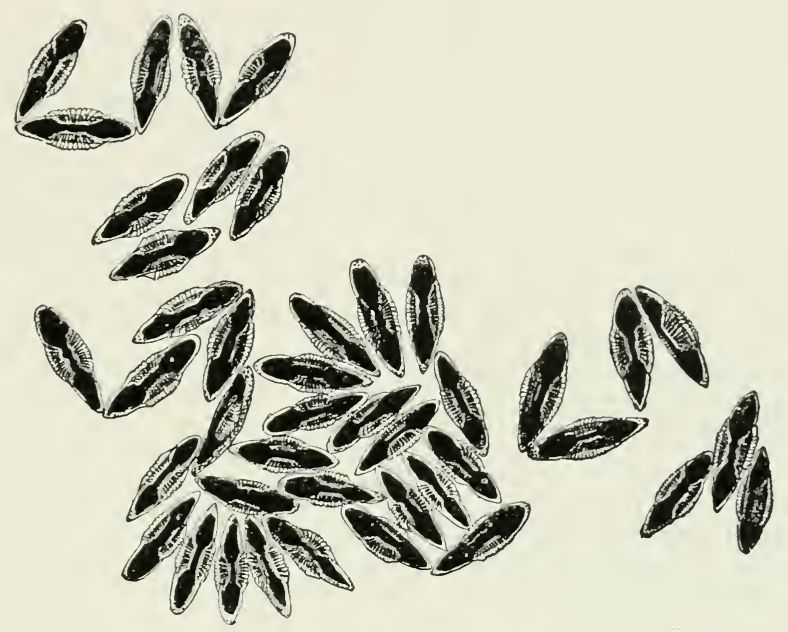

Fig. 16.-Erg Mass of Anopheles maculipennis; enlarged. (Author's illustration.)

after listening to them in breeding-jar's that the statement is correct.

These olservations have been made with an abundance of material, nearly 100 adults having been under observation.

The Eggs.-The well-known and often-mentioned raftshaped masses of egrgs of Culex are not even remotely 
resembled by the Anopheles ovipositions, and the individual eggs are equally dissimilar. In the accompauying illustration (Fig. 16) the egg mass of Anopheles is illustrated for comparison with Fig. 7. In Culex from 200 to 400 eggs are laid in a mass ordinarily shaped like a pointed ellipse, convex below and concave above, all the eggs perpendicular, and stuck closely together at the sides by some gummy secretion, and arranged in rows. The mass with Anopheles, however, is laid loosely upon the surface of the water, each egg lying upon its sicle instead of being placed upon its end as in the egg mass of Culex. They are not attached together except that they naturally float close to each

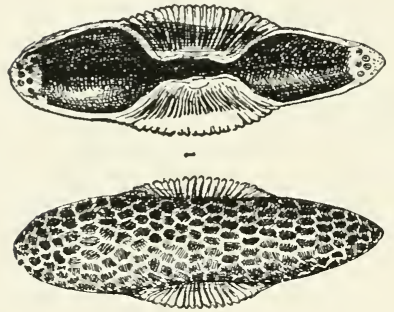

Fig. 17. - Individual Eggs of Anopheles maculipennis, from below at left, from above at right; greatly enlarged. (Author's illustration.) other, and there are from 40 to 100 eggs in each lot. In Culex mungens the individual egg is $0.7 \mathrm{~mm}$. long and 0.16 $\mathrm{mm}$. in diameter at the base. It is slender, broader, and blunt at the bottom, slenderer and more pointed at the tip. The tip is always dark grayish brown in color, while the rest is dirty white. The egg of Anopheles when seen from above is of rather regular elliptical outline, the two ends having practically the same shape; seen from this side, it is strongly convex below and nearly plane above; seen from below, it is dark in color, and when examined with a high power is seen to 
be covered with a reticulate hexagonal sculpturing. At the sides, in the middle, there appears a clasping membrane with many strong transverse wrinkles. Seen from above, the egg is black except for a clasping membrane which nearly meets on the middle line in the middle third of the body, but retires to the extreme sides for the anterior and posterior thirds. At each end the color is lighter, with a group of from 5 to 7 minute dark circular spots. It is $0.57 \mathrm{~mm}$. long. Eggs laid April 26th hatched April 30th. Others laid May 13th and 14th hatched May 16th and 17th.

The Larva.-The larva is quite as unlike that of Culex pungens as is the egg. It differs in structure, in its foodhabits, and in its customary position, so markedly, that it ean at once be distinguished with the utmost ease. The larva of Culex, it will be remembered, comes to the surface of the water to breathe, thrusting its breathing tube through the surface layer and holding its body at an angle of about forty-five degrees with the surface of the water. While in this position its mouth-parts are in motion and it is taking into its alimentary eanal such minute particles as may be in the water at that depth, but these are naturally few in number and the larva descends at frequent intervals toward the bottom to feed. The want of oxygen, however, causes it to wriggle up again to the surface at very frequent intervals. Its specifie gravity seems greater than that of water, so that it reaches the surface only by an effort, and the writer has already pointed out, in the case of Culex pungens, that when the larva becomes enfeebled and is not strong enough to 
wriggle up to the surface, it drowns. Feeding as it does at the bottom upon the heavier particles which sink, its specific gravity is explained. The larva of Anopheles muculipennis, however, habitually remains at the surface of the water. Its breathing tube is very much shorter than that of Culex, and its body is held not at an angle at the surface, but practically parallel with the surface and immediately below the surface film, so that portions of its head, as well as its breathing tube, are practically out

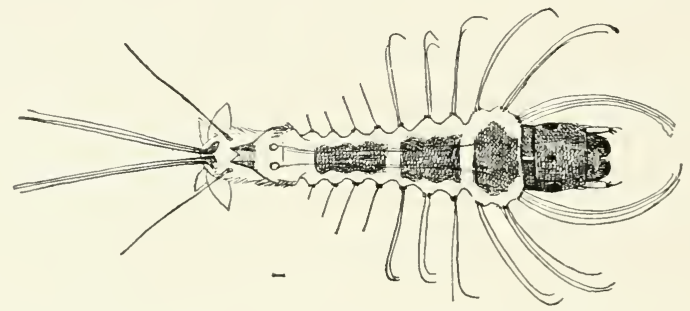

Fig. 18.-Young Larva of Anopheles maculipennis ; enlarged. (Author's illustration.)

of the water. Its head rotates upon its neck in a most extraordinary way, so that the larva can turn it completely around with the utmost ease, and feeds habitually with the under side of the head toward the surface of the water, whereas the upper side of the body is toward the surface. In this customary resting position the mouth parts are working violently, the long fringes of the mouth-parts causing a constant current toward the mouth of particles floating on the surface of the water in the neighborhood, which thus gradually converge to this 
miniature maelstrom and enter the alimentary canal. The spores of algæe, bits of dust, minute sticks, bits of cast lar-

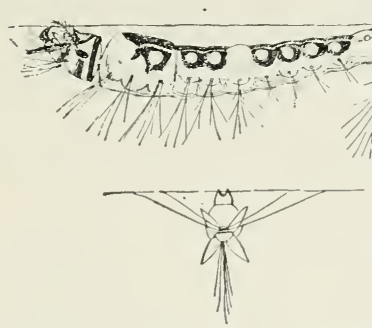

Fig. 19. -Half-grown Larva of Anopheles maculipennis; enlarged. (Author's illustration.) val skins, everything in fact which floats, follow this course, and, watching the larva under the microscope, they can plainly be seen to pass through the head into the thorax until they are obscured by the dark color of the insect's back. Occasionally, too large a fragment to be swallowed with ease

clogs the mouth. Sometimes it enters the mouth and sticks. In such cases the head of the larva revolves with lightning-like rapidity and the fragment is nearly always disgorged, although sometimes it is swal. lowed with an evident effort. Since the Anopheles larva feeds only upon these light, floating particles, its specific gravity is nearly that of the water

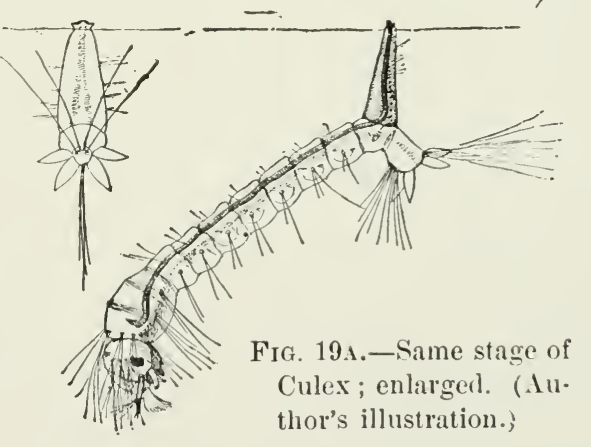
itself, and it supports this horizontal position just beneath the surface film with comparative ease, and, in fact, without effort, the tension of the surface film itself being hardly 
needed to hold it. It requires an effort, in fact, for the Anopheles larva to descend (which it apparently rever does up to the period of the final larval stage, except when alarmed), while it requires an effort for the Culex larva to ascend.

Structurally the differences between the half-grown larve of Culex and Anopheles are well shown in Figs. 19, $19 A$, and 20. The great size of the head of Culex, as contrasted with the small head of Anopheles, is a most strik-

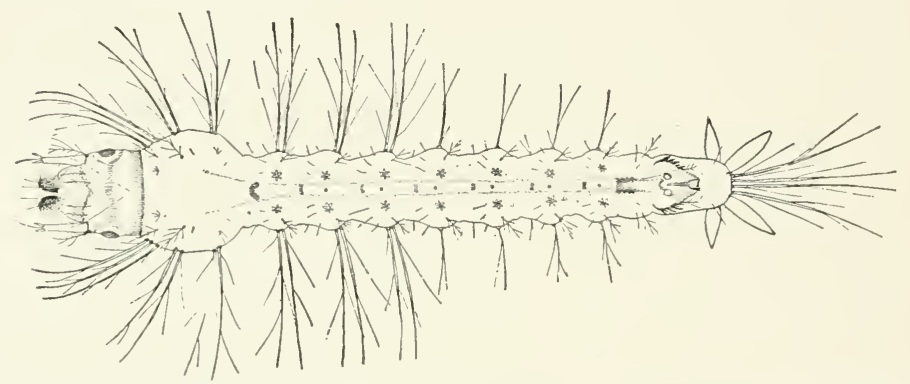

Frg. 20.-Half-grown Larva of Anopheles maculipennis; enlarged. (Author's illustration.)

ing difference. The very long respiratory siphon (as Miall calls it) of Culex contrasts markedly with the short one of Anopheles. The arrangement of the hairs is entirely different; the branching of the hairs of Anopheles, as contrasted with the simple hairs of Culex and the little paired star-shaped (apparently branchial) tufts on the dorsum of Anopheles, is entirely absent with Culex. The flaps at the tail end of the body are similar in number, but are held in a somewhat different position. 
The larve first studied-those which hatched from the eggs on April 30th-grew very slowly for a number of days. This was partly owing to cool weather in the early part of May, and partly, I believe, to the absence of proper food. They were reared in glass jars of water, with sand at the bottom and a willow twig rooting in the sand.

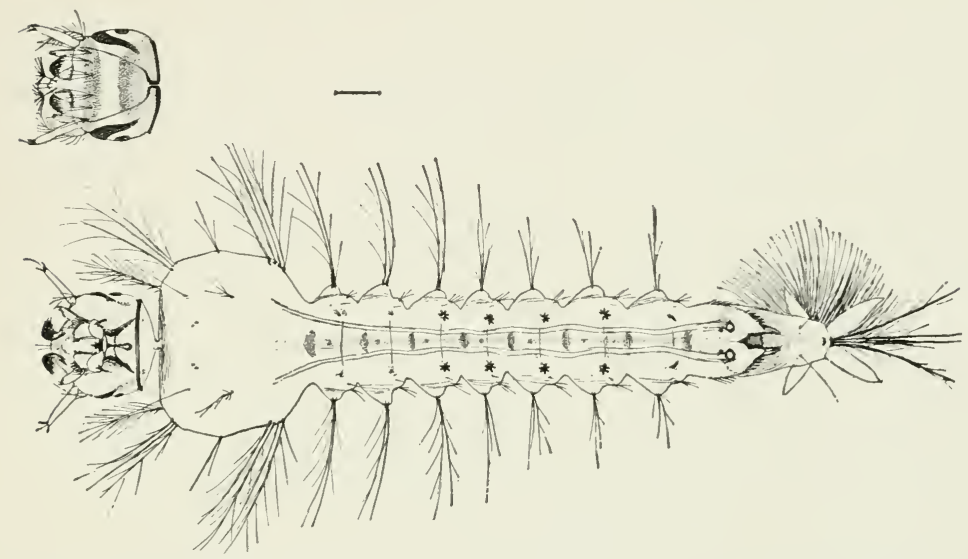

FIG. 21.-Full-grown Larva of Anopheles maculipennis slonwing head upside down, with top of head above, at left; greatly enlarged. (Author's illustration.)

As above noted, they swallowed every small particle floating on the surface of the water, and the dark coloration shown in Fig. 18 was largely dne to the fact that most of these food particles were dark colored. About the 10th of Nay, the larre having passed through two molts, a small quantity of the green algre growing on the lily ponds on the Department grounds was placed in the jar. The 
larre commenced to thrive much better, grew rapidly, and the general color of the body changed to green. The description of the habits given above held well until after the last molt preceding the change to pupx. In this final larval stage, as shown in Fig. 21, the diameter of the thorax became much greater in comparison with the rest

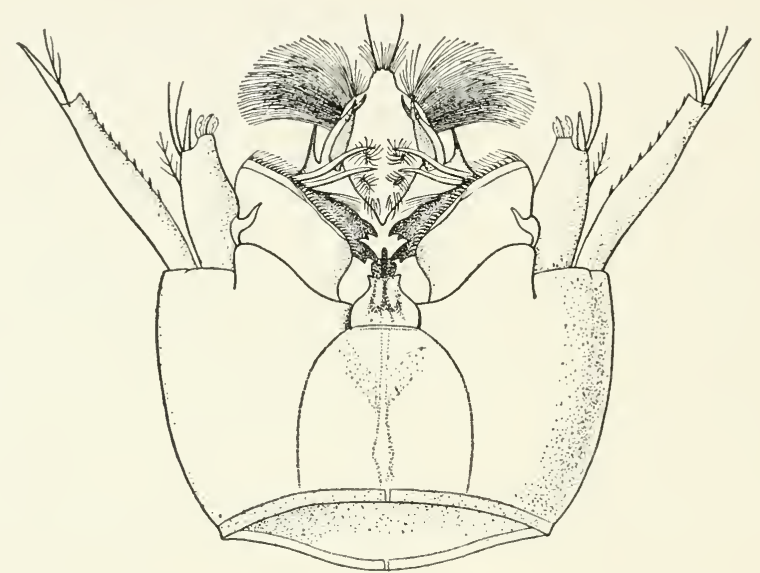

FIG. 22.-Head of Larva of Anopheles maculipennis, under side; greatly enlarged. (After Nuttall.)

of the body. The larva was less marked, more inconspicnons, and altered its feeding habits to some extent. After remaining at the surface of the water, feeding, as before, upon floating particles, for some time, it would wriggle violently and descend to the bottom, where it would remain frequently as long as ten minutes before reascending to the top. Its appetite was evidently so 
great that it was not satisfied with the floating particles, and when it descended to the bottom it mouthed the particles of sand, apparently swallowing the slime on the little stones and frequently even picking up quite a large sand pebble and then dropping it again. In this stage the individual which grew most rapidly remained only four days, and transformed to pupa on the morning of the

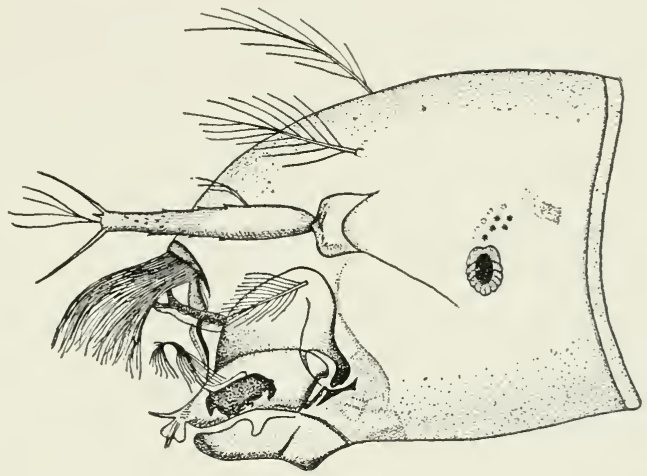

Fig. 23. -Enlarged Head of Larva of Anopheles maculipennis, from side; greatly enlarged. (After Nuttall.)

17th, after a larval existence of sixteen days. The accompanying figures of the larve have been drawn with such care that detailed description will be unnecessary. They were drawn from life under the compound microscope. Some of the structures are puzzling, notably the organs occurring on the dorsum of the abdominal segments. shown most plainly in Fig. 20, and which look as though they might be spiracles until they are examined under a 
high power in the cast skin. The writer does not care to risk an expression of opinion as to their function, although possibly it is known, and they possibly occur in other dipterous larve. In the early stages of the larve they resemble minute branchial tufts, but no tracheal comnection has been found.

The Pupa.-The accompanying figure (Fig. 24) well represents the differences between the pupa of Culex and
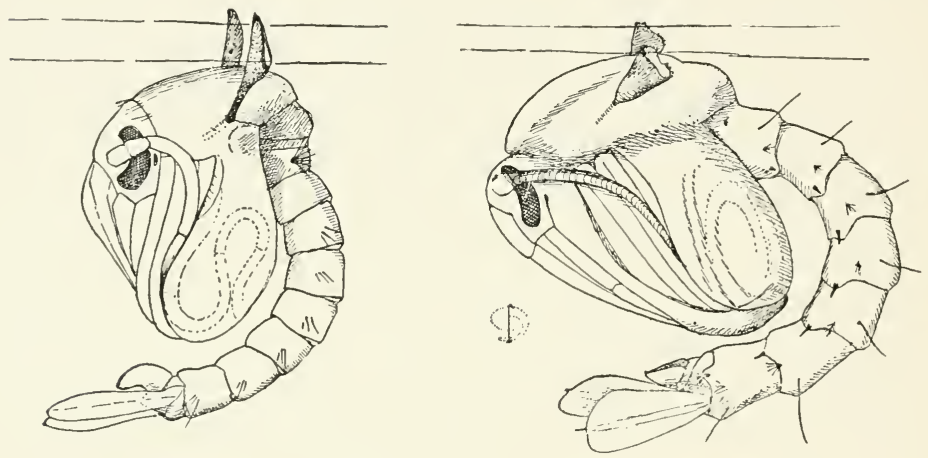

Fig. 24.-Pupa of Anopheles at right; Culex at left; enlarged.

(Author's illustration.)

that of Anopheles. In this stage the insects of the two genera are not so markedly different as in the larval stage. Structural differences need not be described, as they are sufficiently shown in the illustration. The eye will at once be canght by the difference in position, the pupa of Culex resting in a more perpendicular attitude than that of Anopheles; and the marked difference in shape between the respiratory siphons, which issue from the thorax in- 
stead of from the anal end of the abdomen, will at once be noticed. The pupa of Anopheles is quite as active, when disturbed, as is that of Culex. If one tonches the surface of the water near it with the finger, the pupa at once wriggles violently away, returning shortly to the surface for air.

The duration of the pupal stage in Anopheles raries according to the weather. Five days was the minimum observed during June, although several specimens remained in this stage for ten days. The adults issue as do those of Culex.

The entire life round, therefore, of Amoplieles maculipemis in the generation studied by the writer is as follows: egg stage, three days; larval stage, sixteen days; pupal stage, five days; making a total period in the early stages of twenty-four days. It should be stated, howerer, that during the early larval existence, toward the end of May there occurred nearly a week of cool weather, so that it is certain that in the hot season in July and August the growth and transformations will be more rapid. It will be remembered that the writer traced Culex pungens through an entire generation in the latter part of June, in ten days.

European Observations on the Same Species.

Nuttall and Shipley state that when the eggs are first deposited they are white, but that they soon blacken. They are boat-shaped, and one end is slightly deeper and fuller than the other. The thickening at the edge, which in previous paragraphs was called the clasping membrane, is 
composed of air chambers, and is used to keep the boatshaped egg with its flat surface uppermost. The English writers have observed that when the eggs have been much rubbed, the delicate membrane splits off and the egg appears with a glistening black surface like patent leather.

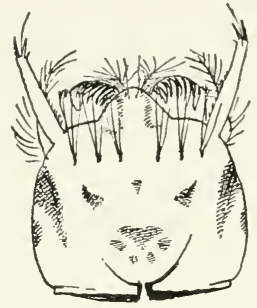

Fig. 2.j.-Head of Full-

grown Larva of Anopheles puncti. pennis; en larged. (Author's illustration.)

They have noted also that when the egg, as frequently happens, is drawn by capillary action a little way up from the water on a leaf, the head or blunt end always points downward, so that when the larva emerges it drops into the water, and not up in the air. Grassi says that the eggs of this species lie in groups of from three to twenty, sicle by side, like a briclge of boats, but Nuttall and Shipley find them in open pools in Great Britain scattered about. According to these observers the eggs hatch on the second or third day after being laid, depending on the temperature, the young issuing through a circular split near the blunt end of the egg. They also state that eggs which were dried less than five days did not hatch. Full and detailed accounts of the anatomy of the larva and pupa are given by the English writers in a paper entitled "The Structure and Biology of Anopheles" (A.maculipennis) in the Journal of ITygieme, vol. i., No. 1, January, 1901 ; this article is beautifully illustrated. 


\section{Natural Breeding Places of Anopheles.}

A number of the natural breeding-places of Anopheles maculipennis and A.punctipennis have been found by the writer in the United States. They have always been found in more or less permanent pools of water, either in the bed of an old canal or in spring-fed woodland streams, or in the side pools or shallows of field springs, or in artificial excavations filled with surface water. In such places, when supplied with a certain amount of green scum, the little larva will often be found resting at the surface of the water, and occasionally darting from one spot to another.

The larve of $A$. punctipennis differ from those of $A$. maculipennis largely in the marking of the head, as indicated in the accompanying figure. The temperature of the water which they inhabit varies from $18^{\circ} \mathrm{C}$. to $25^{\circ} \mathrm{C}$. Nuttall and Shipley state that in England these larvæ are to be found in pools, ditches, backwaters of rivers and canals, and in other slow-flowing waters ; almost invariably in such waters as are clear and very rarely in impure or brackish water. In their experience, they prefer pools which are not shaded by trees, although I have found them in this country on several occusions in a dense shade. They are very rarely found in water contained in barrels and troughs and fountain basins, and they are very rarely found in the same water with the larve of Culex. Mr. E. E. Austin, in "The Report of the Proceedings of the Expectition for the Study of the 
Causes of Malaria at Sierra Leone," states that on Angust 26, 1899, Dr. Pront and Dr. Berkeley found Anopheles larve mingled with those of Culex in a tub of

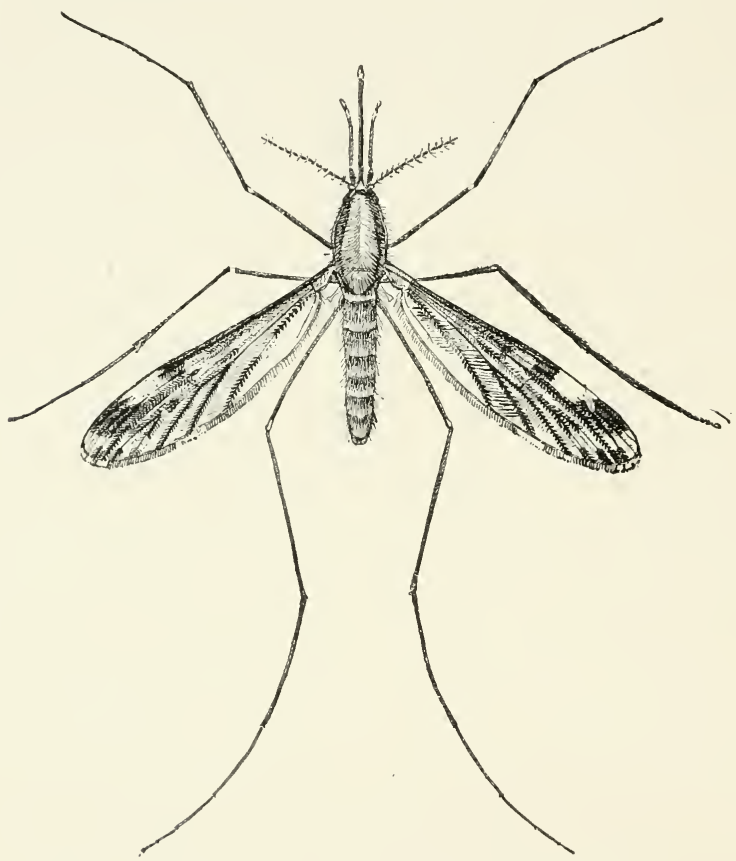

FIG. 26. - Female of Anopheles punctipennis; enlarged. (Author's illustration.)

water in a yard at the Sanitary Office. With one exception this is the only instance in which he found Anopheles breeding elsewhere than in a roadside puddle or ditch. Dr. C. WV. Daniels, in the "Royal Society Reports 
to the Malarial Committee," December 31, 1900, says that in Africa either larvie may be found alone, but in many situations both are found together and even several species of each. At least five species of Culex were found with Anopheles larvæ. "The less the movement of the water the greater the probability of Culex larve being also found, and in a grass-grown river, the Anopheles

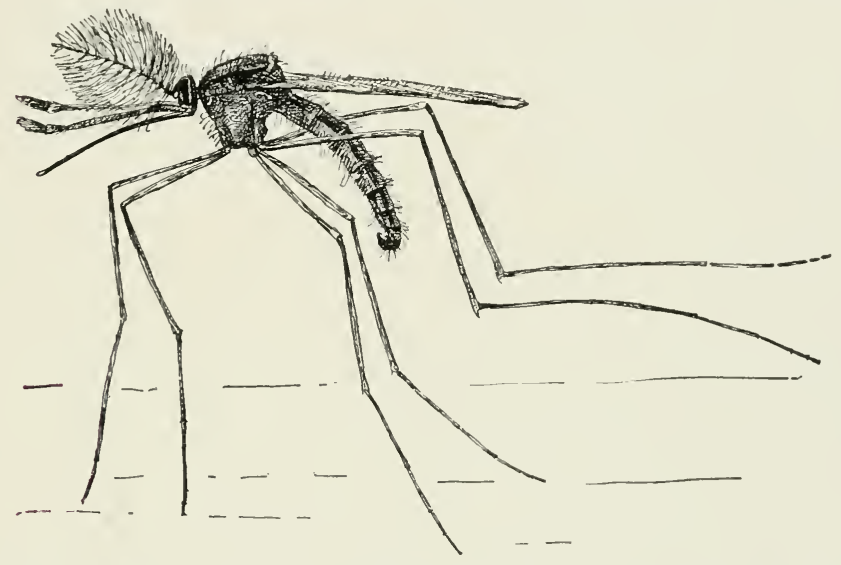

Fig. 27.-Male of Anopheles punctipennis, from side; enlarged. (Original.)

larvie will be more abundant near the stream and the Culex larvie near the bank."

Nuttall, Cobbett, and Strangeways-Pigg, in England, captured Anopheles nine times with Culex in ponds and also took them with Culex in ditches in which the water scarcely flowed, in water-logged boats, in stone troughs, and in fact found them fourteen times together with 
Culex and ten times with fish. Dr. F. A. Young, a British army surgeon, has told me that in his experience if the larve of Culex and Anopheles are put into the same ressel those of Anopheles will disappear.

Lieutenant-Colonel Yerbury says that "the natural home of Anopheles seems to be damp swampy ground, but not necessarily so wet as a marsh or a fen." Grassi and Ficalbi state that $A$. maculipennis is most frequently found in flat land in Italy, the larve requiring clear water rich in regetable food. E. E. Austen found in Freetown that Anopheles larve were in stagnant puddles, varying from a foot to several feet, at the sides of the streets, but many were met in the still water in little bays at the sicle of slowly rumning shallow ditches. Whether the water was clear or muddy seemed to make no difference, but green algae were nearly always present and in some puddles tadpoles were numerous. Dr. H. A. Veazie, of New Orleans, has found Anopheles larve in the ponds ont in the suburbs in the swamps back of the city. Dr. Woldert, of Philadelphia, has found the larve of both A. maculipennis and A. punctipennis breeding in the same narrow and slowly flowing stream of fresh water, which drained a marshy district formed by a railroad embankment. He found larve in this stream from June 19th to November 11th and located five localities within the city limits of Philadelphia where Anopheles breeds. Grassi, at Metaponto, Italy, is said to have found Anopheles in brackish water. 
The North American Species of Anopheles.

So far as known at the present time we have but three species of the malarial genus in the United States, namely A. maculipennis Meigen (equals A. quadrimaculatus Say), A. punctipennis Say, and A. crucians Wied., although $\mathrm{Mr}$. Theobald, in his monograph, which will include the mosquitoes of the world, will describe forty-two species of this genus, and possibly more.

A. maculipennis is a rather insignificant species, which is well illustrated in Figure 15, its wings being nearly clear, but marked with four rather small dark spots composed of groups of darker scales. Its palpi are entirely black.

A. punctipennis is our handsomest species, and has a yellowish white spot occupying about three-fourths of the length of the front margin of the wing. The scales on the last vein are white and those at each end black.

A. crucians has the palpi marked with white at the bases of the last four joints, and the scales of the last wing vein white, marked with three black spots. The accompanying figures will enable a much readier differentiation of this species than will any description.

As to distribution, A. maculipennis and A. punctipennis are found almost everywhere in this country. I have seen specimens of A. maculipennis from New Hampshire, Connecticut, New York, District of Columbia, Maryland, Virginia, Florida, Texas, Louisiana, Indiana, Illinois, Minnesota, and Oregon. Dr. A. S. Packard has recorded its 
occurrence at Brunswick, Me., in 1861-63. A. punctipennis I have seen from Vermont, Massachusetts, Connecticut, New York, New Jersey, Pennsylvania, District of Columbia, Maryland, Mississippi, Texas, New Mexico,

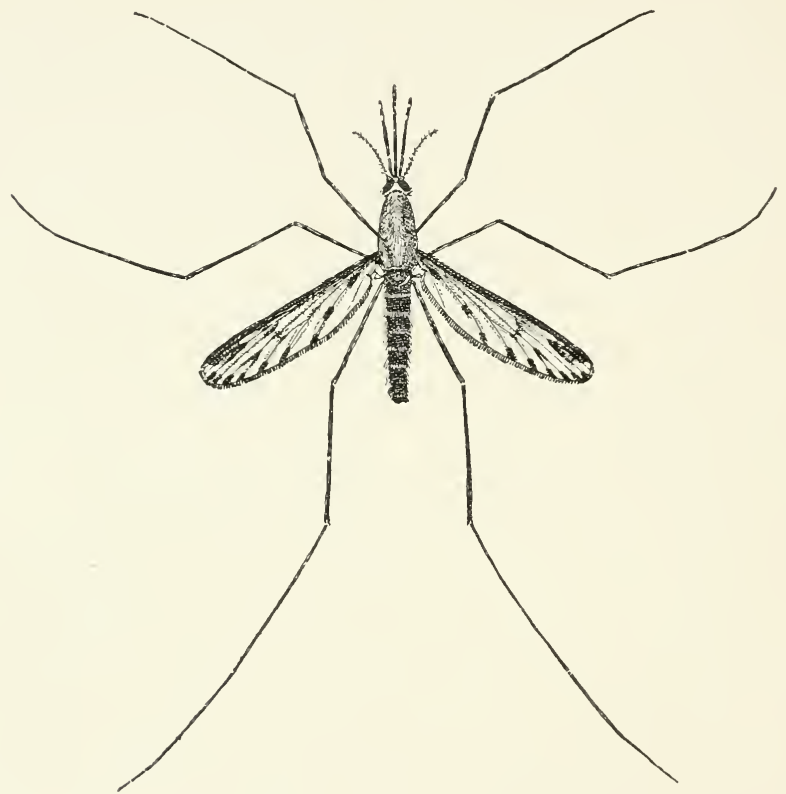

FIg. 28.-Anopletes crucians, adult female; enlarged. (Author's illustration.)

Kansas, Illinois, Indiana, Oregon, and Jamaica (B. W. I.). Professor C. H. Fernald writes me that he has taken it at Orono, Me., and that it is rather common at Amherst, Mass. A. cruciuns I have seen only from the District of 
Columbia, Virginia, Georgia, Florida, and Lonisiana. The last species therefore seems to be a more southern form, while the other two have a very wide distribution, including a considerable distribution to the North.

Dr. W. N. Berkeley, of New York, in the Medical Record for January 26, 1901, states that A. punctipennis is abundant in certain parts of Bronx Borough, particularly Jerome Park. A. maculipennis appears to be universally distributed in the suburbs of New York. Since he learned how and where to look for it, he found it nearly co-extensive with all the cases of fresh malaria that he had the leisure to go to and look into. It was present in such widely separated places as Passaic, N. J., Tuxedo, Now York, Fordham, and Jerome Park, Mount Vernon, and East Hampton. In East Hampton, on the authority of Dr. F. P. Rolley, Dr. Berkeley says that until the summer of 1900 no native malaria had been known at East Hampton, in spite of a large number of malarial mosquitoes. He explains this in two ways: (1) That no malarious case had recently been imported there to start an infection among the mosquitoes, and (2) that the nights are cold, the night temperature being considerably below the minimum $\left(77^{\circ} \mathrm{F}\right.$.) at which the malarial bodies are believed, according to Koch, to develop in the stomach of the mosquito. The Anopheles was always found in buildings, oftenest on walls and ceilings of recently used bedrooms, and far most abundantly in the foul and ill-ventilated bedrooms of the poor. The house females were usually gorged with blood, and sluggish enough to be easily caught. They were numerous in outdoor privies. $\mathrm{He}$ 
never found them out of doors. Males were caught in houses also, but generally only one male to twenty

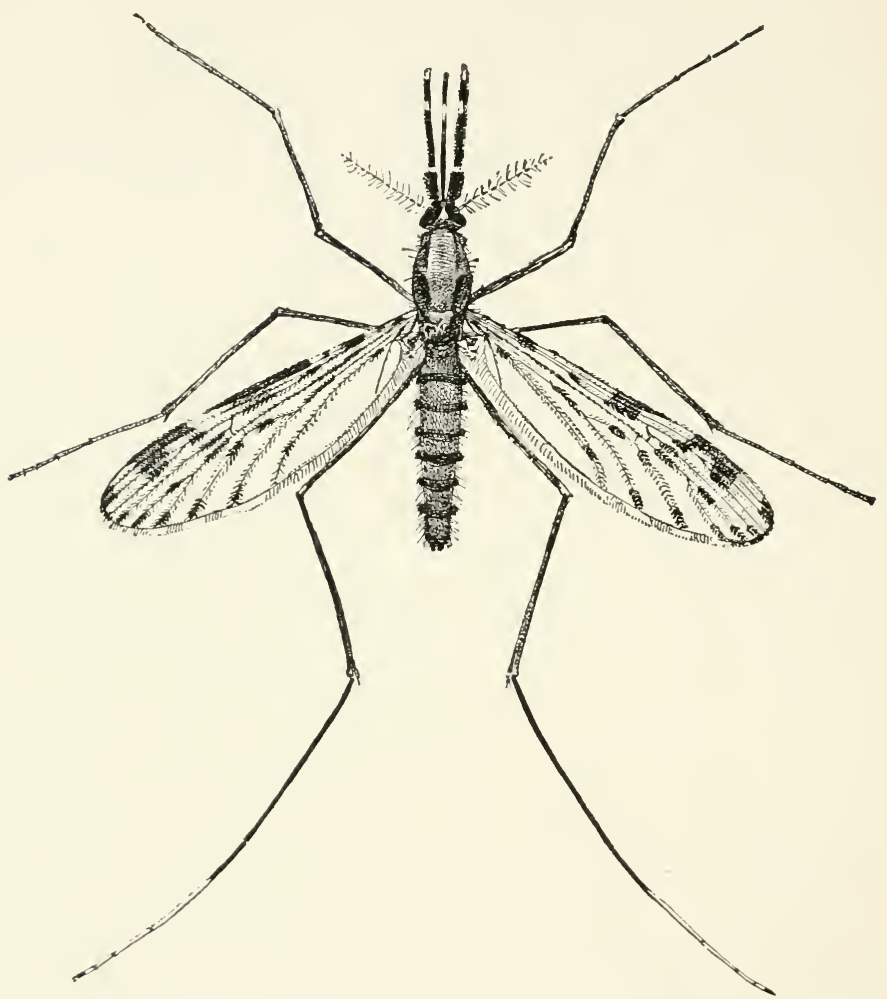

Fic. 29.-Anopheles argyritarsis, adult female; enlarged. (Original.)

females. He caught Anopheles in a house in the Bronx on November 6th and on Christmas day. In a dranghty, cold, underground cellar in the same house he caught a dozen 
or more, all females, mostly muctipennis and a few maculipennis. They were in complete hibernation, and had to be knocked from the wall as if dead, but revived in a glass tube under the warmth of the hand. So far as Dr. Berkeley's observations go, the hypothesis of the Italian workers that only fertilized females survive the winter, is true.

Dr. Theobald Smith, of the Bussy Institute, has published a paper entitled, "Notes on the Occurrence of Anopleeles punctipennis and A.quadrimaculatus in the Boston Suburbs," in the Journal of the Boston Society of Medical Sciences (vol. v., pp. 321-324, January, 1901) in which he shows that he has found both species at Jamaica Plain, although malaria does not exist there. The occurrence of the Anopheles, muless their breeding-places are wiped out, shows that if malaria patients should come to Jamaica Plain, the disease would rapidly sprear.

The species Anopheles argyritursis, mentioned in Chapter $\mathrm{X}$. and illustrated in Fig. 29, is a very beautiful species which occurs in Cuba, where it has been captured by Dr. James Carroll of the Army Yellow-fever Commission.

\section{Food of Anopheles Larve.}

As already indicated, the principal food of the larre of Anopheles seem to be the spores of algre, but, as we have pointed out, they will swallow anything which floats on the surface of the water. I liave seen one nearly choke to death in the attempt to swallow a good sized bit. The English observer, Dr. Daniels, in the course of his in- 
restigations in Africa, found that the contents of the intestines of the larve are mainly vegetable matter-in some cases entirely so. Occasionally limbs of minute insects or crustaceans were found, as well as scales of mosquitoes or other insects. "On watching them feeding it is seen that all minute particles are drawn to the mouth, but many of them are rejected. This rejection is somewhat arbitrary, as a particle at first rejected is often subsequently swallowed. Among the bodies seen to be swallowed I have seen living minute crustaceans and young larve, both of Anopheles and Culices, but as a rule living animals either escape or are rejected." Christophers and. Stephens state that in their observations in Sierra Leone the food of the majority of the Anopheles larve seemed to be a unicellular protococcus.

Length of Life of Adult Anopheles.

Physicians studying the adults in order to determine the duration of the different stages of the malarial organism have occasion to keep adult Anopheles alive in confinement. This has been accomplished up to eight weeks by feeding them occasionally upon sliced bananas or other fruits. The adults live for very considerable spaces of time, as has, in fact, been pointed out in the first chapter of this book. In colder climates the adults hibernate often in houses, and in tropical climates the adults live through the dry spell to lay thcir eggs when the rains come and breeding-pools are re-established. The hibernation of Anopheles in this country has been frequently 
observel. Dr. W. S. Thayer has informed me that he found Anopheles crucians and Anopheles muculipennis hibernating in enormous numbers in barns near New Orleans, and in early February, 1901, Dr. H. A. Veazie wrote me that Anopheles munctipemis had been captured in his honse, in his office, and in the show-window of a shop on Canal Street. Dr. A. Hassel, of Baltimore, found Anopleeles punctipenmis in his house in Jannary, 1901, and during this month his son and daughter developed malaria, the diagnosis being perfectly confirmed by blood examination. About a week before this were several warm days. Probably the mosquitoes had been hibernating in his house and had become active on account of tho warm spell.

\section{How Anopheles Bites.}

It is the experience of a number of observers, as recorded, that the bite of Anopheles is more insidions than that of Culex. When not occurring in numbers, they may bite a person while asleep and not be detected. This point is especially used in answering the broad and general statement that malaria may be developed where there are no mosquitoes. Professor E. W. Hilgard, of the University of California, wrote me in September, 1900 , to the effect that in the coast marshes of the Mississippi Sound, he has seen Anopheles in great numbers, probably punctipennis. Down there this insect is called the black mosquito, and, as Professor Hilgard states, "is noted for biting without a moment's reflection, plunging 
head foremost right into you, while Culex always meditates for a while before biting." Professor Hilgard further stated that in those marshes there is little or no malaria and that he had been exposed there for weeks without injury, nor did the inhabitants complain of chills or fever. But in the Arkansas bottoms it took him only a few days to succumb, and the natives "luxuriated in 'ague cake." " 


\section{V}

\section{Mosquitoes and Yellow Fever; Mosquitoes and Filiariasis}

$I^{1}$

1881, Dr. Carlos Finlay, of Harana, noticed a correspondence between the abundance of mosquitoes antumn, while during the summer yellow ferer had been scarce and mosquitoes also scarce. This suggested to him the idea that mosquitoes are responsible for the transfer of the disease, and he conducted certain experiments in which he claimed to have transmitted the disease by the bites of the mosquitoes which had previously sucked the blood of persons suffering with the disease. Carrying on his idlea further he proposed a plan of inoculating non-immunes by the bites of infected mosquitoes, on the theory that a mild type of the disease would be prodnced which would afterward be protective against reinfection of a more severe character.

Dr. Finlay's theory was received with interest by physicians and investigators, but with a very pronomeed general incredulity. His experimental work did not seem to have been definite enongh to attract confidence to his conclusions, nor was there enough of it. It is 
rather strange that his published papers did not excite sufficient interest to induce other investigators to undertake any experimental work in the same direction. This fact in itself shows plainly the almost perfect incredulity with which they were received. When, however, the beautiful results of the malarial investigators had become generally accepted and it was shown beyond all peralventure that not only do certain mosquitoes carry filiaria, but also that some of them are necessary secondary hosts of the malarial micro-organisms, then it was that a few people began to think of Dr. Finlay and his theory. In the meantime, strong efforts had been made to find the cause of yellow fever. Several micro-organisms had been discovered and several investigators announced the probable discovery of the causative germ. Nearly all of these discoveries have been discredited by subsequent observations. The organism which has received the most support has been the Bacillus icteroides of Sanarelli, but down to a very recent date the insistent claim by the Italian investigator of the value of his discovery has been disputed by competent observers.

The occupation of the island of Cuba by American troops attracted the attention of Dr. Sternberg, SurgeonGeneral of the Army, more strongly than ever before, to the subject of yellow fever, although he had long been an ardent investigator of the cause of the disease, and, in fact, was one of the Yellow-fever Commission who visited Cuba in 1879, in an effort to investigate scientifically and by modern bacteriological methods the causation of the fever. In this early Cuban residence he became ac- 
quainted with Dr. Finlay and with his mosquito theory, and therefore, under these late conditions and with the malaria case proven, he established a commission of army surgeons, composed of Major Walter C. Reed, Surgeon, U. S. A., Dr. James Carroll, Acting Assistant Surgeon, U.

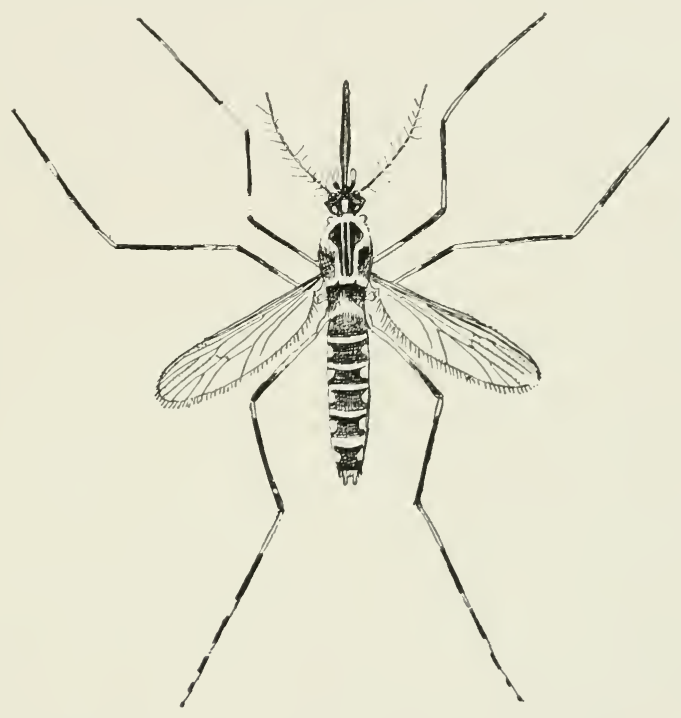

FIG. 30.-Stegomyia fasciata, adult female; enlarged. (Author's illustration.)

S. A., Dr. Jesse W. Lazear, Acting Assistant Surgeon, U. S. A., and 1)r. A. Agramonte, Acting Assistant Surgeon, U. S. A., and instructed them to investigate the disease from the mosquito standpoint. The investigations carried on by this commission during the early 
part of 1900 were extremely suggestive in their results. In the course of the investigations, both 1)rs. Carroll and Lazear were attacked by the disease. Dr. Carroll recovered, but Dr. Lazear died-another of the long list of martyrs who have suffered in the cause of scientific research. In this preliminary work, which Dr. Reed reported upon at the twenty-eighth annual meeting of the American Public Health Association, Indianapolis, Ind., October 23, 1900, it was shown that eleren nonimmune individuals had been inoculated by the bites of the species then known as Culex fusciatus, which had previously fed upon blood of patients sick with yellow fever. Dr. Reed was able to report two positive results in which an attack of yellow ferer followed the bite of a mosquito within the usual period of incubation of the disease. In one of the cases all other sources of infection could positively be excluded. The results of this preliminary work were summed up in two conclusions: 1. Bacillus icteroides Sanarelli stands in no causative relation to yellow fever, but when present should be considered as a secondary invader in this disease. 2. The mosquito serves as the intermediate host for the parasite of yellow fever.

The amnouncements made in this preliminary note excited much attention. The scientific standing of the investigators, as well as the positive result announced in one of the cases, made the theory at once one of serious importance. Medical men, however, were inclined to wait for further developments before expressing an opinion. 'Their point of view was perhaps well summed up by the Biritish Mertical .Joumal, which stated that although the 
experiments "appear to show almost conclusively that the germ is conveyed by a special species of mosquito and that the insect becomes infected only after ten to thirteen days from the time of the ingestion of the germ, the experiments are really by no means conclusive. At the most they are suggestive."

But the investigators themselves were by no means satisfied with the proof which they had gained. They returned to Cuba in the autumn of 1900 , and spent the remainder of the antumu and the whole winter in further experimental work. The results obtained were so positive and striking that, with the permission of the Surgeon-General, they presented an additional note before the Pan-American Medical Congress, held in Havana, February 4-7, 1901 . This paper, presented by Major Reed, records the details of the work done up to that time and announces its results.

An experimental sanitary station was established in an open, uncultivated field, about one mile from the town of Quemados, Cuba, under the complete control of Major Reed. The station was named Camp Lazear, in honor of the brave physician who went to his death in the early summer of 1900. A most careful series of experiments was carried on to see whether yellow ferer can be conveyed by fomites, that is, by personal contact with the clothes or belongings of yellow-fever patients. As is well-known, the consensus of opinion, both of the medical profession and of others, is in finvor of the conveyance of yellow fever in this way, and every effort is made to disinfect clothing and bedding shipped from ports where 
yellow fever prevails. All articles of personal apparel are subjected to disinfection and, as everyone knows, during a time when the ferer is epidemic in any of our Southern States even the mails are disinfected before being allowed to go North. There was further erected at Camp Lazear a small frame house with a cubic capacity of 2,800 feet, tightly ceiled and battened, provided with small windows, so as to prevent a thorough circulation of air through the house, and with wooden shutters to prevent the disinfecting qualities of sunlight. The windows were closed by permanent wire screens with a 5-millimetre mesh. The vestibule was protected by a solid door and a wire screendoor, and the inner entrance by a second wire screendoor. In this way the passage of mosquitoes into the room was effectually excluded. The average temperature was kept at $76.2^{\circ} \mathrm{F}$. for a period of sixty-three days, and precaution was taken to maintain sufficient humidity of the atmosphere. On November 30th, three large boxes filled with sheets, pillowslips, blankets, and so on, contaminated by contact with cases of yellow fever and their discharges, were received and placed in the room. Most of these articles had been taken from the beds of patients sick with yellow ferer in Havana. Nany of them had been purposely soiled with the excretions of patients. These soiled sheets, pilloweases, and blankets were used in preparing the beds in which the members of the hospital corps slept. During sixty-three days this building, thus furnished, was occupied by seven non-immune persons. Three of them occupied the room each night for twenty days. Later a fourth box of clothing and bed- 


\section{MOSQUITOES AND YELLOIV FEIER 127}

ding was added, some of it purposely soiled with the bloody stools of a fatal case of yellow fever. Two of them occupied beds from December 21st to January 10th, every night, wearing the very garments worn by yellow-fever patients throughout their entire attacks,

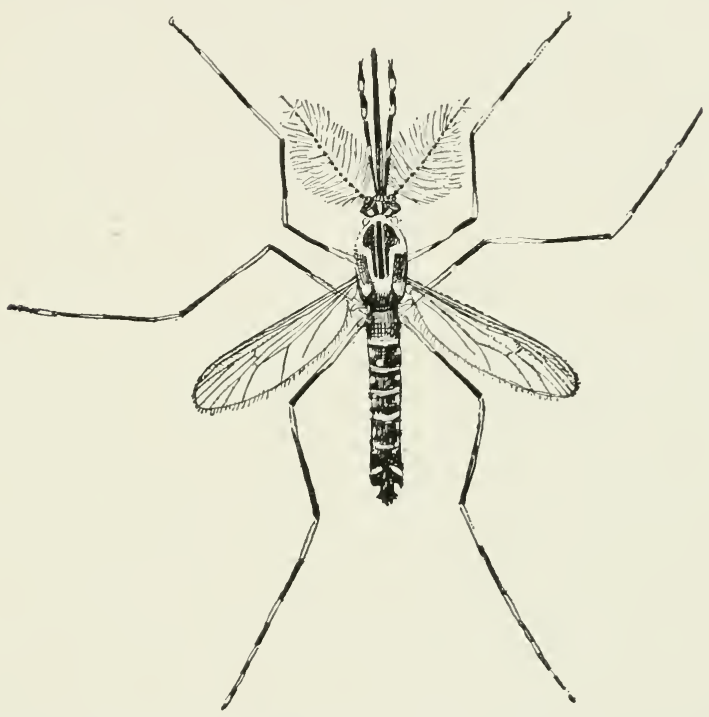

FIG. 31.-Stegomyiu fusciata, adult male; enlarged. (Original.)

making use exchusively of their much-soiled pillowslips, sheets, and blankets. At the end of twenty-one nights they went into quarantine (as had the former three) and were released five days later. Two other non-immunes ocenpied the same beds for twenty days more. The attempt therefore which was made to infect this building 
and its seren non-immune occupants during a period of sixty-three days was an absolute failure; all seven were released from quarantine in excellent health.

A precisely similar building was erected at Camp Lazear, which was known as the infected mosquito building. The door and windows were placed on opposite sides of the building so as to give a thorough ventilation. It was divided into two rooms by a wire screen partition extending from floor to ceiling. All articles admitted to the building were carefully disinfected by steam before being placed therein. Into the large room of this building mosquitoes which had previously been contaminated by biting yellow-fever patients were admitted. Nonimmunes were placed in both rooms. In the room in which mosquitoes were not admitted the experimentalists remained in perfect health. In the other room six out of seven persons bitten by infected mosquitoes came down with yellow fever. In all, of persons bitten by infected mosquitoes that had been kept twelve days or more after biting yellow-fever patients before being allowed to bite them, eighty per cent. were taken with the disease.

The conclusions reached after this careful experimentation, have been summarized under eleven heads, as follows :

1. The mosquito-C. fasciutus-serves as the intermediate host for the parasite of yellow fever.

2. Yellow fever is transmitted to the non-immune individual by means of the bite of the mosquito that has previously fed on the blood of those sick with this disease. 
3. An interval of about twelve days or more after contamination appears to be necessary before the mosquito is capable of conveying the infection.

4. The bite of the mosquito at an earlier period after contamination does not appear to confer any immunity against a subsequent attack.

5. Yellow fever can also be experimentally produced by the subcutaneous injection of blood taken from the general circulation during the first and second days of this disease.

6. An attack of yellow fever, produced by the bite of the mosquito, confers immunity against the subsequent injection of the blood of an individual suffering from the non-experimental form of this disease.

7. The period of incubation in thirteen cases of experimental yellow fever has varied from forty-one hours to five days and seventeen hours.

8. Yellow fever is not conveyed by fomites, and hence disinfection of articles of clothing, bedding, or merchandise, supposedly contaminated by contact with those sick with this disease, is umnecessary.

9. A house may be said to be infected with yellow fever only when there are present within its walls contaminated mosquitoes capable of conveying the parasite of this disease.

10. The spread of yellow fever can be most effectually controlled by measures directed to the destruction of mosquitoes and the protection of the sick against the bites of these insects.

11. While the mole of propagation of yellow fever has 
now been definitely determined, the specific cause of this disease remains to be discovered.

A large supply of contaminated mosquitoes, carefully preserved, has been brought to Washington by Drs. Reed and Carroll and careful work is now being carried on in an effort to find the causative organism of the disease. It seems quite probable that it will prove to be some sporozoön, following in a measure a somewhat similar life-round to that of the malarial organisms.

It is interesting to note that the very recently published "Interim Report" of Herbert E. Durham and the late Walter Myers, to the Liverpool School of Tropical Medicine, based on observations on yellow fever in Brazil, in the course of which Dr. Myers died, just as did Dr. Lazear in Cuba, indicates the belief of these investigators in the causative effect of a small bacillus which they found in the organs of ail fatal cases. They conclude that the yellow fever is not due to a protozoön, and with regard to the American results, they make the following comment: "The endeavor to prove a man-to-man transference of yellow fever by means of a particular kind of gnat, by the recent American Commission, is hardly intelligible for bacillary diseases. Moreover, it does not seem to be borne out by their experiments, nor does it appear to satisfy endemiological conditions." It is obvious that this report of the English investigators was prepared before the final and more complete paper of the American Commission was read by Dr. Reed in Havana, and even with this granted, it was hardly fair in them to style the investigations of the Americans "an endeavor" 
to prove," etc. The Americans were after the truth, and had no desire to learn anything but the truth, that is to say, they did not endeavor to substantiate any particular theory.

As a result of the investigations, the Governor-General of Cuba, himself a medical man, General Leonard Wood, became so impressed with the accuracy of the conclusions that he authorized the promulgation of instructions to conmanding officers in Cuba, relative to protection against mosquitoes and remedial measures in connection with their breeding-places. General orders were issued requiring the enforcement of the use of moscuito bars in all barracks, and especially in all hospitals, and the destruction of the larve hy the use of petroleum on the water where they breed. (See Chapter VIII.) The medical officer who makes the sanitary inspection at each post is charged with the supervision of the details of these precautions. As a result, the writer understands that the prevalence of malaria has been greatly reduced in western Cuba, and it is hoped that with regard to yellow fever similar results will be shown during the coming year.

The Yellow-ferer Mosquito.

The particular species of mosquito which was used by Dr: Finlay in his original experiments, and which is the only form which has been shown by our Army Commission to transmit the disease, is the one which has been referred to in this conntry as Culex fiesciutus Fabricius. It was so termed in the writer's bulletin, entitled "Notes on 
Mosquitoes," published as Bulletin 25, new series, of the Division of Entomology, of the United States Department of Agriculture, August, 1900, and has been so named in the published reports of the Commission. 'There now seems very good ground for the belief that the wille-spread

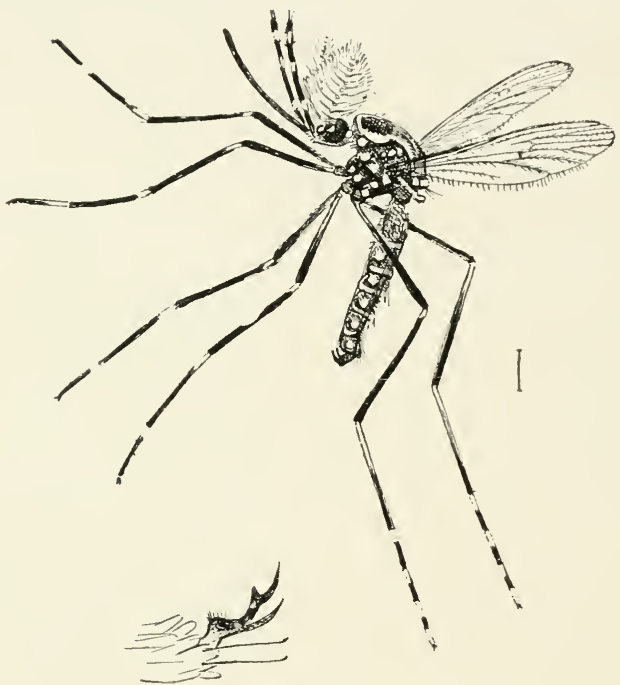

Fig. 32.-Adult Male of Stegomyia fasciata from side; enlarged. (Author's illustration.)

tropical mosquito usually referred to as Culex treniatus of Wielemamn, is really a synonym of this species. It will be remembered that down to the present time we have no evidence that any other mosquitoes than those of the genus Anopheles transmit malaria, and that so far as known all species of this genus have this pathological 


\section{MOSQUTTOES ANII YELLOW FEIER 133}

characteristic. In the case of yellow fever, why should one species of Culex be able to transmit the disease and not another species, assuming, as it will be quite proper to assume, that since this capacity appears to be of generic importance with Anopheles, it would be of generic im-

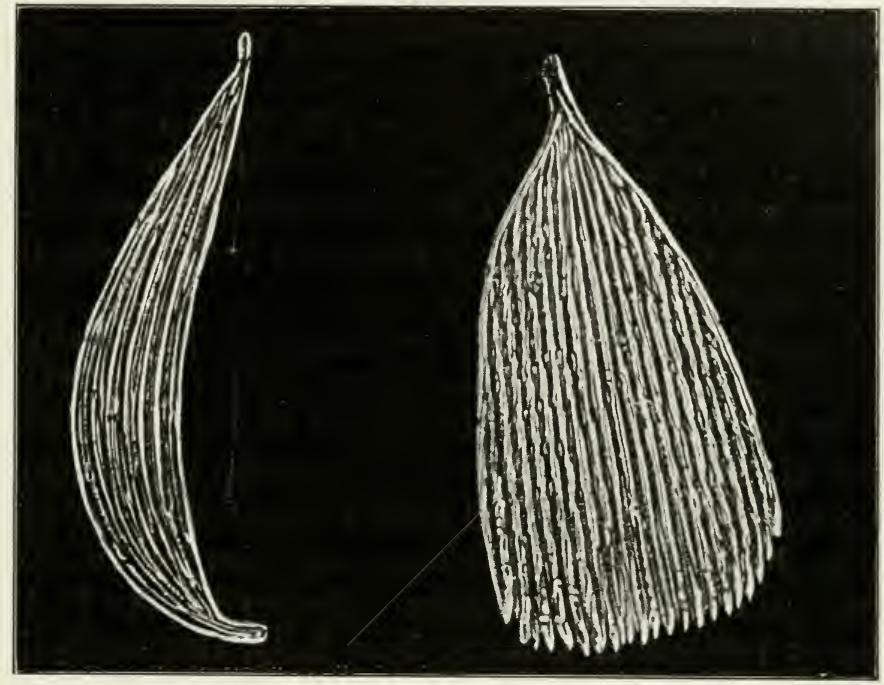

Fis. 33.--Body Scales from Stegomyia fasciata; the broad one from a white stripe and the narrow one from a dark surface; greatly enlarged. (From Photo-micrograph by Dr. Erwin F. Smith.)

portance in the case of yellow fever? It happens that the British Mnseum is investigating the mosquitoes of the world. Specimens have been sent to the expert, Mr. F. $V$. Theobald, who has charge of the work, from all quarters of the globe, and Mr. 'Theobald has made a special 
study of the morphological features of these insects. Without knowing the results of the American Commission, Mr. Theobald had decided that Culex fisciotus or tremiutus is not to be contained in the genus Culex, but that on account of scale structure and other structural peculiarities it must be placed in another genus for which he has proposed the name of Stegomyia. A few other species formerly placed in the genus Culex he also puts in this new genus of his, which arouses the presmmption that they also may be capable of transmitting yellow ferer. At all events, we have here a most interesting and suggestive co-relation between obvions structural peculiarities and pathological possibilities.

Stermmyiu fusciutu, as we must now, at least for the present, call the only yellow-fever mosquito about which we are at all certain, is an inhabitant of the warmer portions of the globe. Mr. Theobald writes me that it oceurs in abundance in Cuba and all the West Indies, and that he has had it from all the warmer comntries, but not from arctic and temperate climates. He has it even in the warmer portions of Europe, from Italy, Greece, Spain, Portugal, Gibraltar, and Malta. He generalizes that it is found north and south of the equator to $38^{\circ}$ north and sonth latitude. In the United States it is common in most of our Sonthern States. I have seen specimens from New Orleans, Lar. (Dr. H. A. Teazie and Dr. W. S. Thayer), from Natchitoches, La. (Mr. C. IV. Johnson), from Napoleonville, La. (Dr. L. E. Flamagan), from eastern Texas (Dr. A. E. Woldert), from Hot Springs, Ark. (Dr. A. W. Wright), from Pelham, Ga. (Mr. D. IT. Coquillett), 
and from as far north as Virginia Beach, Va. (Mr. F. C. Pratt). From the West Indies, I have seen specimens

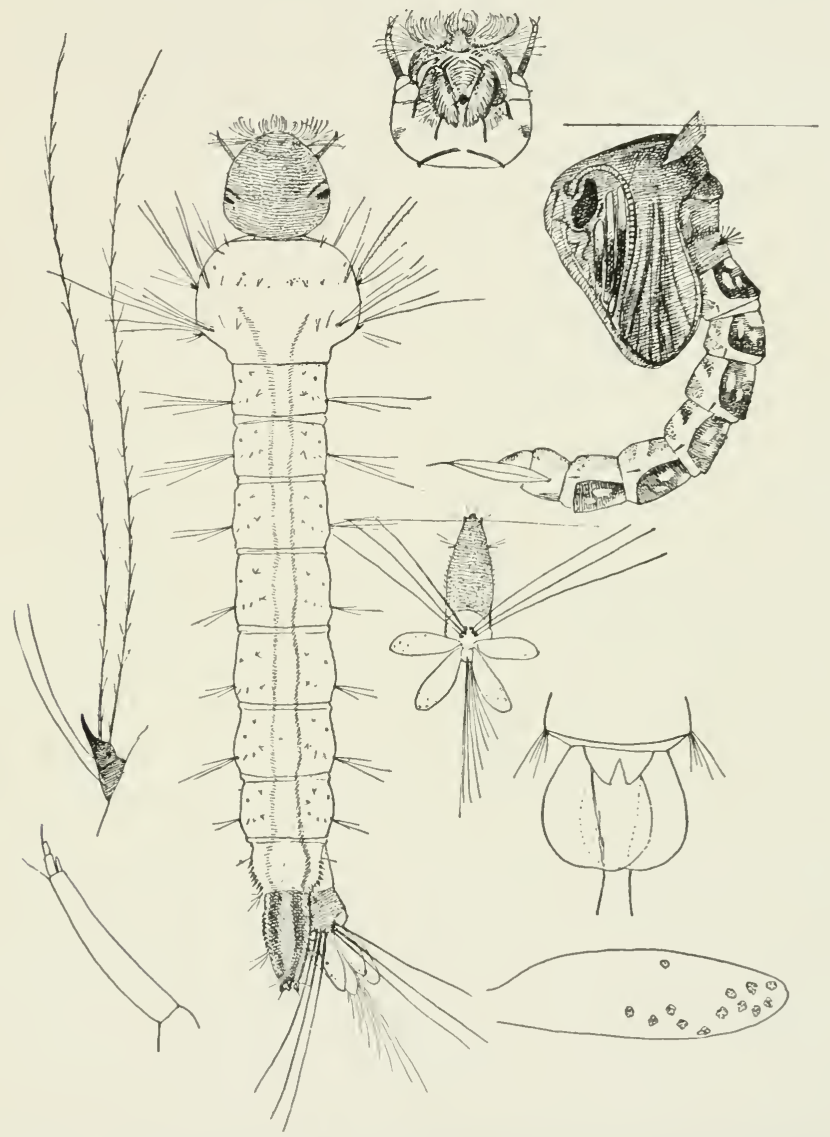

Fig. 34.-Larva and Pupa of Stegomyin fusciuta, with enlarged parts ; enlarged. (Original.) 
from the Isle of Pines (Mr. S. H. Scudder), from Kingston, Jamaica (Mr. C. W. Johnson), from Cuba (Drs. Reed, Carroll, and Lazear), and from Bluefields, Nicaragua (1)r. L. A. Wailes). Nearly all these places are well within the yellow-fever belt. Virginia Beach, the northermmost locality indicated, is only a short distance from Norfolk, Va., which in former years has suffered from yellow-fever epidemics. It must be said that the collections of mosquitoes which have been made are more or less accidental and that no thorough means have been taken to ascertain the exact geographic range of this or any other species of mosquito. It is quite likely that thorongh collecting would show the existence of this species at a more northern locality. In fact, if it should prove to be the only species of mosquito which is capable of transferring this fever, the epidemics of yellow fever in Philadelphia and New York, and even in New Haven and Providence, about the beginning of the last century, would indicate that at that time, at least, this mosquito had a more northern range, or at all events that it had been introduced at those points by sailing vessels coming from the Sonth, and that it succeeded in breeding there at least for some part of a year.

The insect itself is a very handsome one. The banded legs and the conspicuous silver stripes upon its thorax and abdomen render it rather readily recognizable. It is well shown in the accompanying illustrations. It breeds almost everywhere in standing water. So far as has been ascertained, it does not breed in brackish water. Dr. Flanagan sent me specimens in November, 1900, and wrote that the 

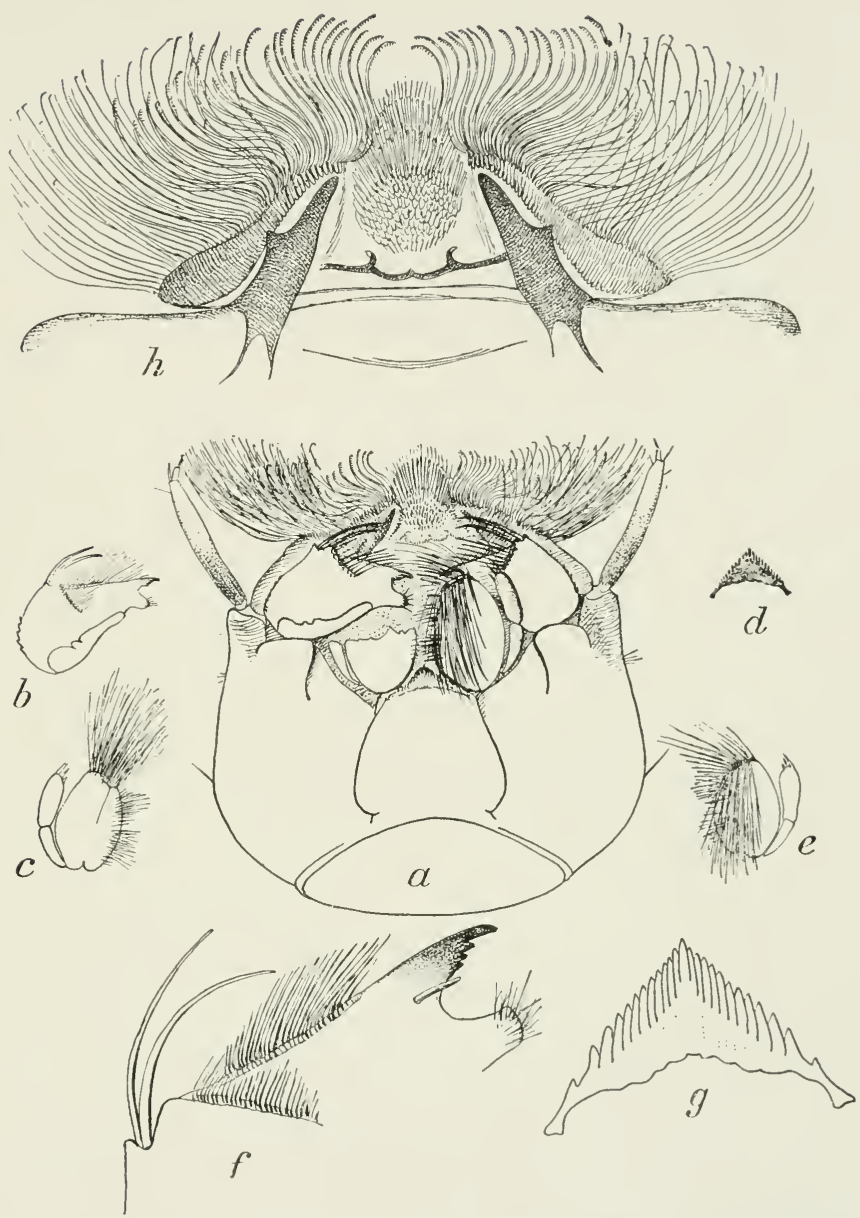

FIa. 35. - Mouth-parts of Larva of Stegomyiu fasciata ; greatly cularged (() riginal, C. L. Marlatt, (lel.) 
bite of this species is worse in the autumn than in the summer, and that it breeds in cisterns, which, in that section, are in universal use for obtaining drinking-water. Mr. Pratt male some interesting observations on the species at an Atlantic Coast summer resort, in a latitude of about $36^{\circ} 50^{\prime} \mathrm{N}$., and succeeded in obtaining the larve and pupre, from which the accompanying drawings were made. At that point he also found it breeding in the rain-water tanks. Neither larva nor pupa differs greatly from that of the species of the genus Culex, the characteristics of which have been described in an earlier chapter. It may be of interest to note that before this insect was comnected with yellow fever, I learned that in certain of the West Indies and in Lowisiana it is known as the "day mosquito." Dr. Veazie, of New Orleans, and Dr. St. George Gray, of St. Lucia, communicated this fact. 'The latter writes that it is very vigorous and troublesome in the early afternoon, from 12 м. to 3 P.M., after which it takes a rest until 9 or 10 P.M.

It should be stated emphatically that it is probable that this species has a wide range south of Mason and Dixon's line, and that it probably occurs everywhere in what is termed the lower austral life zone, extending to some extent into the upper austral zone. This fact, however, and the existence of this mosquito in a given locality, does not mean that there is any danger in such localities of yellow fever, unless one or more cases of the disease are brought into the locality and exposed in such a way that mosquitoes have the opportunity to suck their blood and fly away untrammelled to some healthy individual. 
Hon. John R. Procter, in a paper entitled "Notes on the Yellow-fever Outbreak at Hickman, Ky., 1878," published in bulletin of the Kentucky Geological Surrey, No. 1, 1879 (?), pp. 63-99, two maps, gave a most careful history of all of the cases of yellow ferer which occurred at Hickman in the summer of 1878 , from which it appears that the cansation of many of the cases which remained obscure is readily explainable on the theory of the transfer of the disease by mosquitoes. Mr. Procter (now President of the United States Civil Service Commission) on learning of the thesis supported by the Army Yellowfever Commission, was struck by the fact that the mosquito theory explained away these doubtful cases, and called the writer's attention to his publication. This is the only yellow-fever report which the writer has examined carefully, but very likely many others have been published which should be critically examined from this point of riew. Surely the detailed accounts of the older epidemies in this comntry, so carefully described in La Roche's ardmirable monograph on yellow fever, do not, on cursory examination, offer any facts inconsistent with the adoption of the mosquito explanation of the spread of the dread disease.

The importance of this discovery to Cuba and other tropical regions cannot be minimized. Word came tc us, April 1st, from Havana, that for the first time in the history of that city the month of April began, in 1901, withont a single case of yellow ferer within the city limits. Mnch of this result is attributed to the admirable methods of sanitation introduced by our army soon after the occupation 
of the city. Some part of it must also be attributer to the excellent quarantine service under the charge of the United States Marine Hospital Service, but also, without doubt, much of the result must further be attributed to the hospital and barrack methods, and treatment of mosquito hreeding-places carried on under the direction of the medical corps of the army.

\section{Mosquitoes and Filariasis.}

The first evidence scientifically obtained that mosquitoes play a part in the spread of a disease was in the case of the parasitic worms of the genus Filaria, which are responsible in Oriental tropical regions for the terrible disease known as clephantiasis. The adult worm lives in the skin of different parts of the body, lodged in the lymphatic ressels. The two sexes are found side by side, and are capable of living there a long time. They obstruct at certain points the flow of the lymph. This accumulates and dilates the vessels and the lymphatic spaces. This mechanical distention is accompanied by an irritation of the ressels and of the surromnding connective tissue. Thus, elephantiasis becomes established, which, as is generally known, manifests itself in very different legrees and occupies different parts of the body, such as the arm, the leg, or the scrotum.

The female Filaria enclosed in the lymphatic vessels is viriparons. The embryos to which she gives birth spreat in the lymph and then with it into the blood, and it is in the blood that they are commonly observed. 
They are found in abundance in the blood during the night or during sleep, but during the day, or, rather, while the patient is awake, they cannot be found. There seems to be no good explanation of this periodicity, nor is it absolutely exact, but it constitutes a very curions adaptation of the parasite to the nocturnal habits of the

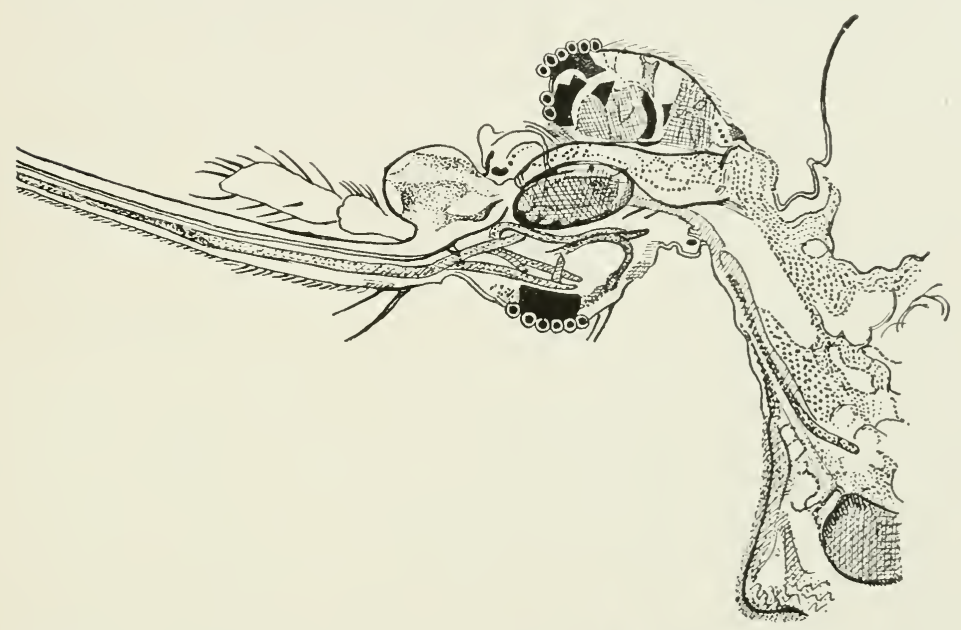

Fig, 36. --Cross Section of Ifead and Beak of Mosquito, showing Filarias entering Beak; cularged. (Redrawn from British Medical Journal.)

mosquito, whicl serves as an intermediary host. Having more than twenty years ago proved this periodicity of the embryos, Dr. Patrick Manson had the happy thought that as mosquitoes bite men during sleep, perhaps they may be agents in the transmission of the disease, and his subsequent observations proved the correctness of this idea. The Filaria embryos, accorting to his olsserva- 
tions, sucked into the stomachs of mosquitoes, lose their hyaline envelope, work through the wall of the stomach and enter the muscles of the thorax, where they lodge between the muscle bundles, remaining there for two or three weeks, growing and taking on the character of the larva. This is as far as the evolution was for a long time observed, but upon it was based a theory by which the etiology of filariasis was explained. This was, that the bodies of the mosquitoes falling in water, at death rapidly disintegrated, liberating the parasites into the water, which when drunk by human beings carried the parasites once more into the human body.

- Although plausible, it was difficult by this theory, as Blanchard has pointed out, to explain the constant presence of the parasite in the lymphatics in the skin. How can the animal introduced into the intestinal tube make its way into the lymphatics of the arms and legs? It is difficult to suppose that it does this by going through the lymph vessels, which are provided with valves. Bancroft, of Australia, suggested that possibly the Filaria might be introduced into the blood of a healthy person by the bite of the same mosquito, assuming that the embryos in their penetration into the muscular part of the thorax might work into the beak.

Through the researches of Bancroft, Manson, and Low, following this idea, it was discovered that up to the seventeenth day the larval Filarias in the mosquitoes are found exclusively in the thoracic muscles, but after that some of them begin to travel. They collect in the connective tissue in the anterior part of the thorax in front 
of the muscles. They are then about eighteen to twenty micromillimetres in diameter, and a little slenderer than those which remain in the muscles. By the twentieth day those remaining in the thorax have grown larger and have begun to break down the muscular tissue. Those which have migrated are found to have penetrated the neck, accumulating in the head, and penetrating into the beak. The question of transmission then becomes very much like that of the transmission of the malarial germs, and it seems reasonably sure that the Filaria is inocnlated directly into the skin by the beak of the mosquito, and it is in the skin of man that the parasite accomplishes its last metamorphosis and becomes adult. In the skin they pair, and the embryos, issuing in the lymphatic spaces or vessels, are carried by the lymph into the blood. Thus the life round is complete.

The mosquito which is concerned in this work is not an Anopheles, as is the case with malaria, but a Culex. The one studied by Bancroft in Australia is one of the common domestic Australian mosquitoes, C'ulere ciliuris Linn., which is possibly a synonym of C'ulex pipiens Linn. Other species may be involved, and, in fact, other biting insects than mosquitoes, but these points are not yet thoronghly determined. 
Other Genera of North Amerian Nosquitoes

$\mathrm{H}$

AVTNG given a full consideration to the common mosquitoes of the genus Culex, which includes by far the majority of all of the mosquitoes which inhabit North America, and having paid special attention to the forms of the genus Anopheles, which comprises all the species which have been proved to carry the malarial germs, and having also told the story of the yellow-fever mosquito, there remain for brief consideration the mosquitoes of the six additional genera known to occur in the United States. The structural peculiarities of these six genera are described in full in Chapter $\mathrm{X}$., and since they are few in number of species, and since until recently all of them were unknown except in the adult condition, this consideration must necessarily be brief.

\section{Genus Psorophora Desvoidy}

The insects of this genus are large mosquitoes, and only one species, I'sorom hurce ciliatu of Fabricins, inhabits the United States. In this insect the palpi in the male are longer than the proboscis, while in the female they are less than one-half as long as the proboscis. The 


\section{OTHER GENERA OF WOSQUITOES 145}

proboscis itself is straight. The most striking characteristic, however, is the presence of very peculiar erect scales on the legs. The hind legs especially are fur-

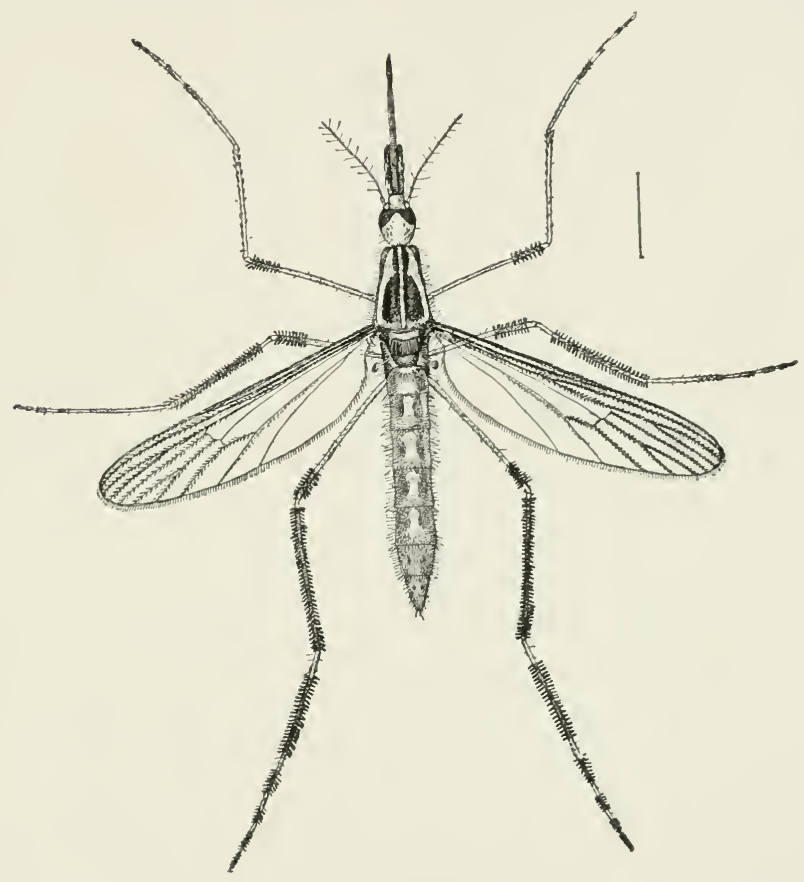

Fig. 37.-Adult Female of Psorophora ciliata; enlarged. (Author's illustration.)

nished with large scales which are placed at right angles to the leg itself, and similar scales are present in smaller numbers upon the midille legs, and in very small numbers upon the end of the thighs of the front legs. $P$. 
cilicata is a very large mosquito and is undonbtedly one of the forms known in the South as gallinippers. It is really yellowish in color, yet the general effect whon one glances at it or sees it flying is that it is very dark-al-

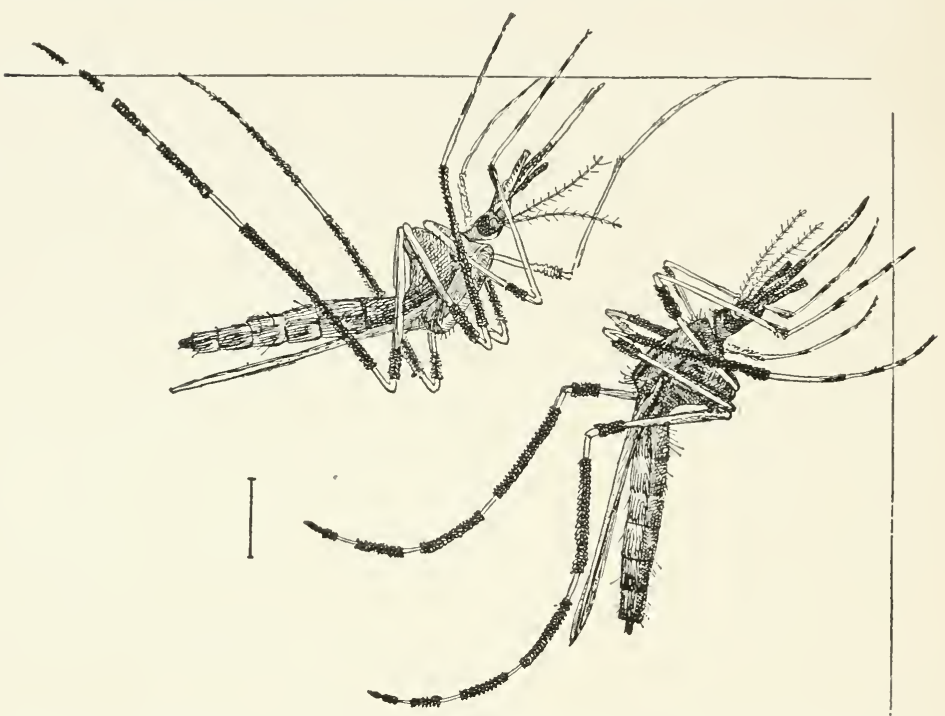

FIG. 38. -Females of Psorophora ciliata at rest on side wall and ceiling ; enlarged. (Author's illustration.)

most black. The wings are not really spotted or dusky but the very numerous dark scales on the main veins make them appear dark. When seen in certain lights they are prismatic in their color effect. I have said that they are large. The length of the body of the female is about ten millimetres, but the length from the tip of the beak to the tip of the hind legs is nearly twice this. 
This large and handsome mosquito* is a wide-spread species and is known to oceur in Massachusetts, New Jersey, Pennsylvania, District of Columbia, Virginia, Connecticut, Illinois, Indiana, Florida, Louisiana, Arkansas, Nebraska, Texas, and California. It is, however, rare in its northern range, and in Massachusetts and New Jersey, for example, it is found only in low-lying

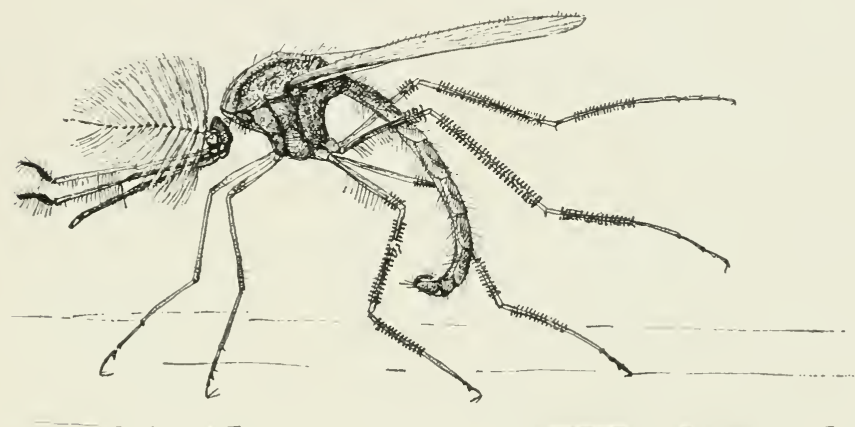

Fig. 39.-Male of Psorophora ciliata, from side; enlarged. (Original.)

regions. As a matter of fact, it seems to be really one of those species which is a true inhabitant of what is called the lower austral life zone, which comprises most of our Southern States. It may have a tropical range, but among the many mosquitoes which I have receiver from Mexico, Nicaragua, and Cuba, this species does not occur. Neither Psorophora nor the next genus, Mega-

* Many mosquitoes are really handsome, when seen under the lens, but few people will arlmit that creatures which they so heartily detest have any aesthetic value whatever. This is plainly to be seen in the case of suakes. 
rhinus, have been studied by investigators working upon the transfer of blook-inhabiting parsitic germs by nosquitoes, and I have urged that physicians and bacteriologists in our Southern States pay some attention to them

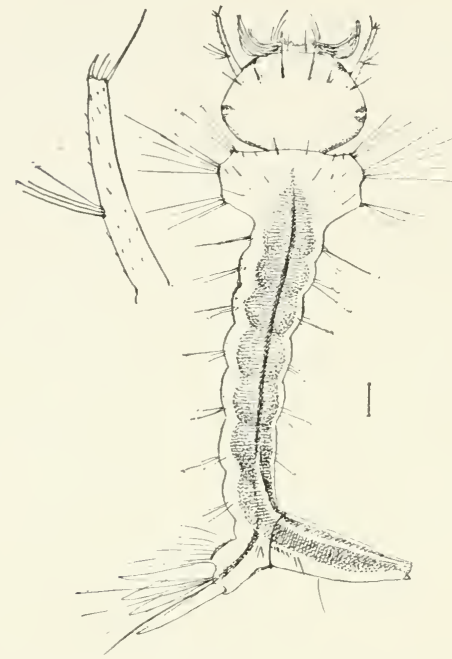

Fici. 40.- Yomug Larva of Psoroph. ora ciliuta; enlarged. (Author's illustration.) from this point of view.

Nothing was known about the early stages of Psorophora mutil the end of August, 1900. In the early part of the summer (in June), a large series of living specimens was captured at St. Elmo, Va., by one of my assistants, Mr. F. C. Pratt, and we expected that we should be able to secure eggs without difficulty and to study the insect in its different stages. The females were placed alive in large battery jars, muder conditions which had repeatedly been successful with mosquitoes of the gewera Culex and Anopheles, but no egos were deposited. This hronght me to the conchusion thit either the confined spocimens were not impregnated or that they had already deposited all their eggs, or that their breeding habits differ from those of other 1uosquitoes. On Angust 30th some very large mosquito larve and pupe were received from $\mathbf{M r}$. 
William P. Seal, of the Aquarium Supply Company, : t Delair, N. J. On examining them I felt sure that they

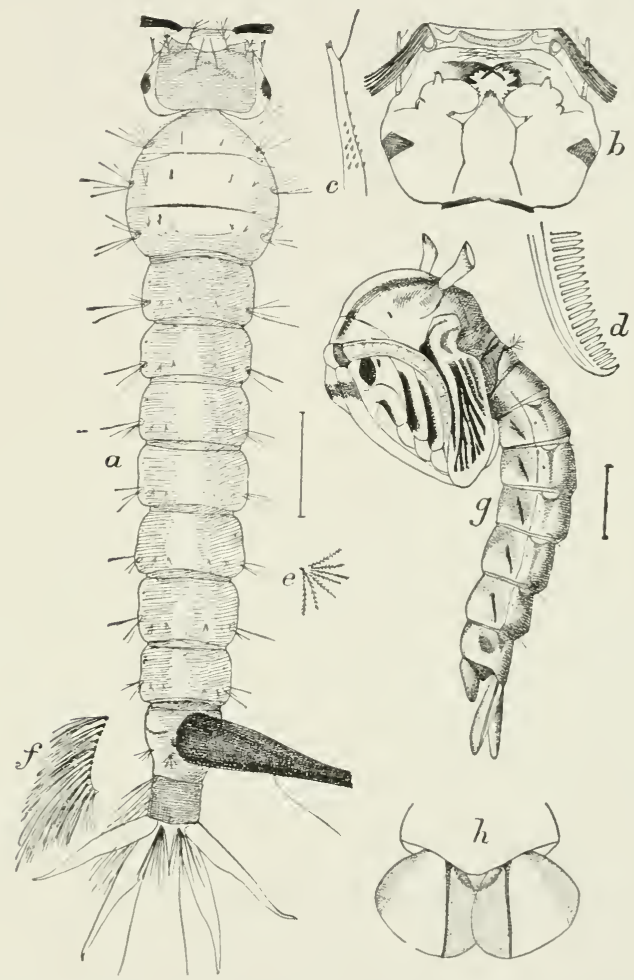

Fig. 41. - Full-grown Larvat and Pupa of P'sorophore ciliute. with enlarged parts; cularged. (Author's illustration,)

could be nothing less than the larve and pupe of P'sorophoia ciliata. The first specimens received were in alcohol, and Mr. Seal was informed of their probable identity, 
and urged to send on living specimens in water, and to endearor to rear the adult. It was then, however, unfortumately, too late. He wrote that during the summer a small creek and some earth ponds on his place became entirely dry, in consequence of which all fish in them died. Some time in August there was a sufticient rainfall to fill a few of the deepest places, which soon after became almost alive with mosquito larve. These were used for fish-food, until it was noticed that they were developing to the pupa stage, when coal oil was immediately poured on the water. It was while the coal oil was being applied that the big larve and pupæe were first noticed. Mr. Seal had been a collecting naturalist for twenty-six years, supplying material for the aquarium and for biological research, and had discorered some low forms of life new to science, which were described by Leidy and Ryder, but in all his experience he had never seen such large mosquito larve.

On being assured of the novelty and importance of his observation, he promised to watch for the subsequent appearance of similar larve, and on September 20th found other specimens which appeared after a rain which occurred on September 15th or a little before. Mr. Seal was able to distinguish between them aud the Culex larva, and wrote that they were very scarce-perhaps one of them to many thousands of the others. On September 25th alditional larve and pupæ were sent in, and from these specimens the accompanying illustrations were made.

The larva is structurally of great interest. On com. 
parison with larva of Culex, which it resembles more nearly than that of Anopheles, it will be seen that the breathing tube is longer; that the anal flaps are longer and more pointed, and the hair fringe on the under side of the last segment of the body is much longer and denser, while the mouth-parts are quite different. The jaws are sharply toothed, and very long, and are used in the mastication of food. Other mosquito larve feed upon spores of algæ and other small particles which appear to require no mastication, but this larva descends to the bottom of the water and has been noticed to grasp a bit of water-plant half an inch long and actually to chew it.

The duration of the pupal stage was from four to five days, and the adult insects issued on September 27th and 28th. Young larve were also found in this sending, and one of them is shown in Figure 40.

The breeding-places in which these larve were found were small depressions in the bed of a small stream, and similar hollows in certain small ponds, all of which were dry the greater part of the summer. After they first dried in the spring they were barren of fish and regetation. Mr. Seal is satisfied that the insect is rare in the vicinity of Philadelphia, and thinks that possibly he may have brought this species from the Sonth, as he is in the habit of shipping large quantities of aquatic plants from the Sonth, from Jamuary th to about May 10th of each year. He has a place some miles from Delair where he grows Cabomba. The plant is very dense, and the creek is full of fish, but in the water on top of the plant, which grows to the surface, are liarge numbers of mosquito 
larve. They are out of sight and practically out of reach of the fish.

The eggs of this interesting mosquito are yet to be found, and it will be most interesting to see in what respects they differ from the eggs of Culex and Anopheles.

\section{Genus Megarhinus Desvoidy.}

Another of the large mosquitoes which seem to be collectively known in the South as gallinippers (probably also some of the harmless crane-flies are so dubbed) belong to this genus. In fact there are two of them known in North America, namely Meycrlinus lecemerrhoidulis $F$. (Mexico and Cuba), and $I$. portoricensis Roeder (Mississippi). These mosquitoes also should be investigated by Sonthern observers in regard to their possible connection with malaria, or some other blood disease. They are readily distinguished from other mosquitoes by the curved beak. The palpi in the male are as long as the proboscis, but are short in the female. The colors are bluish or greenish.

Nothing is known of the life history of the mosquitoes of the genus Megarhinus, and some Sonthern observer has an admirable chance to add to the sum total of human knowledge by a series of careful observations on one of these forms. 
Genus Aëles Meigen.

The mosquitoes of this genus are minute forms, insignificant in color, and apparently rare. One species, dëdes fuscus Osten Sacken, has been found at Cambridge, Mass.

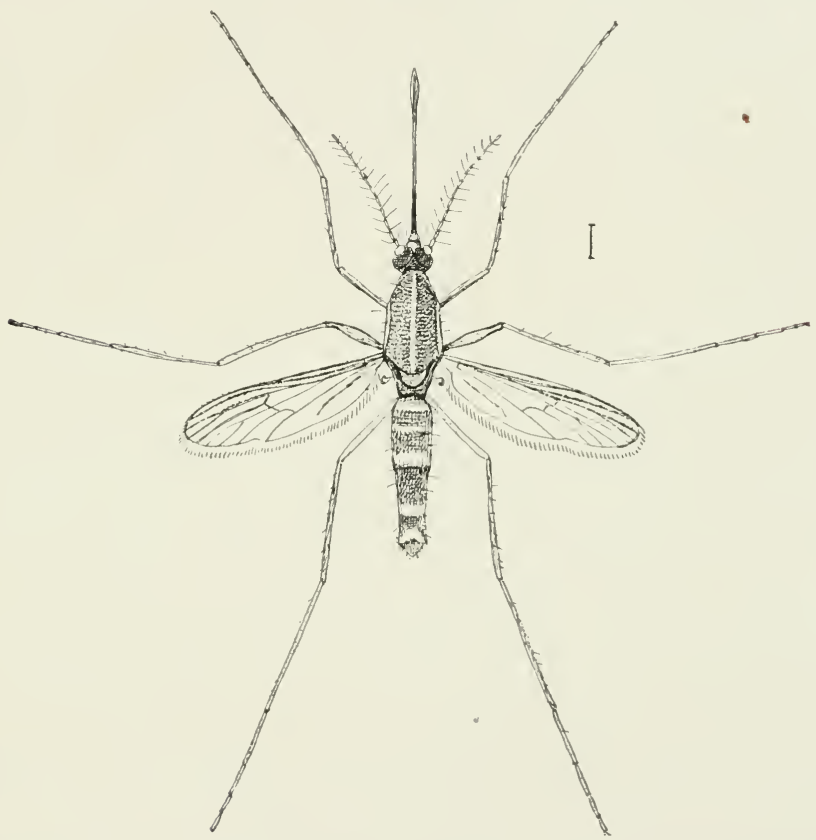

FIt. 42.-Aedes fuscus, female ; enlarged. (Author's illustration.)

Aërles fuscus, according to a recently published note by Dr. J. B. Smith, has been reared hy Mr. J. Turner Brakeley at Hornerstown, N. J., from larve found in the pitchers 
of the pitcher-plant (Surracenia). The determination was made by Mr. C. Wr. Johnson, of Philadelphia, and is therefore undoubtedly correct.

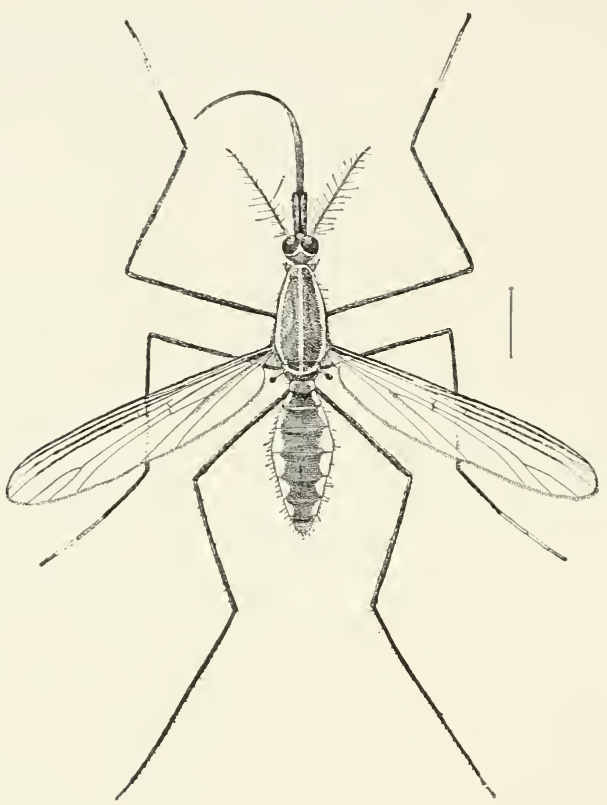

FIG. 43.-Toxorhynchites rutilus, female; exlarged. (Author's illustration.)

As pointed out in the synoptic tables in Chapter $\mathrm{X}$. the palpi in both sexes are short, which distinguishes these little mosquitoes from other North American forms. 
Stegomyia, Toxorhynchites, Uranotienia and Conchyliastes.

As will be pointerl out and fully explained in Chapter $\mathrm{X}$., these four generic names are here used for certain American mosquitoes for the first time. I am able to use them in this book through the great courtesy of $\mathrm{Mr}$. F. V. Theobald, of Wye, England, who has sent me proof sheets of his monograph of the mosquitoes of the world, now being published by the British Museum. Stegomyia includes, as has already been shown, the yellow-ferer mosquito, S. fasciatu, and it also includes the species mentioned in my previous writings as Culex signifer Coquillett, and which has been captured in the District of Columbia and Virginia by Messrs. Coquillett, Barber, and Pratt. Toxorhynchites includes the species previously referred to as Meygrhinus rutilus and which must now be known as Toxorlynclites mutilus. Uranotrnia includes the North American species previously known as Aërles sr(ppirlimus. Conchyliastes includes two species formerly placed in the genus Culex and which must now be known as Conchyliestes musions. Say and c'onchylirestes posticatus Wied. The former species has been taken in Pennsylvania, Virginia, District of Columbia, and Texas by Messis. Johnson, Pratt, Thayer, and Barber. 


\section{VII}

\section{Nutural Enemies of Wospruitoes}

W

HERE mosquitoes exist in rain-water buckets and barrels they are apt to have none or very few natural enemies. Their principal enemies when in the aquatic larval and pupal stages are fishes and carnivorous insects. Most carnivorous insects are rather slow breeders, and as a consequence they seldom deposit their eggs except in rather permanent pools, and naturally fish are found only in such places. There are, however, other enemies aside from these. Dr. C. W. Stiles informs me that during the summer of 1889 , when working with C. H. Hurst, they collected at Leipsic a large number of mosquito larve and pupre, and that many of them died in the laboratory. Upon opening one of the bodies, which was quite distended, he found a species of Mermis, one of the hair worms or hair snakes, coiled up in the body cavity. Examination of other dead larva or pupre disclosed the fact that nearly every one was parasitized by the same species of Mermis. He showed the worms to Professor Rudolph Leuckart, who informed him that he had repeatedly found the same Nematode in former years, and that he had observed that in years when mosquitoes were numerous the worm is very scarce. This led him to be- 


\section{N.TTRAL ENEAIES OF MOSQUITOES 157}

lieve that the parasite was a not unimportant factor in destroying mosquitoes near Leipsic. Later, Dr. Stiles found the same worm in mosquito larvie and pupe taken from other breeding-places, and it was quite noticeable that the parasitized insects were weaker in their movements than those that were not infected with the worm. In the next summer (1890) he again looked for the worm, but found none, and it appeared to him that mosquitoes were more abundant that year than in 1889.

Dr. Stiles also informs me that a Sporozoan of the genus Glugea is referred to as parasitic in mosquitoes, but that Labbé, in his recent monograph of the Sporozoa, does not give Culex in his list of hosts. Dr. Stiles does not recall who found this parasite, nor does he know whether it is of any particular economic importance.

By far the most effective natural enemies of mosquito larve and pupre are fish. Almost all of the small carnivorous fish which inhabit swamp pools and still water will feed upon mosquito larve. Nearly all of the mimnows, especially those forms known as top-minnows, of the genera Fundulus and Gambusia, feed abundantly upon insects found near the surface of canals, slow streams, mill. ponds, and other similar places, and, althongl not at all specific in their choice of the early stages of the mosquitoes, eat them perhaps with even more aviclity than other aquatic insects, especially such as are hard-shelled. Then, too, the voracions little creatures lnown as sticklebacks, and especially the forms known as Gusterosteus uc"

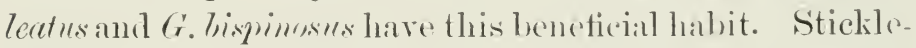
backs, however, are by no means contined to insects for 
food, but will feed upon other animals, including goodsized tadpoles. Anyone who has attempted to keep tadpoles and sticklebacks in the same aquarium will realize the truth of this statement. I once kept a large sized tadpole in the same aquarium with a stickleback, which it exceeded at least five times in size, and its personal beauty was soon sally damaged by the fact that the stickleback subsisted upon meals taken from the edge of the tadpole's tail. In his previously published bulletin

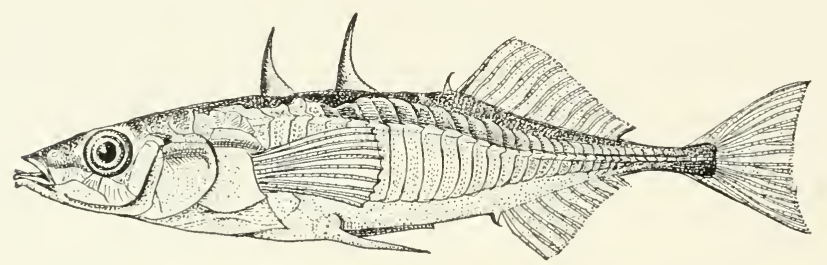

FIG. 44.-Stickleback (Gasterosteus aculeatus); somewhat enlarged. (After Jordan and Evermann.)

on mosquitoes the writer recommended sticklebacks for introduction into fishless ponds to destroy mosquito larvæ, but Mr. W. P. Seal, of the Aquarium Supply Company of Delair, N. J., recommends the so-called top-minnows of the genus Gambusia, common in the brackish waters of the Chesapeake system and southward. He says these are the only fish he knows which will kill Notonecta (the water-boatman), but they do this only when other food is scarce, and when the bugs are small. The fish vary in size from an inch for the males, to about one and three-quarter inches for the females. They live equally 
well in purely fresh water. He has raised them to the fourth generation in tubs and ponds, and they will breed readily in tubs or aquaria. As destroyers of eggs and larræ, and adults as well, of such insects as infest and
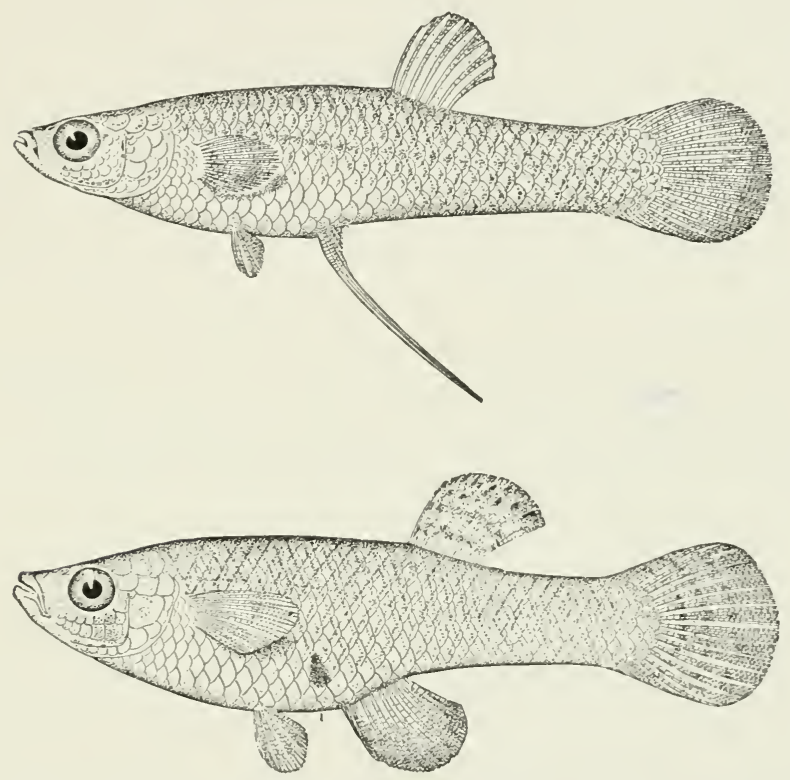

Fig. 45.-Top-minnow (Gambusia affinis); male above; female below; somewhat enlarged. (After Jordan and Evermann.)

mutilate aquatic plants or lay their eggs in the water, Mr. Seal finds these top-minnows rastly superior to any other species of fish. Dr. H. F. Moore, of the United States Commission of Fish and Fisheries, informs me that the top-minnow, known scientifically as Gumbusia affinis, is 
abundant in sluggish waters, fresh or brackish, almost everywhere south of the Ohio River. It feeds largely on vegetable matter, but also on insects. Larval mosquitoes have been found in its stomach. The species is viviparous, as indeed are most of the minnows of this genus, as well as of the genus Fundulus, the young when born being about three-eighths of an inch long. It is specially abundant in the Gulf States. Dr. H. A. Veazie, of New Orleans, writes me that this little fish is common abont New Orleans, and that where it is present he has not been able to find mosquito larve of any kind. He has looked in

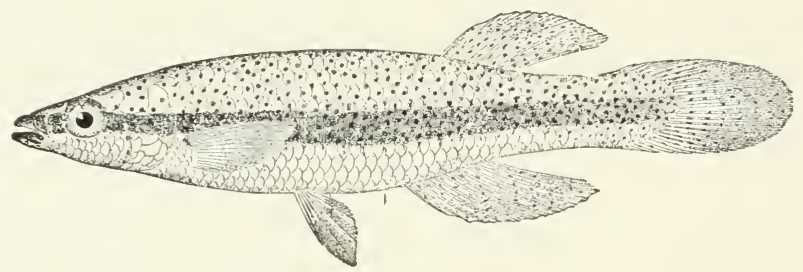

Fig. 46.-Top minnow (Fundulus notatus) ; slightly enlarged. (After Jordan and Evermann.)

gutters and ponds where to all appearances there should be plenty of larve, and has found none, and very shortly he saw the little minnows patrolling the pools. He says they are great breeders, and ravenous eaters. They are so small that they will go into the shallowest places, and even wriggle on the side of the body to catch their prey. They seem to live under the most adrerse circumstances, and do not die until all water is gone. He has seen them so thick in a partly dried-up pond that they had no room 
to swim, "yet they seemed happy." As elsewhere stated, they are viviparous, and Dr. Veazie says that a little female will expel large numbers of the young at one time, and that they can be raised in almost anything that holds water. He has seen them swimming around under a layer of ice, as inconcerned and active as they would have been on a hot July or August day.

I have been thus explicit in referring to these fish, and have illustrated the best forms, for the reason that a very practical use can be made of them. It was stated a number of years ago in Insect Life, that mosquitoes were at one time rery abundant on the Riviera in South Europe, and that one of the English residents found that they bred abundantly in the water tanks, and introduced carp into the tanks for the purpose of destroying the larrie. It is said that this was done with success, but the wellknown food-habits of the carp seem to indicate that there is something wrong with the story. If top-minnows or sticklebacks had been introduced, however, the story would have been perfectly credible, and it points to the practical use of fish under many conditions. Some years ago Mr. C. H. Russell, of Bridgeport, Conn., described a case in which a very high tide broke away a like and flooded the salt meadows of Stratford, a small town on the north side of Long Island Sound. The receling tide left two small lakes nearly side by side, and of the same size. In one lake the tide left a dozen or more small fish, while the other was fishless. An examination by Mr. Russell in the summer of 1891, showed that while the fishless lake contained tens of thousands of mosquito 
larve, that containing the fish had no larve. Mr. E. A. Schwarz informs me that in Beeville, Tex., a little fish which is known locally as a perch is put into rain-water tanks for this express purpose.

There occur on many large estates in the northeast and elsewhere, ponds which are used for watering stock. These are sometimes artificial ponds built with rock bottoms to prevent the exit of the water. They camnot be drained, and on account of their purpose they camnot be treated with kerosene. Into such ponds should be introduced a plentiful supply of top-minnows or some other voracious mosquito-eating fish.

In a later conversation with $\mathrm{Mr}$. Seal, he told me that the top-minnow was suggested because it is a top-feeder, and being very small and slender, it penetrates to the remotest shallows of the waters which it may inhabit, especially where plants abound and where larve of mosquitoes are sure to be found. On second thought, he was inclined to think, however, that for general purposes the common little flat sunfish, or "pumpkin-seed" as it is sometimes called, would be a good fish to introduce into fishless ponds. It grows much larger, of course, but is very prolific, and the young do not make a very great growth in a year, so that the young of each year remain comparatively small, say from three-fourths of an inch to a halfinch, until the young of the following year would be ready for business, which would be by July 1st. The topminnow, he says, being a soft-rayed fish, becomes the easy prey of larger fishes introduced into the same waters, but the sunfish, being protected by spine-rayed 
fins, enjoys greater freedom from molestation. The sunfish, he says, abounds in every pond and strean where fish are plentiful, excepting cold mountain-streams. Every aquarium dealer in any large eity will be able to supply the common sunfish. Mr. Seal further notes that the common suntish is the most voracious of the smaller fishes. It has a larger nouth than the top-minnow

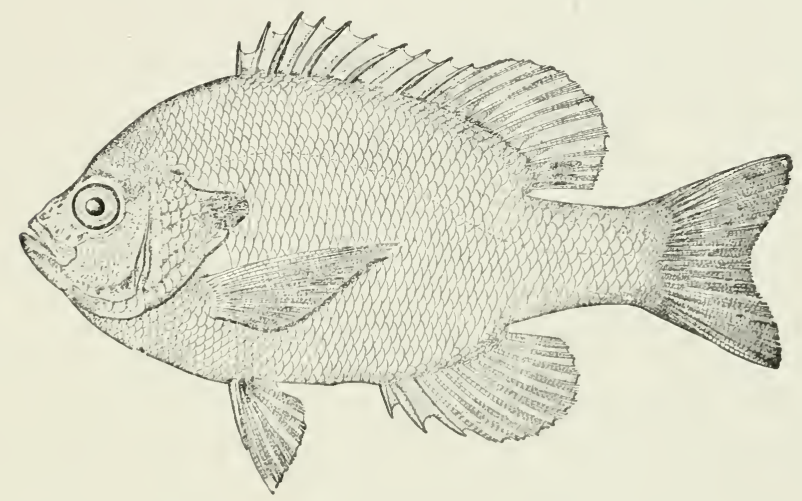

Fig. 47.-Common Sunfish or "Pumplin-seed"; reduced. (After Jordan and Evermann.)

and is wholly earnivorons, whereas the top-minnow is omnivorons. On mature consideration, he gives preference to the sunfish as most completely filling the bill.

There are other aquatic vertebrates, besides fish, which destroy mosquito larve. I am not sure that tadpoles eat them-there seems to be some loulst on that point-but my friend, Mr. Allert Koebele, informs me that he imported into Hawaii from California a large 
number of the western salamander (Diemyctylus torosus Esch.) which were liberated in the upper part of the Makiki stream in the hope of reducing the large number of mosquitoes breeding everywhere in small pools and taro fields. He kept two of these salamanders for several weeks in an open tank, and they devoured, and kept the water free from, the mosquito larva that bred there. While hundreds of the newly hatched mosquito larre could always be observed, none of them ever reached full growth. Mr. Koebele says, "It is to be greatly desired that this valuable batrachian will increase to such numbèrs as to be able to help us keep in check the most troublesome insect on these islands."

Then there are many predatory insects which feed upon mosquitoes. The late Dr. R. H. Lamborn, of New York and Philadelphia, was so impressed with the voracity of dragon-flies that he offered a series of prizes for the three best essays regarding the methods of destroying mosquitoes and house-flies, especially designating the dragon-fly for careful investigation. The prizes were awarded and the successful essays were published in an entertaining volume entitled "Dragon-flies rs. Mosquitoes. The Lamborn Prize Essays." None of the essays were able to solve the problem of the practical breeding on a large scale of dragon-flies for mosquito extermination, and, in fact, the insect enemies of the mosquitoes cannot be practically handled. Dragon-flies as larve feed upon mosquito larre, just as they feed upon all other aquatic insects and even upon small fish. As winged adults they capture mosquitoes on the wing, just 
as they capture other insects on the wing. The same may be said of other predatory aquatic insects. Some of the aquatic beetle larrse and some of the predatory waterbugs undoubtedly destroy hundreds of mosquitoes. Any stagnant pool, when carefully watched, will be found to swarm with predatory animal life. From such a pool I once took a lualf gallon of water which was teeming with aquatic insects, including hundreds of mosquito larve. Among these insects there were three water-beetle larve of the family Hydrophilidie, and in the course of a week these three larve practically devoured all of the other animal life in the jar.

The adult mosquito also has its natural enemies. Tre have already mentioned the dragon-flies, and many nightflying birds, such as night-hawks and whippoorwills, destroy them on the wing; and bats, of course, feed upon them. An observation is on record by the late Prof. F. L. Harvey, in which he states that he found six hundred mosquitoes in the crop of a single night-hawk. In November, 1900, Mr. E. P. Salmon, of Beloit, Wis., wrote me, "There is a parasite, a little red louse, which attacks the mosquitoes on Madeline Island a few weeks after their appearance in .June, and from the time this little red louse shows itself on the mosquito muder the mosquito's wings, the moscpuito begins to lose lis strength. After a few weeks, along toward the end of July, the mosquito ceases to be very tronblesome and seems to be fighting with his parasite for his life." This parasite is probably one of the little red mites which are found upon flies, and particularly upon the common house-fly. 
The mosquito being an aquatic insect, the mite observed by Mr. Salmon may be one of the little water-mites of the family Hychachnidie, but the mosquito issues from its pupa so rapidly that this is hardly likely. It is more likely to be one of the Trombidiicle, the young of which may crawl upon the mosquito when it is at rest upon the plants.

Some observations upon the natural enemies of the malarial mosquitoes of the genus Anopheles have been marle by Dr. C. IV. Daniels in East Africa ("Reports to the Malaria Committee of the Royal Society," December $31,1900)$. He says that fish, and especially young fry and small fishes, will speedily destroy the mosyuito larve, but in spite of this, Anopheles larve are often fomd in pools, rivers, etc., where fish are abundant, and pupa and mature larve among them. This is seen in open pools as well as in the grass-grown rivers. He also says that talpoles do not attack the larve even in captivity, and goes on to say that larre of Coleoptera and dragon-flies, often found in numbers in water with abundant Anoph. eles larve, even in captivity do not seem to devour them.

In ponds where there are large-leafed water-plants, mosquitoes frequently escape the attacks of fish, and many more of their natural enemies, by holding to the water-surface, especially above partly submerged leaves. This is especially the case with Anopheles larve, which remain quite at the surface during the best part of their existence 


\section{VIII \\ Remedies Aguinst Mosquitoes}

FTER a number of year's' experience in fighting
mosquitoes, the present writer has come to the
conclusion that there is no reason why any community should submit to the mosquito plague. At first he only went so far as to state that there are many places where the somree of the mosquito supply is circumscribed and limited, and easily handled, and that in such places, with a comparatively slight effort and small expense, mosquitoes could be controlled. As the work went on and as experiments were tried on a grachally increasing scale, it became more and more obvious that any neighborhood, if it cares to take the tronble and go to the expense, may place its mosquito denizens hors du comlunt. But with mosquito work, just as with so many other public measures, what is everybody's business is nobody's business, and the result is that in many localities everyone submits to the mosquito evil. In some instances, indivinlual effort is all that is necessary ; in others, miter action on the part of the residents of a given neighborhood or a given community is needed, and, as will he later shown, there are still other measures which should 
be handled by still larger organizations-even by States. Mr. Matheson's clever phrase, referred to in the introduction to this book, "There is no more reason why people should suffer from mosquitoes than that they should suffer from smallpox," is not an over-statement; and that the effort should be made when it promises suceess is so self-erident that it only requires a few enthusiastic and enlightened individuals in a community to convince everyone of the desirability of an organized effort.

Setting aside the question of yellow ferer, which only at intervals concerns even the States along the Gulf of Mexico, and is of vital and constant importance only in tropical regions, a mere passing thought shows the economic loss to a neighborhood in the prevalence of malaria. While the actual death-rate may not be high, the number of persons incapacitated for their full share of work is always great. Families suffer in one way or another, and the community, when the matter is considered in a broad way, is a great loser. Aside, too, from malaria, it is perfectly obrious that a mosquito-ridden neighborhood is not a desirable place of residence. The very fact of the abundance of mosquitoes keeps real estate values at a depressed point. I know of one case where a stretch of land near a large body of water afforded many excellent coxtage and rilla sites, but mosquitoes were so numerons that even domestic animals could not be kept in a healthy condition, and the sole population consisted of a few smoke-dried fishermen and their dogs. In this locality, by enterprising work on the part of one man, who organized a company for the pur- 
pose, the land was bought, the mosquito-breeding places were practically abolished, summer residences were built, and the company realized many thousands of dollars in the course of two years. There are, within a humdred miles of New York City, for example, hundreds of beantifully situated localities which are not ntilized to their full possibilities largely on account of the prevalence of mosquitoes. There are many small towns which are undesirable for summer residence on account of the abundance of mosquitoes, though in all other respects their qualifications for this purpose are perfect.

Aside from the main questions of health and of the value of land, come the other subsidiary questions of comfort, and of the unnecessary expense of screening houses with the thoronghness necessary in many localities, which, when considered in bulk, become important. It seems then evident that it would be a positive economy for a community to spend, if necessary, even a large sum of money in attempting mosquito-extermination. In very many (ases, howerer, a small sum will suftice, provided it is arministered with intelligence.

Dr. C. Fermi, after giving an account before the Medicophysical Society of the Tuiversity of Sassari, March 23, 1900 , of his efforts to free the town from mosquitoes, estimated the expense of freeing a town of 50,000 inhabitants at from $\$ 200$ to $\$ 300$. This smm seems extremely small, even with the low price of lahor over there, hut in the case of Sassari the mosquito-supply was local, and the insects bred almost entirely in honsehold tanks and water receptacles. It is with large marsh-areas or numerous 
ponds in neighboring woods, and especially with the high brackish sea-coast marshes, that the expense would become very great.

The consideration of the question of remedies may most conveniently be divided into the following main categories: (1) Remedial work against the early stages ; (2) liemedial work against the adults.

\section{Remedial Work Against the Early Stages.}

In considering the question of remedies against the early stages, we again find it most convenient to subdivide the subject as follows: (1) The treatment of breeding-places with insecticicles; (2) The abolition of breeding-places by drainage, and (3) The introduction of natural enemies into breeding-pools, which for any reason it may be molesirable to drain, or to treat with oil.

Before mdertaking work against the early stages of mosquitoes in any given neighborhood, it becomes necessary to make a thorough survey of the immediate surroundings, and to learn with great accuracy all of the places in which mosquitoes are breeding or may breed. In the section entitled "Queer Places in which Mosquitoes Breed" (Chapter I.) an effort has been made to cover the gromed rather thoroughly as an indication of what must be looked for. All accidental receptacles for standing water must be emptied and must be kept emptied: waste ground in the vicinity must be thoroughly examined, in order to find whether there are hollows in which rain-water accumulates or whether there are broken 
bottles, empty cans, or discarded vessels of any kind. About louses, the greatest care must be taken to examine every possible spot where still water may occur ; cisterns must be covered tightly, with, however, a sufficient aperture covered with wire gauze to admit of a plentiful aëration of the water; rain-water barrels should be either covered or treated with kerosene. In the surrounding ground every permanent pool and every swamp-area should be charted and the method of treatment determined upon; permanent pools not used for watering stock should be treated with kerosene; swamp-areas should be drained; and small depressions shonld be filled with earth. All such work must be thorough and practically perfect, else it is hardly worth while to undertake it.

\section{The Use of Kerosene on Breeding Pools.}

As long ago as 1812, the writer of a work pullished in London, entitled, "Ommiana or Horse Otiosiores," suggested that by pouring oil upon water the number of mosquitoes may be diminished. Delbouf, in the Revre Scientifique, 1895, says that he used kerosene in this way fifty years before. H. E. Weed, in 1895, stated that in the French quarter of New Orleans it has been a common practice for many years to place kerosene in the water tanks to lessen the number of mosquitoes in a given locality. Suggestions as to the use of kerosene were made by Mrs. Aaron, and by Bentenmiller, in the Lamborn Prize Essays, "Dragon-flies rersus Mosquitoes" (D. Appletou \& Co., 1890). In 1867 the present writer used 
kerosene in a watering trough at Ithaca, N. Y., and found that mosquito larve were killed by it, and in 1892 conducted an experiment upon a larger scale in the Catskill Mountains, inclicating the quantity of kerosene necessary for a giren water-surface and showing that adult mosquitoes are captured by a kerosene film ; that is to say, they alight on the surface of the water in an attempt to deposit eggs and are destroyed by the kerosene before the eggs are laid. A full account of this last experiment was published in Insect Life, vol. ii., 1892, and, since it attracted consideralle notice in newspapers, additional experiments by others upon a larger or smaller scale were speedily made. Mr. H. E. Weed rid the college campus of the Mississippi Agricultural College of mosquitoes by the treatment with kerosene of eleren large water-tanks. Dr. John B. Smith recorded in Insect Life (rol. vi). success with this remedy in two cases on Long Island. Professor V. L. Kellogg conducted a similar series of experiments upon the campus of Stanford University, California, in which cases post-holes filled with surface water were giving out large numbers of mosquitoes, but when a little kerosene was poured into each hole the mosquito plague was almost immediately alleviated. Rer. John D. Long, at Oak Island Beach, Long Island Sound. and Mrr. W. R. Hopson, near Stratford, Conn., conducted large-scale experiments with good results. Mr. R. MI. Reese, in Baltimore, treated open sewers with kerosene with excellent results. A little later (1898), Mrr. W. C. Kerr, on Staten Island, did some large-scale kerosene work upon ponds and swamps, which resulted most satisfactorily. In 1897 
Mr. M. J. Wightman oiled brackish marshes at an Atlantic coast resort for a radius of about half a mile, reducing the mosquitoes to innoxious numbers for an entire season. Dr. St. George Gray, of st. Lucia, British West Indies, used kerosene in his well and in water-jars in his yard with excellent result.

All of this work was done before the malaria discoveries directed the attention of European observers especially to the question of mosquito control. In the early work of the Italian investigators the use of kerosene was rather discredited, one of the reasons adduced being that although kerosene is abundant and cheap in America, it was not known to the Italians that it was extensively used in this country - a pretty poor reason, but still, more or less effective over there. Even Major Ross, the English expert, seemed at first rather skeptical as to the value of kerosene, but returned from his West African expedition fully convinced of its value (Giles, $1900, \mathrm{pp} .76,77$ ), and since that time the use of petroleum oils has gradually become the standard treatment for mosquito-breeding pools. For example, Fermi and Lumbao, the Italian investigators, think that one man, with one day's teaching, could rid a good-sized city very largely of mosquitoes by repeating ten to twelve times, through a summer of seren months, the application of petroleum to the breedingplaces. Mr. W. J. Matheson, in the summer of 1900 , attained rery suceessful results by treating an area of several square miles on the north shore of Long Island with kerosene, eombined with certin drainage work. The army regulations in Cuba provicle for the treatment 
of breeding-places with lierosene, and the results are reported to have been admirable. 'The city of Winchester, Va., during the summer of 1900, was treated with kerosene, under an ordinance of the city council, with such good results that in the spring of 1901 the city council passed a further regulation providing a penalty for the non-treatment of breeling-places. This instance is one of such wide-spread interest that the ordinances of 1900 and 1901 are printed herewith, together with a letter received in October, 1900, from the mayor of the city.

\section{[First Circular, 1900.]}

\section{PREVEN'T THE MOSQQUITO.}

The City Council has passed the following Ordinance :

1. Be it ordained that on or before March 25, 1900, and at least once each month thereafter until November 1, 1900, each owner or occupier of a house or lot in the city, shall put into every pool or sink which is open, or from which there is any opening or out. let, kerosene oil at the rate of one ounce for fifteen square feet of surface of said pool or sink, and that quantity for any surface less than fifteen square feet.

2. And be it further ordained that one-half an ounce of kerosene oil shall during the same time be put in every open barrel or logshead kept for the purpose of collecting rain-water; and water shall be taken from such barrel or hogshead by a spigot of wood or metal placed as near as convenient to the bottom of said barrel or hogshead.

3. It shall be the duty of the police, by proper inspection, to see to the enforcement of this ordinance, and to supply to persons unable to procure them the necessary oil and spigots. 
I am assured on the highest authority that if this plan is carefully and persistently carried out, it will after athile result in entirely preventing the mosquito, whereas here its existence has not long been established and is wholly due to local causes. But the failure of a few to apply the oil on their premises will defeat all efforts to get rid of this dreadful pest. An ounce of oil will about fill an ordinary teacup : smaller quantities will suffice for spaces less than fifteen feet square; a tablespoonful is enough for an ordinary rain-barrel ; every little pool, however, must have its portion of oil, and the oil must always be renewed when washed away by rain, and this is especially necessary for rain-barrels. In any event the oil must be renewed at least once a month.

I invite the cordial co-operation of all good citizens,

R. T. Bak'TON, Mayor.

\section{[Second Circular, 1:100.]}

\section{FIGH'T THE IIOSQUITO.}

The efforts made hy our eitizens since March 25th, in obedience to the ordinance of the Common Comncil, to prevent the development of the mosquito during this season, seem to have resulted in most encouraging success. It is yet too early to determine to what extent we have destroyed this pest, but there can be no doubt of its having been done to a very large extent. Every experiment carefully watched has demonstrated the efficacy of coal-oil applications and all that seems to be needed is to continue diligently the use of oil, but muless we do, all that we have done in the past will amount to nothing. It is not necessary to repeat suggestions heretofore published, lest, however, some may have forgotten its terms, I append hereto a copy of the ordinatuce :

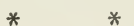

* * * $\quad * \begin{gathered}* \\ \end{gathered}$


[Third Circular, 1900.]

\section{CON'TINUE TO FIGH'T 'THE MOSQUITO.}

Although it is greatly diminished in numbers, even to the extent of being no longer a serious trouble, yet by its ummistakable presence here and there the mosquito has made it evident that all of them are not dead. The success of the plan has far exceeded our expectations for the first season. All that is needed now to eliminate them as a feature of this community is to keep up the fight diligently until November, when we will take a rest until the next season. The chances are that what we will do next year will be mainly as a wise precaution against the possible recurrence of the pest. That you may not forget the history of this insect and why it is possible to destroy them by the use of oil, I repeat a publication made once before.

July 17,1900 .

R. T. BARTon, Mayor.

How the Mosquito is Bred.

Its germinal period is often about twenty-five days from the laying of the mosquito-egg to the full maturity of the insect, of which time only about three days are spent in the eggs. The average germinal period is about three weeks. I say "about" for the time is not always exactly the same, depending, as it does, very much upon the condition of the weather and water.

'The female lays about 300 eggs at a time in some pond, cistern, tank, cesspool, rain-barrel, or any quiet pool of water. The eggs are glued together in the shape of a pretty little boat and left to float and hatch. They retain this "wiggler" condition for from five to fifteen days, remaining all the time in the water but changing their skins several times. 
After from five to fifteen days the larvæ become pupæ or "tumblers," so ealled from their bobbing up and down or turning over in the water. After five to tifteen days of pupa-hood the skin opens at the back and the mosquito comes out. It dries its wings and is then ready for business on dry land. The female is the business member of the house, and it is she who sings and sucks the whole night through.

'The natural food of the mosquito is vegetation, and with this the male contents himself. It is the female alone that develops a carnivorous appetite. The life of the mosquito is short, but from the later hatchings of the fall a great number live over winter in garrets, cellars, etc., for the cold does not kill them.

In early spring the female begins to lay her eggs, and as she lays about 300 in each bunch, the rate of increase is prodigious. Hence the importance of anointing with oil all pools of water. When the female comes to lay her eggs she will desist, and laying them on some twig or leaf, they will perish. If she alights on the oil-anointed water she perishes and her eggs perish with her. If the eggs have been laid before the oil is put in the water and the insects are in either larva or pupa state when the oil is put in, it will destroy them.

The most important time then to fight this insect is just at this season before they have multiplied, as they will do in a few weeks if left alone. Since, however, the mosquito goes on laying and hatching until about November, it is necessary to fight it all the season through, perhaps several seasons through. 


\section{[Letter from the Matyor.]}

Dr. L. O. How ARD,

Wixchestel, VA., Oetuber 5, 1900 .

Entomological Bureau Agricultural Dep't,

Washingtom, I). C.

DEAR SIR: I have for some time had it in mind to write you an account of our war against the mosquitoes in this town; thinking that inasmuch as we made the fight along the line of your published suggestions you would be interested in learning the extent of our success.

Until about ten years ago a mosquito in Winchester was as rare as a horse in Venice. About ten years ago, the increase in their numbers began to be apparent, but it was not until five or six years ago that they became a positive amoyance. Their advent here was attributed to a line of parlor cars estahlished as a night train on the B. \& O. R. R., running from Camden Station, Baltimore, in the summer-time. This may have added to the number, for recent investigation has shown that the returning empty cattle cars, which stand for a time at the stock-yards in Baltimore, bring great numbers of mosquitoes all along this mountain country wherever the trains run.

My own opinion, lowever, is that we owe the great increase to the scanty original stock here, which was enabled vastly to multiply its numbers because of a new and much extended system of water-works, which led to the greatly increased use of bath-tubs and water-closets; and having no system of sewerage, the excessive use and waste of water stands in numerous cesspools, which are the prolific breeding-places of the mosquito. Then, too, there is a strean of water, arched over where the streets cross, which, after heavy rains and when the regular strem has subsided to its ordinary dimensions, consists of a large number 
of still pools, which are fine for the rgge-lıatehing and larva and pupa mising by the mosquito. The arches over this stream I found last spring to have been the favorite hibernating places of the insect, and before they had fully time to wake ul and go to business, I had millions of them destroyed by sprinkling with coal tar.

Last summer my attention was called to your suggestions alout the use of oil, by my brother-in-law, I)r. R. IV. Baker, of your city. At my request he called on you and procured some of the literature issued by you on the subjert. I determined that I would urge the people here to try the experiment. In October, 1899, the matyo having died, I was mnexpectedly chosen in his place, and I then thought of trying to make the matter one for municipal and methodical action. I therefore indueed the Common Council to pass an ordinance, a copy of which I enclose to you.

My proposition was greeted by the papers and by the connmunity generally with much merriment, and I was the subject of some very sharp ridicule from the press at home and abroad.

The ordinance, as you will see, was without penalty, and the course designed to be pursued by me was intended to be persuasive and not coërcive. Early in the spring (March) I discovered the mosquitoes buzzing out from a pile of plank when the snow was six inches deep, and the first reports of the police who undertook to anoint the run and all public pools, was that millions of them were foumd adhering to the arches, and the oil-cams when brought out from use under the arches and in the pools were covered with the deal insects.

I issued to the people small leatlets, griving an account of the habits and gestation period of the mosquito, and urging the people to olory the ordinance and join me in at relentlesif figlit against the insect. I also asked many persons to make experiments and report their suceess to me. I was soon orerwhelmed with re- 
ports and all of them of the most favorable character. One entirely reliable gentleman reported to me that within five minutes after he had anointed a ran-barrel, seventy-five mosquitoes (presumably females) came to the barrel and seventythree of them perished, while the other three made haste to escape. In one case, a lady reported to me that she took nearly a pint of the dead insects from a hogshead the morning after putting the oil in it. These and reports like them greatly encouraged my efforts, and soon the oil was in almost universal use and the town smelled like a standard ()il tank. I continued from time to time to issue the leaflets, and followed them up with a police inspection. The result has been a wonderful success. The plague, while by no means entirely abated, has been decreased to a marked degree. In many parts of the town, the nets used so constantly heretofore have been thrown away, and there are no mosquitoes at all. In other parts, while their numbers are lessened, they still continue to be a nuisance. This difference is doubtless due to the neglect of some persons in the particular neighborhood to use the oil ; and also, no doubt, to peculiar facilities afforded for mosquito breeding in some parts of the town more than in others. I observed a decided increase in the number in the latter part of August and in the month of September.

Just now we are greatly increasing our efforts toward their destruction, so as, if posible, to destroy the crop that would hibernate, and thus reduce the number of hreeders to live over to spring.

There can be no doubt about the success of the scheme. All that is needed is persistent, unremitting application of the oil to all pools, sinks, water-(-losets, old cisterns, etc., etc., and another season we expect to have an ordinance with a penalty attached and to enforce the oil anointing even more systematically than has been done this year. 
To your suggestions we are indebted for what promises to be complete relief from this pest, and for an exemption during the past summer to an extent that has added very much to the pleasmre and to the profit of living in this town. I thank you very much in my own name, and in that of all of our people, for the good that your wise and practical investigations have done. Yours very truly,

R. T. BARTON.

[First Circular, 1901.]

\section{MOSQUI'TO CAMPAIGN OF 1901.}

The admirable results obtained during the last year from fighting the mosquitoes seem to assure us that one more campaign will end them for Winchester, and restore conditions existing a few years ago when this insect was unknown here. The present ordinance is more stringent than that of last year and provides a penalty for its disobedience. Still, it is only the very few who are driven by the fear of the lan!. Its successful enforcement depends after all upon a cheerful compliance by the good and lawabiding citizens. I publish the ordinance now, for your information, calling especial attention to the fact that the use of the oil must begin on March 15th : much earlier than last year, as we learned from observation that we did not begin early enough then. The oil must be renewed at least every three weeks, and I sugrest, so that it may not be overlooked, that the first and tif teenth days of each month be "oil days" in your calendar.

I hope that it will not be necessary either to appoint an inspector or to impose a penalty for disobedience of the ordinance.

R. T. BARTON, Mayor. 
An Ordinance to provide a method for the destruction and prevention of the mosquito in the city of Winchester.

Be it ordained by the Common Council :

1. That on or before March 15, 1901, and at least every three weeks thereafter, until November 15, 1901, there shall be deposited in every open pool or sink, or all from which there is any open ing or outlet, and upon the surface of every barrel or hogshead kept for collecting rain-water ; and upon every receptacle of any sort in which water is allowed to stand for as much as twentyfour hours on every lot in the city of Winchester ; and on every open pool of any sort in every street or square and along the bed or course of the town run, in said city of Winchester ; kerosene oil, at the rate of one ounce for each fifteen square feet, and a proportionate quantity for any less surface.

2. It shall be the duty of every owner or occupier of any house or lot in the city to make the deposits of oil as provided in this ordinance; and in the case of barrels, hogsheads, or other receptarle kept on the premises for the collection of rain-water, water shall be drawn from said receptacle by a spigot of wood or metal placed as near as convenient to the bottom of said receptacle.

3. It shall be the duty of the police, under the instructions of the mayor, to see to the enforcement of this ordinance, and to supply persons unable to secure them with the necessary oil and spigots.

4. The mayor shall have authority, if in his judgment the occasion requires it, to appoint an inspector of pools, sinks, ete., removable at the pleasure of the mayor, and whose duty it shall be to report any failure to comply with the provisions of this ordinance; and who, under the instructions of the mayor, shall have authority to enter any premises, and himself make the required deposit of oil. The pay of said inspector shall not exceed $\$ i$ a week, to be paid by the treasurer ont of the public funds.

5. Every owner or occupier of a lot who shall fail to comply 
with, or shall offend against the provisions of this ordinance, shall for each offence or failure be liable, upon conviction thereof, to pay a fine of one dollar, which shall be recoverable as provided by section 9 of the General Ordinances of the City of Winchester.

6. The sum of $\$ 25$ is hereby appropriated for the enforcenent of this ordinance, in addition to the compensation of the inspector, in case one shall be appointed.

I venture to predict that these papers will eventually possess an historical value, since without doubt other communities will soon follow the example set by this enterprising Virginian town, and that mosquito warfare on these or somewhat similar lines will before long become a part of the duty of very many communities and of all of their citizens.

Taking, therefore, the value of kerosene as proven, a word must be said as to the best grade of kerosene, and the best method of applying it.

In choosing the grade of the oil two factors are to be considered. First, it should spread rapidly. Second, it should not evaporate too rapidly. The heavier grades of oil will not spread readily over the surface of the water, but will cling together in spots, and the coating will be umnecessarily thick. Mr. W. C. Kerr, who conducted the extensive experiments on Staten Island, to which we have several times referred, tried several kinds of oil, and found to be best alapted a low grade of oil known as "fuel oil," supplied by the Standart ()il Company. Of the oils which he tried, some contained too much residumm of a thick nature which appeared as a precipitate, and could 
scarcely be pumped; some were too thick in chilly weather and could not be pumped at all, while some were limp, easily handled, made a good uniform coating on the ponds, and were very effective. So long as the oil flows readily and is cheap enough, the end is gained, provided it is not too light and does not evaporate too rapidly. Mr. Matheson, in his North Shore experiments, arrived at the same conclusion, and the petroleum which he found satisfactory for use on the mosquito-breeding ground was that known by the Standard Oil Company as "light fuel oil."

In the accounts of the early experiments of the English observers in West Africa, it was found, according to their reports, that the petroleum which they placed upon runs was not persistent, and that it was necessary to renew the application at much more frequent intervals than has been found to be the case in this country. The explanation of this is undoubtedly that some light illuminating oil was used, which was more volatile than was at all necessary, and which at the same time was mmecessarily expensive. The army workers in Cuba have been advised by the writer to use this fuel oil of the Standard Oil Company.

I am informed by the Standatd Oil people that at the time Mr. Kerr's work was being carried on the price of this oil was \$2.25 per iarrel, but that in March, 1901, the price had advanced and was $\$ 3$ per barrel, including the barrel, f. o. b. Point Breeze, Philatelphia, or Bayomne, N. J., an allowance for the barrel to be made mpon its return, the allowance, however, depending entirely upon the condition of the barrel when received by the Standarl Oil 
Company. It thus appears that this is not a high-priced oil, and very likely in case of large-scale community work it could be bonght by the tank-car at a very reasonable rate.

Kerosene may be applied simply by pouring it upon the surface of the water, when it will spread of itself, or be spread rapidly by light winds, or it may be spreat through a spraying nozzle. A spraying method was used successfully on Staten Island by Mr. Kerr and his associates. The laborers employed were furnished with bucket-pumps and were able to throw the spray into ponds for a considerable distance from the shore. The use of a spraying nozzle, however, does not seem to me to be desirable. I watched the oiling of ponds by this method at a New Jersey town, where the work was being carried on under the anspices of a ladies' town-improvement association, in the early summer of 1900 . The water treated was all in small woodland ponds and there was a great waste of kerosene. The spray was diffuse, and became scattered over the regetation on the borders of the ponds, a large share of it being wasted in this way. On small ponds the oil can be sprinkled to advantage out of an ordinary watering-pot with a rose nozzle, or, for that matter, pouring it out of a dipper or a cup will satisfactorily treat a small pond of, say a hundred square feet of water surface. With larger ponds, a pump with a straight discharge nozzle may be used. The straight stream will sink and then rise and spread, until the whole surface of the pond can be covered withont waste. The English observers advise mopping the petroleum upon the surface 
of the water by means of cloths tied to the end of a long stick and saturated with kerosene. The use of such a mop may be desirable, even where a straight discharge pump has been used, in order to commingle two surfacesheets of oil.

The question as to the frequency of application of kerosene is an important one. In my early experiments I found that the kerosene was effective for some days after the odlor had disappeared and after the iridescent effect upon the surface of the water had ceased to be perceptible to the eye. A single application to a small pool was certainly effective from twelve to fifteen days. The persistence of the oil, however, will undoubtedly vary with the temperature and with the character of the pool -whether exposed to the direct rays of the sum or shaded by trees. It is, at all events, safe to say that it will be perfectly effective under nearly all circumstances, for at least a week, and probably longer. That means that for a week no mosquito can alight upon the surface and succeed in depositing eggs, and that even if she conld do so the larve hatching from such eggs would be killed. Therefore we must calculate from the end of such an effective period to the end of the growth of larral and pupal life, and just before this second period is reached the application should be renewed. Under the most favorable circumstances it will take from seven to ten days for a mosquito larva to reach full growth, and the pupa to become ready to give ont the adult. Therefore, to the kerosene week must be added at least a week of larval and pupal growth, which would require a second application of kero- 
sene after from fifteen to twenty days, in order to render it impossible that any adult mosquito can be developed. This period is too short, rather than too long, but it is absolutely safe, and in any given locality observations will indicate to what extent it may safely be lengthened. I am quite inclined to believe that, even in tropical regions, serenteen-day intervals will be perfectly safe, if the fuel oil referred to above is used. My own experiments were carried on with illuminating oil, and the fuel oil is more persistent.

The first army order's issued in Cuba (Circular No. 8, Headquarters Department of Western Cuba, October 15, 1900) required the treatment of breeding-pools once a month. The second order (General Orders No. 6, Headquarters Department of Cuba, December 21, 1900) required the application of kerosene twice a month. 'The Winchester ordinance, it will be remembered, designates as the times of application once every three weeks, but the mayor suggests that the first and fifteenth days of each month be "oil days."

As interesting records, the army circular and order are given :

\section{[Circular No. 8.]}

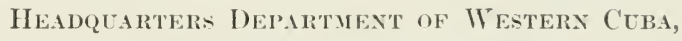 QuEM.IDOs, October 15, 1900.}

The following communiation from the Chief Surgen is puhlished for the information and guidance of commanding oflicers in this department. The necessiry action will be taken as therein recommended. 


\section{Cinef Strgeor's OfFice, Headquarteis Departiext of Westers Cuba, Quemados, Cuba, October 13, 1900.}

To the Adjutant-General of the Department.

SIR : I have the honor to invite your attention to the following farts and their bearing on the health of the command:

The rôle of the mosquito in the transmission of certain diseases is now well established. The evidence is now perfect and conclusive that malaria, as well as filarial infections, are carried by this insect, and there are reasons to suspect that it may be connected with the transmission of yellow fever, also.

Every consideration of prudence, as well as comfort, demands, therefore, the protection from them of the commands at all posts. It is believed that this can be done with a very slight expenditure of time and trouble, by the enforcement by post commanders of two precautions, namely :

1. The enforcement of the use of mosquito-bars in all barracks and especially in all hospitals.

2. The destruction of the larre of young mosquitoes, commonly known as "wiggletails" or "wigglers," by the use of petroleum on the water where they breed.

The mosquito does not fly far, and seeks shelter when the wind blows; so it is usually the case that every community breeds its own supply of mosquitoes, in water-barrels, fire-buckets, or undrained puddles, post-lioles, ete. An application of one ounce of kerosene to each fifteen square feet of water once a month will destroy not only all the young, but the adults who come to lay their eggs. The water in any cistern or tank is not affected in the least for drinking or washing purposes, if only it is drawn from below and not dipped ont. For pools or puddles of a somewhat permanent character, draining or filling-up is the best remedy. It is recommended that the medical officer who makes 
the sanitary inspections at each post be charged with the supervision of the details of these precuntions.

Very respectfully,

Your obedient servant,

J. R. KEAN,

Major and surgeon, U.S.T., Chief Surgeon.

By Command of Brigadier-General Lee :

R. E. L. МiсніЕ, Assistant Adjutant-General.

General Orders, No. 6.

Ineadquarters Departmext of Cuba, HArAx, December 21, 1900 .

The Chief Surgeon of the Department having reported that it is now well established that malaria, yellow fever, and filarial infection are transmitted by the bites of mosquitoes, the following precautions will, upon his recommendation, be taken for the protection of the troops against the bites of these insects :

1. The universal use of mosquito-bars in all barracks and especially in all hospitals, and also in field service when practicable.

2. The destruction of the larve or young mosquitoes, commonly known as "wiggletails," or "wigglers," by the use of petroleum on the water where they breed.

The mosquito does not fly far and seeks shelter when the wind bows ; so it is usually the case that each community breeds its own supply of mosquitoes in water-latrels, fire-buckets, postholes, old cans, cesspools, or undrained puchles.

An application of one ounce of kerosene to each fifteen square feet of water, twice a month, will destroy not only all the young, but the adult females who come to liy their exgos. T'le water in cisterns or tanks is not affected for drinking or washing purposes 
by this application, if only it is drawn from below and not dipped out.

For pools or puddles of a somewhat permanent character, draining or filling-up is the best remedy.

The medical department will furnish oil for the purpose above mentioned.

Post commanders will carefully carry out these precautions. By command of Major-General Wood:

H. L. SCOTT, Adjutant-General.

Dr. Reed informs me that this order was drawn up by Colonel J. R. Kean. United States Army, Acting Chief Surgeon of the Division of Cuba. Colonel Kean wrote, under date of January 12th, that he made the interval between the applications of kerosene twice a month instead of once a month, as he had been mable to find in Cuba an oil of sufficient diffusive quality over the surface of the water, which at the same time would be less volatile than the common illuminating kerosene. The lubricating oils experimented with did not spread readily.

Mr. Kerr's Staten Island experience was an extensive one and led to interesting results. He writes me:

While I do not know how long the protection was afforded by each treatment of the pond-surface, my judgment was that it covered a period of at least several weeks. I think much depends upon the surrounding natural conditions. An exposed pond reasonably clear of weeds and grass and with a fairly clean shoreline, liberally treated with a non-volatile fuel oil, is quickly covered with an oily scum, which the first wind blows over to one side. Then with a change of wind it is blown hither and thither, 
so that the pond is thus automatically treated over its whole surface by the shifting of the wind, so long as there is a surplus of oil present. If the pond is full of grass and weeds and the surface once becones covered, there is, of course, much less shifting, but the accumulation of oil on the foliage keeps the surface well covered, and I assume that this is largely due to the oil working on and off the foliage more or less, due to the disturbance of the wind. In a perfectly sheltered pond; for instance, in a deep) hollow surrounded by large trees, quite protected from wind and containing more or less of weeds and grass, I think the oily scum stays fairly constant, and in thus referring to the surface-coating I mean that which is plainly visible, and it is possible, even probable, that there rematins for much longer periods a minute film of oil over the whole surface, which is not observable through such means as I have used.

The twenty-five or more ponds which were treated under my direction had the oil applied at somewhat irregular intervals, averaging perhaps once a month, and at no time did I find any mosquitoes during that whole summer in their vicinity. The mechanical difficulties of oil application, however, led to resorting to drainage, and therefore my experience with the oil methods ceased. These were hill-top ponds, chiefly in the woods, while the large marsh areas were so meagrely treated on the edges with oil as scarcely to be considered as treated at all, and therefore with them no real experience was gained.

I have thought-but had no opportunity to try the experiment-of anchoring one or more barrels filled with fuel oil in the pond ; for convenience perhaps placing them there in the winter when frozen over and boring small holes in the barrel while the oil is thick with the chill of cold weather. 'Then with the summer's heat this oil will oome out and maintain the supply in places not arcessible by other means. If on experiment the oil oozed out too freely, various expedients could be tried-such as 
making larger holes and filling them with wicking or oakum, through which the oil would filter slowly. Any such method, however, would probably meet some difficulties through the abundant dirty residue which such oil always contains, but I an very sure that such experiments would result in a method of automatic distribution of the oil from such anchored barrels. If the water is deep enough they could be sunk with stones, and with holes on the upper and lower sides, the oil would press upward by the difference in specific gravity and thus give a constant pressure on which to issue slowly.

Mr. Matheson's experience at Lloyd's Neck did not fully coincide with that of Mr. Kerr in regard to the durability of the surface-film. He states that his experiments with oil upon a five-acre pond indicated that the fuel oil would maintain a film for about a week, while the ordinary illuminating oil, with which he first experimented, would last only half that time, the light fuel oil being very much heavier in gravity than the illuminating oil. The periods for which the film persisted varied according to the weather. With a high northwesterly wind the film was broken and the oil driven on the lee shore. He believes that an application every twenty days would be perfectly effective, but the cost of a more frequent application was so slight that he did not care to take the chances and treated the pond mentioned about every two weeks.

Persons who are reading up on th mosquito question will naturally consult the works of the English and Italian investigators, and it may be well to suggest that the word "kerosene" apparently does not occur in the Eng. 
lish language as spoken by Euglishmen, who invariably term it parraffine or paraffine oil. To the Italians we are indebted for a useful expression, which we might just as well adopt, namely to "petrolize," meaning to treat waters with kerosene. Example: The petrolization of mosquitobreeding pools is one of the most important measures to be undertaken in the warfare against mosquitoes.

Many of the small-scale experiments which have been made, notably by the Italians, with a small number of mosquito larvie in small jars or puddles, are not so indicative of the results to be expected as are more natural and large-scale conditions. Mr. Matheson tells me that he once took twenty-five larve in a quart jar and covered it with a thin film of common kerosene oil and noticed that in less than fifteen minutes all larve were dead. At the same time he put a film of oil on the surface of a thirty-gallon tank, and at the end of an hour there were still some few larve wriggling. He questions whether kerosene is as swift a larvicide if put on the surface of deep ponds, as it is on the surface of experimental jars. In my own work I liscovered that where the oil was not distributed equally the larve clustered in the free places and were able to support life for hours.

\section{Other Sulbstunces Aguinst the Eurl! Stuges of Mosquitues.}

The last paragraph indicates plainly the fact that laboratory experiments with other sulstances must not be accepted as conclusive until the substances used are 
treated upon a large scale and out of doors, but if a laboratory experiment fails it may be taken for granted that the outdoor trial will fail even more disastrously. It is for the reason that the much-quoted experiments of Celli and Casagrandi were apparently small-scale experiments that we in the United States have been inclined to give little weight to them. They experimented with a great number of products and decided that petroleum, certain aniline dyes, and regetable powders made from pyrethrum or chrysanthemum plants (which form the socalled Dalmatian and Persian insect powders) are the only substances which are to be recommended. Of the aniline dyes they recommend especially a substance which they call in their published work "Larycith 3," and under this name the writer mentioned it in his Government bulletin. Every effort was made to ascertain what this substance might be, and it eventually dawned upon me that it might be a misprint for "Larricide 3." Under this apprehension, Mr. Matheson, who, by the way, is a manufacturing chemist, succeeded in obtaining samples of the substance and in analyzing it. He finds that it is nothing but dinitrocresol, which is an insecticide that was formerly highly recommended, but which is now scarcely used at all on account of its very poisonous character. It was used, in a solution of one pound to fifteen gallons of water, against caterpillars in Bavarian forests, and has been used to some extent as a germicide in washing down the walls of sick-rooms and also in washing the outside of brewers' casks to prevent mould and fungi. Its poisonous qualities would make 
it dangerous to use as an application to ponds. The pyrethrum powders are expensive and not thoroughly effective.

The use of tar was suggested by Dr. Fielding-Ould, of the English West African Commission, and creosote oil has been suggested as a probable larvicide of value. Experiments made by the writer in the summer of 1900 with coal tar showed that this substance is slow in its action, not perfectly effective, and not at all persistent. Experiments with the two grades of creosote oils (by-products in the manufacture of illuminating gas) indicated that they destroy the larve, but not nearly so rapidly as the various grades of kerosene. It is possible that the creosote oils may prove to be more permanent than the lighter illuminating oils, though they are not as rapid in their effect and not as satisfactory, on the whole, as the grade known as fuel oil.

A great deal has been said about the value of permanganate of potash as a larvicide for mosquitoes. In the summer of 1898 a paragraph was copied in nearly all of the newspapers of the country, which was attributed to the Public Health Journal, and which read as follows:

'Two and one-half hours are required for a mosquito to develop from its first stage, a speck resembling cholera bacteria, to its active and venomous maturity. The insect in all its phases may be instantly killed by contact with minute quantities of permanganate of potash. It is claimed that one part of this substance in 1,500 of solution distributed in mosquito marshes will render the development of larve impossible; that a handful of permanganate will oxidize a ten-acre swamp, kill its embryo insects, and keep 
it free from organic matter for thirty days, at a cost of 25 cents ; that with care a whole state may be kept free of insect pests at a small cost. An efficacious method is to scatter a few crystals widely apart. A single pinch of permanganate has killed all the gerns in a 1,000-gallon tank.

The item is so obviously ridiculous upon its face that it would hardly seem worth while to make any attempt to refute its statements. Nevertheless, it has been so widely real that definite experimentation seems necessary to set the matter at rest. 'The mnknown author's ignorance of the life history of mosquitoes in the opening sentence need not necessarily imply that he would not know a good remedy if he found one. Careful experiments were undertaken by the writer in July, 1898, with various strengths of permanganate of potash, in water containing mosquito larve from one to six clays old. It was found that small amounts of the chemical had no effect whatever upon the larve, which were, however, killed by using amounts so large that, instead of using a "handful to a ten-acre swamp," at least a wagon-load would have to be used to accomplish any result. Moreover, after the use of this large amount and after the larve were killed, the same water, twenty-four hours later, sustained freshly hatched mosquito larve perfectly, so that even were a person to go to the prohibitive expense of killing mosquito larve in the swamp with permanganate of potash, the same task would have to be done over again two days later.

The same conclusion was subsequently reached, after careful experiment, by Dr. Lederle, of the New York 
Health Department, and by the Italians Celli and Casagrandi.

After all, we are practically reduced to the use of oils in this larvicidal work. The question will naturally arise, "Are there any other oils which can be used to better advantage than the best petroleum oils?" Mr. Matheson suggester to me the use of corn-oil, a substance which is rather extensively made in certain parts of the country and which, considering the enormous crops of com grown in our Western States, which, in fact, are so great that sometimes in years of over-production the grain is burned as fuel, might reasonably be supposed to be a cheap oil. At present, however, that does not seem to be the case, and its price in the ordinary market is prohibitive, as compared with ordinary kerosene. Nevertheless, experiments were undertaken with samples received from Mr. Matheson. It was found that the corn-oil did not spread readily and that it gathered together in large patches. Mosquito larve rising to the surface of the water, and finding themselves under a patch of oil, simply wriggled violently until they found the spaces between the patches, where they breathed comfortably and lived for several days. In this experiment the main object was to secure a persistent oil which would not evaporate, but would remain for at least several weeks over the surface of the water. The non-spreading qualities of corn-oil, howerer, as well as its price, remove it from the list of good culicides.

Although a number of proprictary and secret mixtures for mosquito-breeding pools have been sent to the writer for experiment, none of them have been found more satis- 
factory than the cheapest petroleum, and none of them are recommended. In a work of this kind we need not only the best but also the cheapest substances. The large scale on which this work is undertaken, and will be undertaken in the future, demands a cheap substance, and on the whole there can be no doubt that the kerosene known as fuel oil will be found to be the most satisfactory. Of course, the general interest in the subject will induce future additional experimentation, and it is quite within the possibilities that something better will be discovered. Up to the present time, however, nothing definite is known.

\section{The Abolition of Breeding-Places by Drainage or by Filling.}

In the chapter on mosquitoes and malaria is given an account of how, by an expenditure of forty dollars for drainage in the summer of 1900 in a Maryland village, malaria practically ceased to exist, although the previous summer there had been one or more cases in every family in the village. That meant that the breeding-places of Anopheles were abolished. And it should be added that the numbers of mosquitoes of the genus Culex were vastly reduced by this operation. Those which remained probably bred in artificial water-receptacles, such as tanks, tubs, or barrels, not a part of the former permanent supply of the place. This is probably one of the most striking instances of the value of drainage with which this section could appropriately be introduced. 
In the summer of 1900 , at a certain army post, about one-half of the soldier's were ill with malaria. The hospital was not screened, Anopheles were found upon the walls of the malarial ward, bit the malarial patients in their beds, flew out and bit the sentry on guard, and generally behaved themselves in a highly indecorous manner. The early part of the summer was wet, then came a long dry spell. After the drought had continued for some weeks I visited the post, and within a few hmured feet of the door of the hospital found a slight depression in the ground which had contained a surface-pool of water. The water had entirely evaporated during the dry spell, but the drying mud at the bottom was fairly carpeted with the empty pupa skins of Anopheles. This was the only trace of the early stages of Anopheles found in the vicinity. This small depression could have been filled up with two cart-loads of earth, and had this been done at the proper time it would not have been responsible for the birth of a single Anopheles, whereas it had been responsible certainly for several thousands. This is as good an example as could be desired of the desirability and feasibility, as well as economy, in many cases, of filling up breeding-places with earth.

There can be no donbt that there are many cases where a little drainage-work such as was done in the Maryland town, or a little filling-in such as was needed at the army post, will accomplish striking results in the way of reducing the numbers of mosquitoes. There are also many other places where drainage or filling-in upon a large scale would be desirable and necessary. It is difficult in 
any case, and entirely without reference to the question of mosquito-supply, to see why swamp-land should be allowed to exist. 'There are many large tracts of swampland which could be drained with a comparatively slight expenditure of money, and which, when once reclaimed, would be of rery great value for agricultural purposes. There is a great deal of this land in the immediate vicinity of many large conmmities which suffer from the attacks of mosquitoes and which are more or less malarious. In such instances, community drainage-work should be undertaken for the health and comfort of the community. Misguided owners of swamp-land, if they camnot be made to see that such measures would bring dollar's and cents into their pockets, should be coerced.

In many cases such drainage or swamp-reclamation is an expensive and a more or less complicated matter. The swamps, for example, on the borders of the Great Lakes, and of the smaller lakes which abound in central New York, in Wisconsin, and at other points, camnot be thoroughly reclaimed without the expenditure of large amounts of money. The same may be said for such great brackish marshes as the Hackensack mearlows in the vicinity of New York City and the ereat stretches of high marsh-land, occasionally orerflowed only by the highest tides, which exist at many points along the Atlantic coast. In such cases even large communities will not be apt to undertake the responsibility of drainage and diking measures on account of the expense. This means that such measures should be alopted by States. A good practical state drainage law is in these days a 
psactical necessity, and the adoption of such laws by many States should be actirely urged and will be furthered in the immediate future.

In the annual report of the State Geologist of New Jersey for the year 1899 (Trenton, N. J., 1900), it is shown that the general drainage laws of the State provide for the improvement and reclamation of the wet lands of the State, both tidal or salt meadows and wet fresh-water lands. "On the application of at least five owners of separate lots of land, included in any tract of land in the State which is subject to orerflow from freshets, or which is usually in a low, marshy, boggy, or wet condition, the Board of Managers of the Geological Survey is anthorized to make surveys of such tract or tracts and to adopt a system of drainage for the same." The plans and surreys are submitted to the Supreme Court, and commissioners to do the work are appointed by the court. Under the head of "The Reclamation of the Hackensack and Newark Meadows," in the same report, the improvement of four thonsand acres within the corporate limits of Newark is proposed, that within the corporate limits of Jersey City and Elizabeth having been handled by those cities. The extension of the city of Newark orer the marshy tract to the deep water of Staten Island Sonnd would be mate possible by reclamation-work. The depreciation of value and real estate near the meadows, and the increase which would follow the reclamation, are strong arguments, aside from the sanitary benefits to be gained. In the case of the Newark meadows, a report by C. C. Vermenle showed that the city, on advertising for 
plans and proposals, found that the marsh could be rendered suitable for occupation at a contract cost not exceeding $\$ 300$ per acre, an amount which, when compared with the selling price of city lots in Newark, is very small. Drainage not for city purposes, however, Mr. Vermeule shows, can be done for about $\$ 93$ per acre. This would put the land in condition for agriculture or grazing. $\mathrm{He}$ shows that in Nova Scotia, drained marsh-lands sell for $\$ 150$ to $\$ 200$ an acre for agricultural purposes only, and that the diked meadows in Salem and Cumberland Counties in New Jersey have always been worth several times as much as improved upland. "As much as fifty-five bushels of wheat per acre, and heary crops of hay are raised on them. A moderate amount of drained tidemarsh attached to a farm in that vicinity enhances the value of the farm." He urges that a private corporation, if it can secure a sufficiently large area to begin operations, and can drain it and put a small portion under cultivation as a demonstration, could promptly lease the rest for enough money to give a fair return on the investment, and the appreciation in the value of the land in the course of a few years, since it is so near Now York, would undoubtedly make the venture profitable.

An editorial in the New . Jersey Adrestiser of February 9, 1901, advocates work under the Board of Trade against mosquito-breeding places. The reasons are summed up well in the following words:

"There is a sanitary reason for their extirpation. They injure property for sale, so there is a good economic reason. They aftlict the healthy, and torment the sick, and 
the bad name they give a locality keeps population away. A crusade against the mosquito plague should go hand in hand with local enterprise. The abolition of the pest would be the greatest victory achiered in the whole career of the Newark community."

They show that Newark has a magnificent water-supply; possesses a large park area; is about to build a city-hall, is to cleanse the Passaic River of its filth, and dredge it to make a larger channel. Finally it is urged that the meadows be reclaimed, and that the marshes along the bay be diked.

The Hoboken (N. J.) Observer, under date of October 8, 1900 , says that the draining of the meadows and other low lands lying between Hoboken and Jersey City, and between Jersey City and the Passaic River, has become an urgent matter and has long been agitated from a commercial standpoint, but these fens and meadows are breeding-places for mosquitoes. Reports of the bureaus of vital statistics show that the majority of deaths are caused by zymotic diseases.

The Roman correspondent of the London Standard of January 14, 1901, states that the amnual parliamentary report on the measures for improving the sanitary conditions and promoting the agricultural prospect of the Roman Campagna shows that, while the rural popular district is constantly increasing, fever becomes more and more rare. The proportion of fever-stricken land has been reduced fifty per cent. by these measures. The cultivation of the region under the new conditions has in many instances yielded splendid results, and a number 
of private individuals are investing considerable capital in carrying out further improvements.

The question of drainage-work was treated very interestingly and convincingly by Mr. H. C. Weeks, of Bayside, Long Island, in the Scientific American Supplement, January 5, 1901. The following paragraphs are taken from this important article.

There are many causes which militate against reclaiming marshes, which must be done before the largest factor in the spread of mosquitoes is eliminated. Generally they are held in small tracts by a number of owners, and the more the owners, the greater the difficulty of action. This fact suggests the necessity of every state having, as some places have, drainage laws that would relieve such a situation. And that leads to the statement of the necessity of some legislation preventing a small interest in a tide-stream, owned by a few, and used but little, overriding the general interest and preventing a drainage scheme that would improve the health and material interests of a large territory, as well as relieve it of mosquitoes. In passing-how often does it occur that a train-load of passengers is held up by an open bridge over a little stream, and the cause of it all, a sailor standing on his rights and unconcernedly waiting for the ticle or wind to bear his little eraft through the draw. Such things are contrary to the spirit of the age, and should be remedied.

Another difficulty is found in the fact that owners, as a rule, are not informed of the financial side of the case, and they are unwilling, sometimes unable, to invest in a plan for reclamation that will mean an outlay to them, when there is already an income in the salt hay produced, though generally this is of no net profit.

There is, too, a great lack of information on the general sub- 
ject of the reclamation of marshes, and their producing-value is little understood. All know, of course, in a general way, of the notable instance in the case of Holland ; but that nearly a million acres have been rescued from the sea under the greatest difficulties and expense in that land, and have been made to pay on the investment, is not fully realized. And the same may be said on this continent in the upper and middle Atlantic seaboard, as well as on the Pacific side. Many marshes are of alluvial formation, and there are numerous instances of the continuous production of enormous crops of almost every kind for scores of years without the use of any fertilizers. Cases exist, however, of persons being unwilling to be convinced, and continuing their opposition even after a successful reclamation, as are seen in the official records of Massachusetts, where examinations by the state have shown a great improvement in the sanitary and agricultural conditions. In the instance of Green Harbor, in that state, it is shown that the death-rate of the reclaimed district averages lower than the general death-rate of the state, that there is a steady increase in summer visitors, and that many houses are being built. The testimony of persons of wide knowledge and ample experience in the seience and art of agriculture is adduced, showing the good results in that field, and yet it fails to silence opposers. Besides mentioning the remarkably heavy crops of hay, much preferred by his horses to the best from the uplands, also the excellent crops of strawberries and vegetables raised in these lands, one such qualitied observer gives his experience as to asparagus in such convincing words that they are quoted in full : " While visiting the Marshfield Meadows on April 19, 1897, I found asparagus already up, very nearly high enough to cut. I was surprised at this, for my own asparagus had but just appeared above the surface of the ground, although growing on land so warm that I am usually first to ship native asparagus to Boston market. I was also sur- 
prised at the size of the stallis, they being much larger than the first set of stalks that appear on my land. When $I$ consider the fact that the land on which this asparagus was growing has produced large crops every year for twenty years, without fertilizers of any kind, and still produces better crops than my land, which has had $\$ 600$ worth of fertilizers to the acre applied to it during the last twenty years, it convinces me that this land, for garden purposes, surpasses any which I have ever examined. . . We realize, in a measure, the great value of the material which nature has for ages been storing up for man's future use, if he be wise enough to avail himself of it."

It has been too frequently thought that to throw up an embankment to keep out the waters, and to build sluices and gates to let the interior water out, were all that was requisite; and, under this mistaken view, many instances have occurred greatly to the loss of the persons interested, and to the prejudice of the whole subject. An eminent engineer has said of reclamation: "What at first sight seems a mere mud and water proposition really requires, for its proper economic development, the best product of the latest practice in several fields of engineering and other sciences. Although the method of reclamation is centuries old, it may now be worked out by the aid of much that is novel in methods of construction and operation."

Successful reclamation requires a most careful consideration of all the conditions existing, which generally vary in some features at every point, and not the least of the difficulties to be met, and one which to-day accounts for many expensive failures, is the ravages of the musk-rat, and yet even he can be circumvented with proper care. Unsuccessful reclamations can all be accounted for by the neglect of some important point. A partially drained marsh is, no doubt, in a worse sanitary condition-more pestiferous and pestilential - than if not drained at all, and for most crops it is likewise a failure. Besides, the soils in all marshes are 
not snited to the raising of crops, and one reclaiming-failure, even on that account, seems to offset many successful ones. Care must be had in allowing for the subsidence of the marsh, which occurs in more or less degree, depending upon the character of the soil. Usually, where the marsh-level is sufficiently above mean low tide, reclamation can be effected without the use of artificial means to care for the inner water.

The cost of maintaining effective reclamation is slight if thoroughly done in the first instance, but otherwise, becomes expensive and discouraging, and there are many fields once successfully reclaimed but now overflowed, resulting from the attempt at saving a few dollars per acre in the original work.

While it may be argued as against reclamation that there is plenty of cheap land without spending good money to obtain more acreage, yet this is not the way to dispose of the fact that these marshes are the prolific breeding-ground of mosquitoes, and that mosquitoes-how many kinds is not ascertained-bear the germs of a disease that, in its great prevalency, does more to reduce the vigor, which is largely the capital, of a nation, than any other disease.

Mr. Weeks's mention in this article of the crops that can be grown upon reclaimed swamp-lands reminds me that Professor Milton Whitney, Chief of the Division of Soils of the United States Department of Agriculture, has told me that the value of drained salt marsh-lands is very great for meadow purposes, and that when well drained, so as to prevent any langer of seepage waters coming near the surface, they are valuable for truck crops, if situated within easy reach of markets.

In the work which was done by the Richmond County Club of Dongan Hills, Staten Island, muder the leader. 
ship of Mr. W. C. Kerr, of the firm of Westinghouse, Church, Kerr of Co., New York, to which we have several times referred, considerable drainage of fresh-water swamps above the seacoast bluffis was carried on with great success and at a minimum of expense. This work, together with the use of kerosene mpon larger pools, resulted in complete relief from the attacks of the freshwater mosquitoes, which during the early summer hat always been numerous and ferocious, but down the bluffs below the Club there was a large area of salt-marsh, and in the higher portions of this marsh-land the brackish water-mosquito of the Atlantic coast (C'ulex solliciturs) breeds abundantly and puts in its appearance up to the end of July in numbers. An attempt by member's of the club was made to buy this land in order to dike and drain it, with the idea that it could subsequently be let to truck growers, access to New York markets being easy and profits for truck farming in that vicinity being great. In the attempt, however, they found a singular obstinacy on the part of the owners of this worthless land, and the attempt was, at least temporarily, abandoned.

A successful effort of this kind, however, has been recorded by the writer in a previous publication. It comes from one of the editors of the Scientific American, who writes as follows:

In the town of Stratford, Conn., where I have resided for the past forty-five years, we have been greatly plagued by swarms of mosquitoes, so great, in fact, that the "Stratford mosquito" became a well-known characteristic of Stratford. We have in the southern part of our town, bordering on the sound, several acres 
of marsh-land or meadow, which would become periodically overflowed with water in the summer and a tremendous breedingground for mosquitoes, and this plague to the town continued until about 1890-91, when a party from Bridgeport, Conn., purchased a large section of the meadows and began to protect them by a dike, both on the north and south ends, which shut out the water. In addition to this, numerous drain ditches were made which helped to carry the water away. 'The result of this work made the land perfectly dry and spongy, so that after a rain no pools collected on the surface of the meadow and the creation of the mosquitoes was prevented. The transformation was so remarkable that people outside the town would hardly believe that it had been effected, and a year or two later the town voted a special appropriation of $\$ 2,000$ to the party who undertook to build the dike and render the meadows mosquito-proof. It liad also the effect of placing on the market a large tract of land elevated from the sound, for residences, and as many as twenty-five summer residences have been built upon this land bordering on the sound, and the number is increasing each year. They are free from mosquitoes, so that the operation shows the economy and the benefit that will result by using some means for eliminating the mosquito-breeding pools.

As has been pointed ont on earlier pages, nearly all of our mosquitoes breed exchusively in fresh water, and none of the forms which inhabit the United States, so far as ascertained, will breed in sea-water. Therefore, under certain peenliar eonditions, another remedy is indicated by this fact, namely, that near the seashore, by a certain amount of ditching, the water of ponds may be converted from fresh to salt. A rather large-scale operation of this kind was conducted a few years ago at Virginia Beach, 
the well known seacoast resort directly east of Norfolk, Va. Behind the hotels at this place, in former lays-the hotels themselves fronted upon the beach-was a large fresh water lake, which, with its adjoining swamp, was a source of mosquito-supply, and it was further feared (although this was before the mosquito-dissemination of malaria was proven) that it made the neighborhood malarious. Canals were cut, and the water of the lake was changed from a body of fresh to a body of salt water. The lake is now supplied with salt water at daily high tides by an undergromul feeder. Crabs and small fish occur in the lake in numbers, and no mosquito larve are to be found even in August, even in the swampy places at the lake borter. The water itself is very salt to the taste, and samples which have been tested at my request by Mr. E. E. Ewell, a chemist, showed that the total chlorine contained in the samples, calculated as sodium chloride, is equivalent to 22.88 grams of that salt per liter, or 1,336 grains per United States gallon, or 3.05 ounces (avoirdupois) per United States gallon. The chlorine contained in sea-water is equivalent to 31.15 grams of sodium chloride per liter. The samples from Virginia Beach, therefore, contained approximately two-thirds of the quantity of salt usually present in the sea-water.

Even where states or communities cammot be induced to take up the question of marsh drainage and liking, it is possible for public-spirited individuals of means to do work in this direction which will comnt. For example, it is planned by a company of wealthy men who have smmmer homes on the north shore of Long Island, in the 
vicinity of Oyster Bay, Cold Spring Harbor, Lloyd's Neck, and Center Island, to spend several thousand dollars in this kind of work during the summer of 1901, with the sole view of reducing the summer mosquitoes of that region. This is mentioned as an indication of what might be done at other points.

\section{Introduction of Fish inte Fishing Poneds.}

It happens quite often that larger or smaller pouds will be found which for some reason or other are considered too valuable to drain, and which the owners will not permit to be treated with kerosene, and yet in which mosquitoes breed abundantly. Such ponds will, as a rule, be found to be milldams, ice-ponds, or pools artificially constructed with rock and cement bottoms for the purpose of watering stock. Into such ponds it becomes absolutely necessary to introduce fish that will destroy mosquito larve, which will otherwise invariably be found to exist in them in great numbers.

The subject of the appropriate fish to use for this purpose has been considered in Chapter VII., and to that chapter the reater is referred.

\section{Remedies Against Adult Mosquitoes.}

In regions where mosquitoes abound, all houses must, as a matter of course, be thoronghly screened, if a measurable degree of comfort is to be gained. The extreme importanee of the careful screening of windows and doors 
in malarious neighborhoods cannot be too strongly insisted upon, wherever there is any reason to suppose that any work which may have been carried on against breeding-places may not have been so thorough as to be effective. If mosquitoes of the malarial genus Anopheles once gain access to a house they will remain hicllen behind curtains or somewhere upon the walls during the day and at night fly out about the rooms in their search for persons to bite. Some observers of tropical comntries say that in murotected houses, Anopheles will frequently fly out and hide outside during the day, returning to the houses at night, but by far the more usual method seems to be to stay indoors. In addition to this screening, it is recommencled that in tropical countries all the indoor walls of houses should be painted white or whitewashed, in orler that the dark bodies of the mosquitoes may plainly be seen and that they may easily be canght. However, when the walls are not white and when the insects are hidden behind hangings or behind old-fashioned beds or elsewhere, they may be driven ont of their hiding-places with smoke and will then settle on the window-panes in the hope of escaping.

To lill living mosquitoes in houses, Fermi and Lumbao recommend chlorine gas. Pour into a dimner plate containing four or five spoonfuls of chloride of lime five to ten cubic centimetres of crude sulphuric acid. This liberates the chlorine gas, which kills the mosquitoes. The same writer's state that the vapors of chloral act rapidly, killing them in a few seconds, though these vapors 
can be used only in rooms which are not inlıabited, or in which the vapors can be permitted to remain for several hours.

The burning of pyrethrum powder in such a room, when done in a proper way, will also kill the mosquitoes or, at least, stupefy them. The pyrethrum powder should be moistened somewhat and moulded into little cones, which are then dried in the oven. When one of these cones is ignited at its summit by a match it will smoulder slowly, filling the room with smoke, which to most people is not mpleasant, and which smells much like the sticks of punk which boys use to light firecrackers. This smoke seems to stitle the mosquitoes, which fall to the floor. Two or three of these cones burned in a room in an evening will give relief by stupefying the insects, bnt on a warm summer night they will not take the place of screens, since the windows must be closed in case of any morement of the air, otherwise the smoke is not effective.

The use of tin eups or inverted can-covers, the shallower the better, nailed to the end of a stick and containing a very small quantity of kerosene, is very prevalent in some parts of the comutry for catching mosquitoes resting on the ceiling. Where the ceiling is white, the mosquitoes can readily be observed and the tin cup is pushed up under them. When they attempt to fly they are canght by the kerosene and killed. I have seen dozens of them caught in this way of an evening in a mosquito-infested house. The first time I ever saw the apparatus was about 1890, in a New Jersey town. When abont to retire to my 
berlroom at night one of these stick-cups was given to me with a description of how it was to be used. I was too sleepy to experiment, however, and went to bed. On wakening the next morning I thought of the experiment and tested it with great success. Eighteen mosquitoes were caught on the ceiling of the belloom, but as every one of them was full of blood, I regretted that the use of the instrument had come as an after-thought.

Celli and Casagrandi state that the substance which they call Larycith III, which (if I am correct in supposing it to be a misprint for "larvicicle") is dinitrocresol - a yellow aniline color-will when burned in small quantities, kill the adult mosquitoes, and that this method constitutes the most efficacious method of destroying them. The Chinese use pine or juniper sawdust, mixed with a small quantity of brimstone and an ounce of arsenic, rum into slender bags in a lry state. Each bag is coiled like a snake and tied with thread. The outer end is lighted. Two coils are said to be sufficient for an ordinary room, and 100 coils sell for six cents.

There have been many substances recommended for use upon the skin in order to discourage mosquitoes. Camphor, rubbed upon the face and hands, or a few drops upon the pillow at night, will keep away mosquitoes for a time, and this is also a well-known property of oil of pennyroyal. The use of oil of peppermint, lemon juice, and vinegar have all been recommended for use as protectors against mosquitoes, while oil of tar is also nsed in bad mosquito localities. Dr. John B. Smith writes that in the matter of preventives, in his experience noth- 
ing is equal to oil of citronella. He has used this on the seashore with great sucess for three summers, and has recommended it to gunners and others, who have reported good results. Mr. E. H. Gane, of the firm of MIcKesson \& Robbins, of New York, informs me that the essential oils which he has found most effective in keeping away mosquitoes have been the oils of lavender, citronella, and encalyptus, in the order named. The substance, however, which he has found to work with most perfect success is castor oil. He wrote under date of October 3,1900 , "Of course the application of this oil in its natural state is almost as objectionable as the bite of the insect, but by dissolving it in alcohol and adding some kind of essential oil or perfume, a preparation can be made which is not objectionable to most people and is very effective as a preventive of mosquito bites. The formula which I have been using with great satisfaction is : Castor oil, 1 ounce; alcohol, 1 ounce; oil of lavender, 1 drachm. The solution should not contain less than fifty per cent. of the oil, to be satisfactory in all cases.

\section{Eucalyptus.}

In addition to the use of encalyptus oil to keep mosquitoes from biting, as mentioned in the previous para. graphs, the growth of encalyptus trees is said by certain persons to drive mosquitoes away, and trees of the genus Eucalyptus have been especially recommended for planting in malarial regions. In 1893, Mr. Alvilh A. Eaton, of California, wrote that in portions of California where the 
blue gum occurs no other remedy need be songht for. Further than that, he stated that no matter how plentiful the mosquitoes are, a few twigs or leaves laid on the pillow at night will secure perfect immunity. The same year, Mr. W. A. Sanders, of California, wrote that he had planted eucalyptus trees nineteen years previously about his house and that they had reached, some of them, a height of 140 feet. An irrigating ditch ran through the grove, but there was never a single mosquito larva in the ditch in the grove, although on both sides of the grove larve were plentiful. In the grove, mosquitoes were never found, though outside they were plentiful. This seems very strong evidence, but there is also evidence to show that eucalyptus trees are not at all effective. Dr. Alfredo Dugés, the well known naturalist of Gnanajuato, Mexico, wrote me on September 8, 1900: "I have received your very interesting study of the mosquitoes of the United States, and thank you greatly for it. At the end of the book you speak of the utility of encalyptus for driving away insects. I have had some experience with these trees. The fresh leaves placed upon the pillow will attract mosquitoes. Thinking that the mosquitoes loved this plant, I have placed the branches farther away, but without result. I have burned the leaves in my chamber, and the cursed beasts have resisted the smoke." Dr. Nuttall states that malaria still prevails in certain localities outside of Rome, in spite of encalyptus plantings. 


\section{The Castor-oil Plant.}

A great deal was said in the newspapers during the winter of 1900-01 about the planting of the castor-oil plant to prevent mosquitoes. These notes were all based upon a consular report from Captain E. H. Plumacher, United States Consul at Maracaibo, Venezuela. The dispatch, which was taken from Consular Report No. 246, March, 1901, reads as follows:

A simple remedy against mosquitoes has been employed in several places in South Africa, and is equally well-adapted to the temperate zone. It consists in planting the castor-oil plant (Ricinus communis), or "Pahna Christi," around the house and premises.

In cold and temperate climates the castor-oil plant grows to a height of four or five feet; in these countries, it becomes a tall tree and is perennial. It seems that the smell of the plant is disagreeable to mosquitoes and other insects, and it is an acknowledged fact that where these plants grow, few mosquitoes will be found.

My personal experience bears this out. My residence is surrounded by plantain and banana trees, and I have been much troubled in the past by the great number of mosquitoes which gathered between the leaves. Following the example of old settlers in the country, I planted the castor-seeds, which grew up in profusion, and there are now no mosquitoes to be found among the plaintain and banana trees, although I keep the ground well irrigated. By keeping the branches and the seeds of the plant in rooms, the mosquitoes are driven away from the latter.

There are several varieties of the castor-oil plant. In this coun- 
try there are two-one with brown nuts, and the other white in color, with a kernel tasting like the fresh almond.

E. H. Plumacheli, Consul.

Maracaibo, November $30,1900$.

(Copied from Consular Reports, No. 246, March, 1901.)

Persons familiar with this plant, and who have had it growing in their gardens, tell me that although they have heard the idea advanced before, they are convinced that there is nothing in it, and that the growth of this plant does not drive away mosquitoes.

\section{Remedies for the Bites.}

As elsewhere pointed out, different persons differ greatly in the effects which the mosquito-poison produces. Some persons are scarcely troubled by the puncture, while others are quite severely poisoned. It has been my own experience that if I can only refrain from scratching after having been bitten, no swelling results, and the irritation soon disappears. Even a small degree of scratching, however, such as the rubbing of one's cuff, or coatsleeve, or collar, increases the irritation and produces a swelling, and sometimes white spots. Honsehold ammonia has been found by many persons to give relief, and others say that a single tonch of alcohol stops the irritation. Dr. E. O. Peck, of Morristown, N. J., has written me that he has found glycerine a sovereign cure for the bites. Touch the bite with glycerine and in a few minutes the pain is gone. He says also that glycerine takes the pain from bee-stings. Dr. Charles A. Nash, of New York 
City, has written me that whenever a mosquito bites him he rubs the spot and marks it with a lump of indigo. This, he says, instantly stops the irritation, no matter whether the application is made instantly, or after the lapse of a day or so. He stated that he has used it since 1878 , and has a good opportunity to test it, for he lives in a locality where mosquitoes are abundant. 


\section{IX}

\section{How to Collect and Preserve Mosquitoes}

Including an Accomt of How to Raise Mosquitoes and Stucly the Early Stages.

DULT mosquitoes are very fragile creatures. The
scales upon their bodies and legs are easily rubbed
off, and the antennæe, and especially the legs, break with the least handling. Even in their ordinary course of life the scales rub off, and with certain species an adult which is two or three weeks old is quite different in appearance from one which has just emerged from the pupa. Practically, they can not be handled with the fingers, or their value as cabinet specimens or as specimens forstudy is lost. With some forms there are important characters in the arrangement of the scales on the thorax. With others the scales on the wing are of importance and if the front legs are accidentally broken off, an important character to which I have referred in the systematic portion of this book as existing in the claws of the fore feet, is naturally unavailable. In capturing them, therefore, they must not be handled, and I have found the most satisfactory method of capture to consist in simply placing a small, open-mouthed vial over the mosquito while at 
rest. On the wing it cannot be caught, even with a delicate net, without rubbing or leg-breaking. If a mosquito lights upon your hand, or upon a twig or a leaf, or upon a wall of a room, it is quite easy, especially if it be engaged in sucking blood, to cover it adroitly with the vial. It rises almost instantly, and the mouth of the vial is plugged with a plug of absorbent cotton. A drop of chloroform on the cotton will stupefy the specimen almost immediately and another drop will kill it.

The specimen may be kept permanently in the vial and when studied, if the study goes no farther than an examination of the coarser characters in an attempt to determine the species, it will often suffice gently to slide it out upon a sheet of white paper and examine it with a powerful hand lens. With the one-quarter inch achromatic triplet lens made by different firms I have found it possible to distinguish all of the generic and specific characters, even down to the teeth of the tarsal claws. This, however, is difficult to persons who are not accustomed to the use of high-power hand lenses, and in such instances one must break off a tarsus and mount it upon a slide in glycerine or Canada balsam for examination under a compound microscope.

It is not advisable to mount adult mosquitoes bodily on: slides in any medium whatever. They should not be preserved in aleohol or formalin, but should be kept dry in vials. Of course they will rattle around somewhat and there is danger that the legs and the antenne will be lost; therefore, if they are moved from the vial after the collecting and killing, into pill boxes with cotton, they can 
be carried safely or can be sent in the mails. Sereral of the pill boxes may be placed inside a tight tin or wooden box and mailed with perfect security.

A collection of mosquitoes should, however, not be kept in this way, provided it is intended as a study collection. The method which I have adopted and which is the one customarily used for small insects that are not too small for hand-lens work, is the triangular-tag method. 'Take a sheet of stiff paper or very thin cardboard and cut a strip, say, five-sixteenths or three-eighths of an inch wide. Then from this strip, by slightly oblique cuts, cut a series of triangles that will be pointed at the tip and a little less than an eighth of an inch wide at the base. Through the base of the tag may be run an insect pin and to the tip the mosquito should be glued, white or yellow shellac being the best medium for the gluing. The mosrguito should be glued on its side, just behind one wing, so that its back is away from the pin. This enables one readily, by holding the point of the pin in his hand, to examine with a lens all legs, antenno, palpi, one side, and the back. The tag should be pushed up on the pin until it is from two-thirds to three-quarters of the length of the pin away from the point. To the lower part of the pin should be attached a small label, giving date, exact locality, and name of the collector, and below this may be pinned another small label, bearing the name of the insect.

Those who for some reason do not like the paper triangle method of mounting use very minute pins made by Müller in Vienna and known as "minuten insekten nä- 
deln," which are sold by Queen \& Co., Philadelphia, and other large dealers in such things. These pins are so small and delicate that they may be thrust through the thorax of the mosquito and into a little strip of cork, the cork strip itself being pinned upon one of the larger and longer insect pins.

Some collectors, instead of using the chloroform method of killing, prefer the cyanide bottle. The cyanide bottle is made by taking a wide-mouthed Hask, putting a small lump of cyanide of potassium at the bottom and covering it with a layer of liquid plaster of Paris, which, when allowed to set, makes a complete layer over and around the cyanide and prevents the water that comes from the deliquescence of the cyanide from injuring specimens that are placed in the vial, but which at the same time is sufficiently porous to permit the escape of the deadly cyanide fumes. Even with the layer of plaster of Paris, however, the cyanide bottle will sometimes become wet, so that a bit of blotting-paper may with advantage be inserted to cover the plaster of Paris, and to absorb the superfluous moisture. A mosquito captured in one of these cyanide flasks or vials dies very quickly and is in good condition for dry mounting or for transfer to pill boxes. The cyanide bottle is preferably stoppered with a cork stopper, but rubber stoppers are also used.

In collecting early stages of mosquitoes it is only necessary to have a supply of bottles, a little coffee-strainer with a handle, and a large reading-glass. Other apparatus is cumbersome and nunecessary. I have a large 
reating-glass four inches in diameter, with a strong hanAle, which I find very useful in examining the surface of water-pools, especially for Anopheles larve. 'The dipstrainer used is an ordinary cheap coffee-strainer which has been mounted upon a long handle, so that one can reach out two or three feet from the shore and capture larve and pupe. Other larger strainers with a fine mesh are sold at the hardware stores and may be purchased cheaply. In bringing larve and pupse in from the field, too much jarring about in a bottle may result in their death by drowning. It is desirable, therefore, to put moss or water-weed in the bottle with a minimum of water, provided the insects are transferred to an aquarium or a still jar within a few hours.

Nuttall, Cobbett, and Strangeways-Pigg, who have done a great deal of collecting of mosquito larve in England, as shown in one of their important papers, entitled "Studies in Relation to Malaria," published in the .Journul of Hygiene, vol. i., No. 1, January, 1901, used as their collecting apparatus some wide-monthed bottles of medium size with cork stoppers; a white enamelled dipper which, when required, can be tied with a piece of twine to a loug bamboo rod; a small pipette with a rubber bulb and small vials containing dilute alcolıol for the preservation of larve which they did not wish to keep alive. They travelled over England on their collecting trips on bicycles. When the larve or eggs wure captured in the porcelain dippers they were removed with a pipette and put in bottles, which were half filled with water, wrapped in eloths, and attached to the bicycle frame. They found 
that they could be transported for several hours without injury. 'They noted also that the large larvæ did not withstand the shaking as well as the small ones, but that a sufficient number could always be brought back for studying purposes. On expeditions lasting a couple of days they took precaution to remove the corks occasionally to give the insects fresh air. White dippers were used, since they could more easily detect the eggs or larve on the white background, and they found that only rarely could they detect the insects by direct inspection of the surface of the water.

Larve and pupae, when it is desirable to preserve them in these stages, and it is always desirable to keep a small set of each species, may be kept in vials of alcohol or dilute formalin (5 to 10 per cent.). When preserved in alcohol they should be passed through different strengths, beginning witl a weak mixture, in order that they may not shrivel ; or, what is still better, kill the larve or pupæ suddenly in a cyanide bottle, then bring the water nearly to the boiling point in a little porcelain dish over an alcohol lamp and drop the insects in, leave them until the boiling point is just reached and then remove them. An immersion of only a few moments will suffice. Ordinarily the larvie will sink at once to the bottom of the water and very soon thereafter rise to the top. This rising is an indication that the specimen should be removed at once. The specimen may then be preserved in ordinary commercial alcohol and will retain perfectly its color and shape. This method is used successfully with the larve of many insects. It is not necessary to mount either 
larvie or pupie whole on slides. One of these preserved specimens can be put in a cell with alcohol or glycerine and studied nuder a low power with perfect ease, and the examination of minute details of its anatomy, external and internal, may readily be accomplished by dissection, and the parts dissected ont mounted permanently on slides in any of the ordinary media.

In rearing different species of mosquitoes I have had perfect success in the use of large, cylindrical glass jars known as battery jars. They can be bought in almost any city and of various sizes. The size which I find most convenient will hold about a gallon of water. A layer of sand an inch or two deep is placed in the bottom of the jar and a quart or more of water poured over it. After the sand has settled and the water has cleared, a bit of almost any small water-plant may be inserted to advantage, provided mosquitoes of the genus Culex are being reared. If the experiment is with Anopheles, however, some fresh-water alga is introduced, such as Spirogyra, Mongeotia, Edogonium, Cladophora, or Oscillaria-almost any green scum from stagnant water, in fact. Over the top of the jar is placed a piece of swiss, or other fine, translucent cloth, held down by a large rubber band.

The eggs of Culex may be had with ease by exposing a bucket of water out of door's in a mosquito locality on almost any summer night. If the egg masses be transferred from the bucket to the prepared breeding-jar the growth of the larvie can be watched and their transformations cau be observed with perfect ease. Occasional 
specimens can be taken out and preserved, to illustrate variations of different stages of growtl. Accurate notes can be kept as to temperature, periods of transformation, and so on. A series of dates, provided several jars are under observation, can be written from time to time upon a slip of paper, which may be pinned to the edge of the cloth-covering of each jar.

Where the eggs of Anopheles, for example, have not been found, females collected at large may be liberated in such a prepared breeding-jar. They will rest on the under side of the cloth-covering during the day and at night will lay their eggs on the surface of the water. It is lesirable to have a stick in the water, or a leaf, or a bit of cork, floating on the surface. I have had no difficulty in obtaining the eggs of Anopheles in large numbers in this way and the eggs of Culex as well, but although as many as fifty females of Psorophora have been liberated in breeding-jars prepareci in this way, $I$ have not been able to get the eggrs of this genus, which, as a matter of fact, are yet unknown. It is possible that Psorophora does not deposit its eggs upon the surface of water. This, however, is unlikely and it is rather to be supposed that the females used in my experiments were not old enough for oviposition and died from the confinement of the jar before the egg-laying period arrived.

When one wishes to study closely the movements and intimate habits of the early stages of mosquitoes a great deal may be observed through the glass sides of the jar, by using a coarse lens and studying those near the edge. But when a closer study is desired, individual larve or 
pupe may be lifted out with a strainer and put in a shallow porcelain vessel where they can be watched with ease under a dissecting microscope. Anopheles larve may be studied in this way very easily, and no nature study could be of more fascinating interest than the observation of these creatures, lying as they do with the body practically in a single plaue, so that they may be casily watched, with the month-parts in constant action, and the heal occasionally tuming upside down and the reverse with lightning-like rapidity. 


\section{CHAPTER X}

\section{The Classificution of the United Strtes Mos- quitoes}

7 HE mosquitoes belong to that order of insects known as the Diptera. The Diptera are the true flies. They

1. possess but two wings, the second pair being represented only by two little projections known as halteres or poisers. The mouth-parts are formed for sucking and the transformations are complete, that is to say, the early stages differ radically from the adult. In the order Diptera the mosquitoes are separated into a distinct family known as the Culicidre, the family name being derived from the name of the typical genus Culex (see Chapter III.), the generic name Culex being taken from the Latin word culex, which means a midge or a gnat. The true mosquitoes of the family Culicidre are distinguished by having the antenne furnished with whorls of hairs, which are very delicate and long in the male, and sparse in the female. The head is furnished with a long, projecting beak, which in the female is capable of piercing the skin of human beings. The wings are as a rule transparent, but to the veins, when seen under the compound microscope, are attached scales of different shapes, something like 
the scales of a butterfly's wing. The Culicidie that occur in the United States are divided into nine genera and about twenty-four recognized species. More species have been named, but some of them have been shown to be the same as others which were previously named, so they are included as synonyms. In the analytical tables which follow, the characters which distinguish these different genera and species are given. These tables have been drawn up by Mr. D. W. Coquillett, a well-known writer
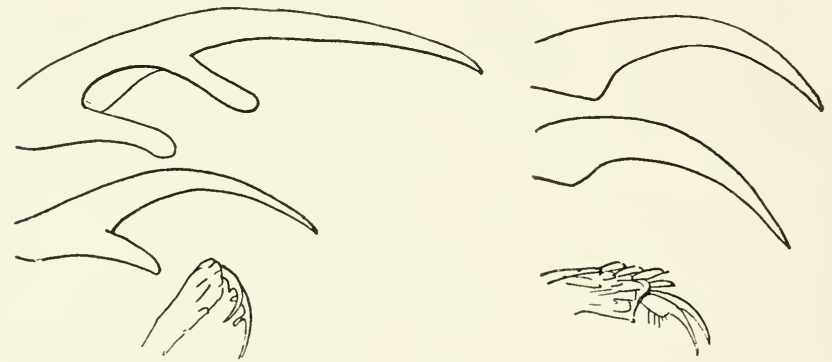

Fia. 48.-Claws of Front Feet of Culex stimulans ; fenale at right, male at left greatly enlarged. (Original.)

on insects of the order Diptera, who has made at my request a study of the North American species of the family Culicidre. The tables have been made as plain and as non-technical as possible, but there are a few points which shonld perhaps be explained. In unrevised form, these tables appeared in the writer's bulletm on mosquitoes, published in Angust, 1900, and I have noticed that some observers have found difficulty with the characters relating to the teeth of the tarsal claws 
and to the one which is mentioned as the "petiole of the first submarginal cell." In order to study the teeth of the claws of the front feet, it is necessary for most people to break off a foot and mount it on a microscope slide, for study with the compound microscope. One who is keensighted and expert with the hand lens can make them out pretty well with a rather high power (say a quarter-inch Tolles triplet) hand lens, but many others have great diffi-
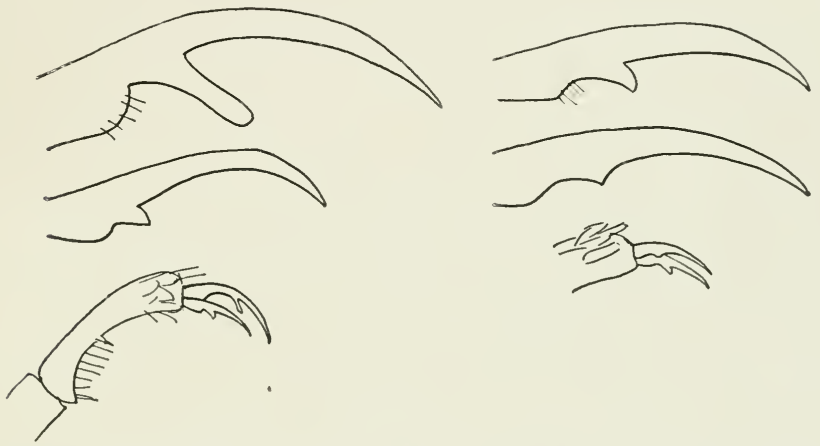

Fig. 49.-Claws of Front Feet of Culex perturbans; female at right, male at left; greatly enlarged. (Original.)

culty in detecting them in this way. This, curiously enough, is especially true of those skilled in the use of the compound microscope. The terminal claws of the front feet of nearly all mosquitoes possess good characters in the teeth, and in order that readers may know just what to look for, the claws of the front feet of two species are shown on the accompanying ents, with the teeth plainly indicated. Whether a claw bears one tooth, or two, or none, is rery important in the classification. 
The expression "petiole of the first submarginal cell" is, I realize, incomprehensible to anyone not familiar with the vocabulary of scientific entomology. Therefore on the accompanying cuts are indicated this first submarginal cell and its petiole. The petiole is the vein which rums
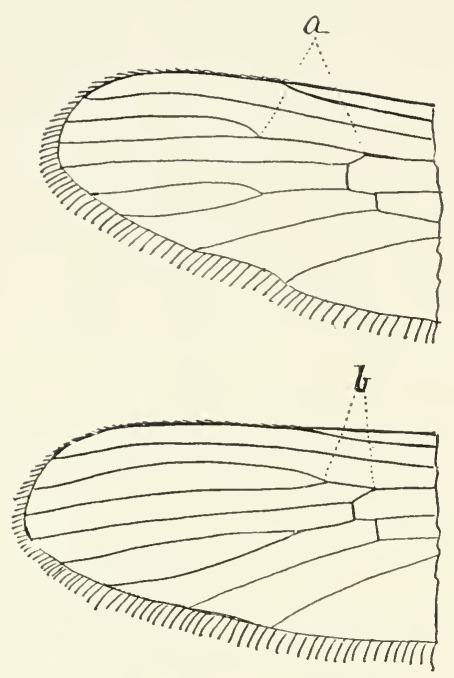

Fig. 50.- Wing of Culex consobrinus (above); and C.pipiens (below) ; showing petiole of first submarginal cell; enlarged. (Original.) from the end of the cell back to the first cross-vein, and the relative length of this petiole and of the cell itself are of importance in the classification.

The names nsed in this series of tables, and in this book, as a whole, differ in some slight degree from those which have been used in the previous writings of the anthor, and of $\mathrm{Mr}$. Coquillett. Culex trmiatus, for example, a name which was used in Bulletin 25, has been deciled to be a synonym of Stegomyia fusciutu. In this conclusion Mr. Coquillett is joined by Mr. Theobald, the

English author. Culex excitans of Bulletin 25, is stated by Mr. Theobald to be also a synonym of $\checkmark$. fasciutu, from a stuciy of the type specimen. Anoplectes argyritarsis has been added, since, although it is not known to occur in the United States, it has been found in Cuba by the Army 
Yellow-fever Commission, and is of some importance to us, as Cuba is so near our Southern States, and American citizens have so many interests in Cuba. Another species of Megarhinus, namely, grandiosa, Williston, has been added by Mr. Coquillett.

It is unfortunate that this table has to be published be. fore the monographic work by $\mathrm{Mr}$. F. V. Theobald, the Englisin expert, who has had exceptional advantages in his studies, for the British Museum, of the mosquitoes of the whole world, makes its appearance. From correspondence with Mr. Theobald I learn that his opinions differ in some respects from those of $\mathrm{Mr}$. Coquillett in regard to the proper names for some of our mosquitoes. For example, the brownish, sordid mosquito which we called Culex pungens is, in Mr. Theobald's opinion, composed of two distinct species, namely, Culex pipiens (a common European mosquito), and Culex futiguns, an East Indian species which he says is identical with Culex pungens, and which he states occurs abundantly in many parts of the world, extending north and south of the Equator to about $38^{\circ}$ north and south latitude (just about the range of the yellow-fever mosquito). Mr. Theobald is also inclined to think that the Culer impiger of Walker is identical with the species known to entomologists as Culex nigripes of Zetterstedt, and he also has a mosquito from North America which he thinks is Culex ammulutus Meigen, a form which we have not recognized in the United States. Mrr. Theobald has also received from Canada an Anopheles which lie thinks is a variety of 1 . lifurcetus. This also is a species which is unknown to us in the United States. 
It will be noticed in the tables which follow, and in the consideration of mosquitoes and yellow fever in Chapter $\mathrm{V}$. that Mr. Coquillett and the writer have adopted the generic name Stegomyia for the mosquito which has in our previous writings been named Culex fusciutus. I have been induced to adopt this name through correspondence with Mr. Theobald, who writes me that he has discovered characters which separate this mosquito from the old genus Culex, and that he has proposed the name Stegomyia for the genus. He has given me no clew as to the characters upon which he has founded this genus, except that they are "scale characters." A study of the scale structure of this insect and other mosquitoes of the genus Culex does not reveal any very important differences, but Mr. Coquillett, from other characters, has concluded to adopt $\mathrm{Mr}$. Theobald's generic name, and it is here used with the characters pointed ont in the table. It will be unfortunate should this use of the name antedate the publication of Mr. Theobald's monograph, since the genus should be his and not ours. Two other new generic names proposed by Mr. Theobald, viz.: Toxorhynchites and Conchyliastes, have been adopted and are characterized in the tables. It will be noticed that the characterizations are printed with quotation marks, and that they are followed by Mr. Theobald's name in parenthesis. This method of printing will make $\mathrm{Mr}$. Theobald responsible for these genera as well as for Stegomyia, in the event that this book is issned from the press in advance of his publication.

With these words of explanation, the following tables, 
for which it must be distinctly understood Mr. Coquillett is responsible, and for which I owe him many thanks, will probably enable those who are at all in earnest in the matter to distinguish our species without great difficulty.

\section{I. - G FENERIC SYMOPSIS.}

The following table contains all the genera of the long-beaked mosquitoes known to occur in North America. The males are readily recognized by the antennse being densely covered with long hairs; in the females the hairs of the antenne are short and very sparse :

1. Palpi in the male at least nearly as long as the proboscis ; in the female less than one-half as $\operatorname{long} . \ldots \ldots \ldots \ldots \ldots \ldots$. . . .

Palpi in both sexes at least almost as long as the proboscis . 2 Palpi in both sexes less than one-half as long as the pro-

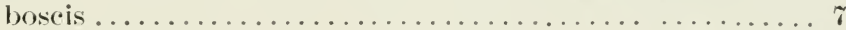

2. Proboseis straight or nearly so, colors of body brown and yel-

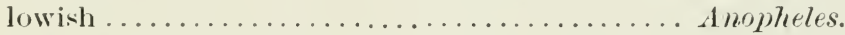
Proboseis very strongly eurved, colors bluish or greenish.

Megarhimus.

3. Legs bearing many nearly erect scales ......... Psorophora. Legs destitute of such scales .................. 4

4. Colors, black, brown and yellowish, proboscis almost straight . . . . . . . . . . .

"Colors, green and bluish, proboscis very strongly curved" ('Theobald) ..................... Toxorhyme.

5. "Thorax marked with lines of silvery scales" ('Theobald) .............................. stegomyia.

Thorax not marked in this way. .................6

6. "Hind feet black, their apices snow white" (Theo-

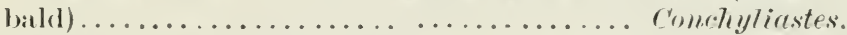
Hind feet not marked like this .............. Culex.

7. Upper side of thomax with line of bluish sables. E Tramoteniu. Upper side of thorax not niarked in this way ........ Aërles. 


\section{Genus Uranothita.}

Our single species is rarely met with; it is among the smallest of mosquitoes and will readily be recognized by the stripe of violet-blue scales on the thorax :

sapphirima O.S.

\section{II. (iEves Ä̈DEs.}

The single species is likewise rarely met with, and like the preceding, is of very small size ; it is of a brownish color with golden-yellow soales on the thorax and cross-bands of white ones on the ablomen :

fuscus $\mathrm{O}$. s.

\section{GeNus CONChYLIASTES.}

Our two species are of medium size and of rather rare occurrence : they may be distinguished as follows:

With the last two joints of the hind feet white....musicus Say. With only the last joint of the hind feet white. posticatus Wied.

\section{GENUS STEGONIIA.}

Our two species are of rather small size, and may be distinguished by the following characters :

Front claws of the female toothed on the under side, the outer silvery stripes of the thorax greatly widened in front of the wings.................... fasciata Fabr.

Front claws not toothed, the outer silvery stripes of the thor-

ax very narrow throughout their entire coursesignifera Coq. fasciute Fabr.

excitans Walk.

frater Desv.

mosquito Desv.

temiatus Wied.

signifera $\mathrm{Cog}$. 


\title{
CLASSIFICATION OF THE MOSTUITOES 237
}

\author{
VI.-GiENGS CULEX.
}

(a) RECOGNIZED SPECIES.

\section{Males.}

1. Front tarsal elaws bearing a distinct tooth near the middle of the under side of each. . ....................

Front tarsal claws bearing two teeth on the under side of one claw, and one on under side of the other, proboscis destitute of a whitish band near the middle ................

2. Feet distinctly white at bases of the joints sollicituns Walk. Feet not white at bases of the joints...... comsobriuus Desv.

3. Proboscis destitute of a whitish ring near the midlle...... 4 Proboscis with such a ring, ends of tarsal joints white tarsalis Coq.

4. Bases of tarsal joints not white ................. Bases of tarsal joints white ........... stimulans Walk.

5. Palpi not dilated ....................... 6 Palpi strongly dilated toward the apex. ... impiger Walk.

6. Petiole of first submarginal cell at most one-fourth the length of that cell .................... pipiens Limne. Petiole at least almost half as long as the cell. pungens Wied.

\section{Females.}

1. Front tarsal claws bearing a distinct tooth near midclle of

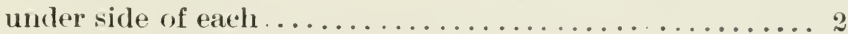
Front tarsal claws destitute of teeth .............. 7

2. Proboscis destitute of a white ring near the middle ..... 4 Proboseis marked with such a ring, bases of tarsal joints

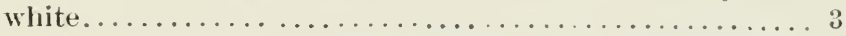

3. With a stripe of yellowish seales in middle of the abdomen........................ solliciturs Walk. Without such a stripe............. tentorhynchess Wied.

4. Bases of tarsal joints distinctly white......stimuluus WValk. Bases of tarsal joints never white ............... 
5. Abdomen marked with a cross-band of whitish seales at base of each segment.............. impiger Walk.

6. Abdomen never marked in this manner, but with a cluster of whitish scales at front angles of some of the segments ........................ triseriatus say.

7. Proboscis marked with a distinct whitish ring near the middle, feet white at sutures of the joints ......... 8 Proboscis destitute of a whitish ring near the middle .... a 8. Tarsal joints white at bases only.........perturbans Walk. Tarsal joints white at both ends.............tarsalis Coq.

9. Feet white at bases of joints...........excmucians Walk. Feet never white at bases of the joints ............ 10

10. Petiole of first submarginal cell about one-eighth the length of that cell................. pripiens Linne. Petiole one-fourth the length of that cell...mungens Wied. Petiole at least almost half the length of that cell.

consobrinus Desv.

(b) UNRECOGNIZED SPECIES.

annulatus Schrank. This European species was eredited to our fauna by Osten Sacken.

boscii Desv. Probably a rubbed specimen of pungens.

nigripes Zett. Black, the legs of the male lark yellow, hairs of pleura of female gray, a band of white scales at base of each segment of her abdomen.

rubidus Desv. The description was apparently founded on a rubbed specimen of Psorophora ciliata.

testaceus v. d. Wulp. Must closely resemble consobrimus.

imcidens Thomson. Is evidently a synonym of impiger Walker.

bigoti Bellardi. Aceording to the figure and description, the bands of black seales are at the bases of the abdominal segments; in the recognized species these bands are always at the apices of the segments. In other respects this species must greatly resemble pungens.

cubensis Bigot. Apparently founded on a badly rubbed specimen of pungens. 
frater Desv. 'This name was proposed for the Culex fasciatus of Wiedemann, under the impression that this is not the same species as the one described by Fabricius under the same name. It seems quite certain, however, that the word "proboscis" in Fabricius's description was simply a lapsus for " palpi," and with this emendation the two descriptions agree very well.

mexicamus Bellardi. Is evidently a synonym of posticatus.

pipiens Linne. A European species recently reported by Mr. Theobald as occurring in this country.

provocans Walker. Is a synon ym of nemorosus Meig., according to 'Theobald.

territans Walker. Is apparently related to pungens.

Our recognized species of Culex and their synonyms may be listed as follows, the symonyms indented:
consobrinus Desv.
? annulimanus. IV ulp (Anopheles).
impatiens Walker.
inornatus Williston.
pinguis Walker.
punctor Kirby.
impiger Walker.
implacabilis Walker.
incidens Thomson.
? quinquefasciatus Say. perturbans Walker.

pipiens Limne.

jungens Wied. ? boscii Desv.

? cubensis Bigot.

? fatigans Wied.

stimulans Walker.

taniorhynchus Wied.

damnosus say. sollicitans Walker. tarsalis Coquillett. triseriatus say.

\section{VII.-Geives Psorophora.}

Our single species is of a yellowish color, usually varied with brown, the bases of the tarsal joints white. It is considerably larger than any of our other species of yellowish or brown mosquitoes:

ciliatus Fabr.

molestus WVied.

? rubidus Desv. 


\section{VIII.-(iENUS TOXORHYNCHITES.}

These are among the largest of our mosquitoes, and closely resemble those of the following genus. Our single species has all of the feet marked with white:

rutilus Coq.

\section{IX.-Genus Megarhinus.}

Our three species are among the largest in this family, and are not known to occur north of the District of Columbia. They niay be separated as follows:

Hind feet alone marked with white ................. 1 None of the feet marked with white..... hamorrhoidalis Fabr. 1. Front and middle feet wholly black.... portoricensis Roeder. Front and middle feet yellow, first joint of the front ones black . . . . . . . . . . . . ......... ${ }^{*}$ grandiosa Will.

\section{X. -Gexus Axopheles. \\ (a) RECOGNIZED SPECIES.}

1. With a yellowish white spot near three-fourths the length of

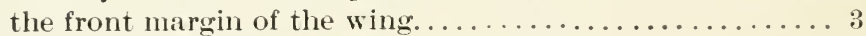

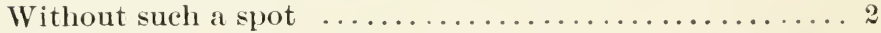

2. Scales of last vein wholly black, palpi wholly black maculipennis Meig.

Scales of last vein white, marked with three black spots, palpi marked with white at bases of last four joints. crucians Wierl.

3. Hind feet wholly brown, scales of last vein white, those at each end black.................. punctipennis Say. Hind feet largely snow-white on the apical half.

argyritarsis Desv.

* This species, of which I have never seen a specimen, probably belongs to the preceding genus. - D. W. C. 
(b) UNRECOGNIZED SPECIES.

The following species which have been eredited to our country have not been recognized with certainty; some of them probably do not belong to the present genus, while a few were evidently founded on badly rubbed specimens in which the distinctive characters were therefore wanting :

annulimanus v. d. Wulp. I strongly suspect that this does not belong to the present genus; the description applies fairly well to the male of Culex consobrinus Desv.

ferruginosus Wied. This name was proposed for the species previously described by Say under the name of Culex quinquefasciatus, but the description differs so decidedly from the one published by Say as to give the impression that it is founded on a different species. I strongly suspect that the type of ferruginosus is a rubbed example of Anopheles crucians, which was described from the same locality. Say's description of his Culex quinquefasciatus agrees very well with the species which I have identified as Culex impiger Walker.

maculipennis Meigen. According to Theobald this European form is identical with our Anopheles quadrimaculatus Say.

nigripes Staeger. This European species should be readily recognized by its unspotted wings.

albimanus Wied. Differs from our other species by the snowwhite apices of the tarsi.

pictus Loew. Is evidently elosely related to crucians IVied.

Our recognized species of Anopheles and their synonyms may therefore be listed as follows, the synonyms indented :

argyritarsis Desv. crucians IVied. ?ferruginosus Wied. maculipennis Meigen. quadrimaculatus Say. punctipennis Say. hiemalis Fitch. 

• 


$$
\text { - }
$$




\section{UNIVERSITY OF CALIFORNIA LIBRARY}

Los Angeles

This book is DUE on the last date stamped below.

AAR 6 1958 FEB 22 RECCD

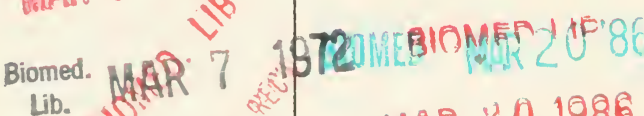

MAR 6 REX

BIOMED LIB.

Plomia

FEB 2 BIOMEC REA 6 'T6

Form L9-20m-8,'65(F6439s8) 4939 


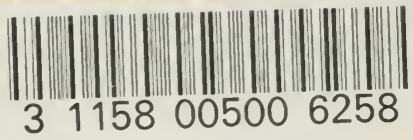


